\title{
ALINE POLIDO
}

Eletromiografia de superfície dos músculos orbicular da boca, bucinador, supra-hióideos e masseter de pacientes com disfunção temporomandibular durante exercícios miofuncionais orais

Dissertação apresentada à Faculdade de Medicina da Univresidade de São Paulo para obtenção do título de Mestre em Ciências 


\section{ALINE POLIDO}

\section{Eletromiografia de superfície dos músculos orbicular da boca, bucinador, supra-hióideos e masseteres de pacientes com disfunção temporomandibular durante exercícios miofuncionais orais}

Dissertação apresentada à Faculdade de Medicina da Universidade de São Paulo para obtenção do título de Mestre em Ciências

Área de concentração: Fisiopatologia Experimental Orientador: Dr. José Tadeu Tesseroli de Siqueira

São Paulo 


\section{AGRADECIMENTOS ESPECIAIS}

Aos meus pais, Sérgio e Geny, responsáveis pela minha formação moral e pelo o que sou hoje; por acreditarem sempre e pelo apoio incondicional.

Minhas irmãs Cris e Cibele, meu cunhado Alexandre e meus lindos sobrinhos Juliana, Gabriel e Isabelle, pelo incentivo e apoio. Obrigada pelos momentos felizes em que passamos juntos.

Ao Elio, que me ajudou com os seus conhecimentos e a controlar as emoções nos momentos de desespero com seu apoio e carinho, me fazendo acreditar que daria certo; que compartilhou comigo dia-a-dia as alegrias e as renúncias desse percurso. Agradeço por estar ao meu lado.

Ao Professor Doutor José Tadeu Tesseroli de Siqueira que me acolheu com carinho; pelos ensinamentos que foram muito além da elaboração e desenvolvimento deste projeto, o meu respeito, a minha admiração e gratidão. Agradeço pela confiança.

Aos meus grandes amigos Adriana, Andressa, Carol, Ligia, Priscila, Cristina e Clermilson sempre dispostos a colaborar, agradeço pelo apoio, carinho e paciência, principalmente, nesta fase.

Ás minhas amigas Fabiane e Érika pelo apoio, ensinamento, disponibilidade e paciência. Obrigada pelo carinho e amizade.

Ao Thiago "meu amigo virtual" que me ajudou, obrigada pela paciência.

Ao Professor Doutor Fausto Bérzin que me recebeu com carinho e me orientou, contribuindo para a realização deste trabalho. Obrigada pela sua contribuição à ciência. 


\section{AGRADECIMENTOS}

Aos participantes desta pesquisa que colaboraram e, sem os quais, o estudo não teria sido realizado.

Aos meus amigos pela compreensão da ausência em alguns momentos e pela paciência que tiveram comigo neste momento difícil.

Aos meus novos amigos da Equipe de Dor Orofacial da Divisão de Odontologia e Neurologia do Hospital das Clínicas da USP pela paciência, acolhimento e ensinamentos.

Ao programa de pós-graduação de Fisiopatologia Experimental, a Professora Doutora Elia Tamaso Espin Garcia Caldini e à secretária Sônia Fernandes sempre disposta e disponível a ajudar.

Ao Jaime Ono, da Empresa Lynx Tecnologia Eletrônica Ltda que cedeu o Eletromiógrafo, que nos ensinou a atualizar, a programar, um pouco de física, fisiologia e engenharia, enfim, mostrou-se sempre disponível e acessível para que o trabalho desse certo. Muito Obrigada!

Ao Departamento de Cirurgia, prótese e Traumatologia Maxilo-Faciais da FOUSP, e em especial aos Professores Doutores da Disciplina de Traumatologia Maxilo-Faciais: Antonio Silvio Procópio Fontão, Francisco Antonio dos Santos Correa, José Benedito Dias Lemos, Antonio Castelo Branco Teixeira e Oswaldo Crivello Júnior pela avaliação dos participantes desta pesquisa. Ao Edison Henrique Vicente que sempre me ajudou, obrigada pela paciência! E ao Carlos de Falco Junior que sempre 
se mostrou solicito. Meu sincero agradecimento pela disponibilidade e prestatividade com que me ajudaram neste trabalho.

Aos Professores Doutores Francisco Antonio dos Santos Correa e Oswaldo Crivello Júnior e a Fonoaudióloga Doutora Fabiane Miron Stefani que além de amigos, fizeram parte da banca da minha qualificação: obrigada pelos conselhos e correções. 


\section{SUMÁRIO}

Lista de abreviaturas

Lista de símbolos

Lista de siglas

Lista de figuras

Lista de tabelas

Lista de gráficos

Resumo

Summary

1 INTRODUÇÃO 1

2

OBJETIVOS 3

3 REVISÃO DA LITERATURA 4

3.1 Anatomia e fisiologia do sistema estomatognático ............4

3.1.1 Músculos da face ............................................................ 4

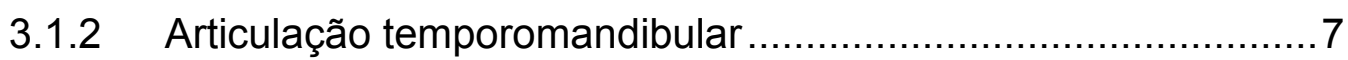

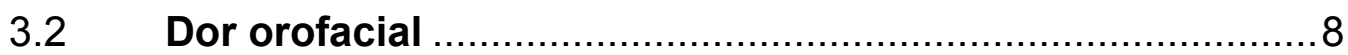

3.2.1 Dor músculo-esquelética ............................................ 10

3.2.2 Disfunção temporomandibular .......................................... 11

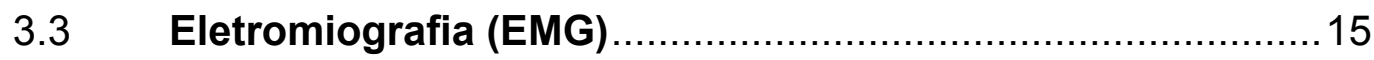

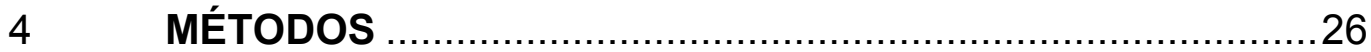

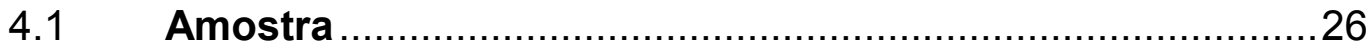

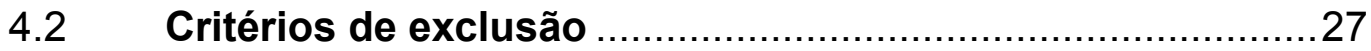

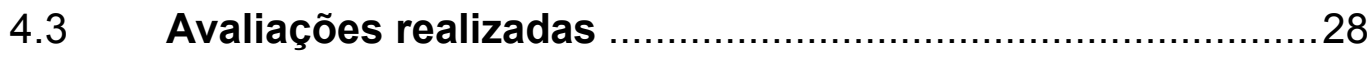

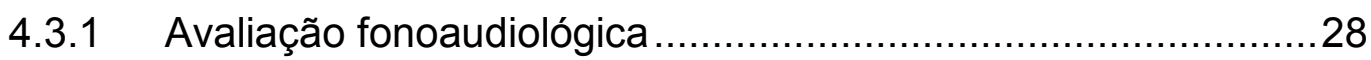

4.3.2 Avaliação eletromiográfica ..............................................29

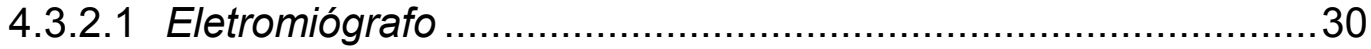

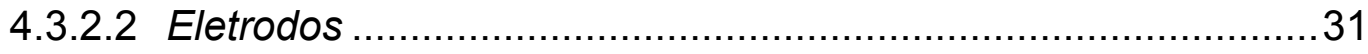




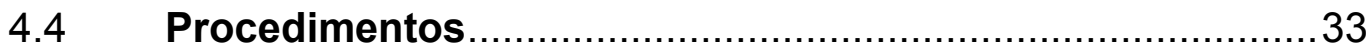

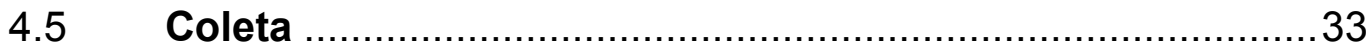

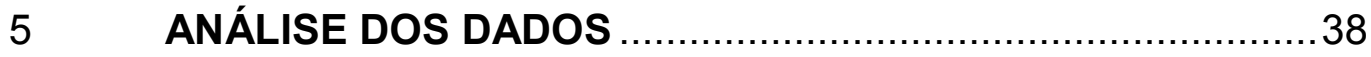

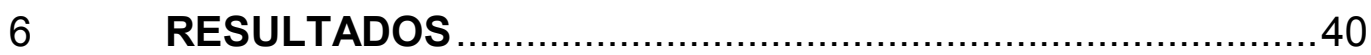

6.1 Avaliação fonoaudiológica ..................................... 40

6.1.1 Anamnese ............................................................... 40

6.1.2 Exame clínico do sistema estomatognático...........................42

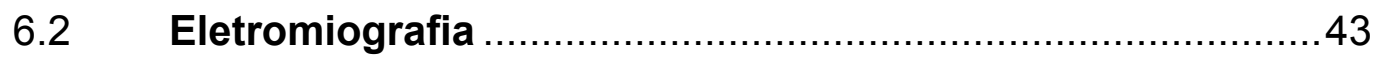

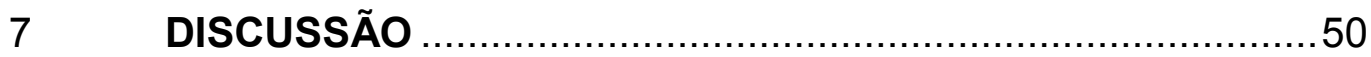

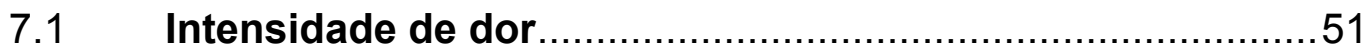

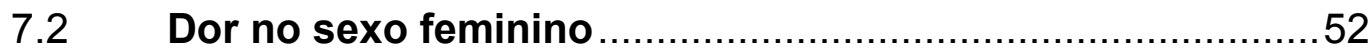

7.3 Alterações fonoaudiológicas..................................... 52

Eletromiografia no repouso ..................................... 53

7.5 Eletromiografia dos músculos da mímica........................55

7.6 Normalização dos dados .............................................. 57

7.7 Importância e limitações do estudo.....................................58

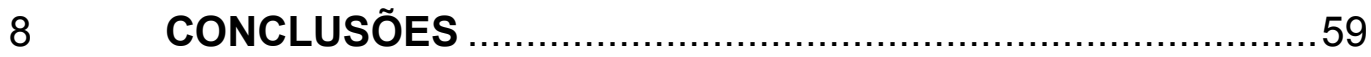

9 ANEXO A - Termo de consentimento livre e esclarecido .........59

ANEXO B - Avaliação fonoaudiológica.................................61

ANEXO C - Parecer do Comitê de Ética do Hospital das

Clínicas da Faculdade de Medicina da Universidade de São Paulo

ANEXO D - Parecer do Comitê de Ética e Pesquisa da Faculdade de Odontologia da Universidade de São Paulo........65

11 REFERÊNCIAS BIBLIOGRÁFICAS .63 Apêndice 


\section{LISTA DE ABREVIATURAS}

$\begin{array}{ll}\text { ATM } & \text { Articulação Temporomandibular } \\ \text { Buc E } & \text { Músculo bucinador esquerdo } \\ \text { Buc D } & \text { Músculo bucinador direito } \\ \text { GC } & \text { Grupo controle } \\ \text { GMM } & \text { Grupo com dor muscular mastigatória } \\ \text { DTM } & \text { Disfunção Temporomandibular } \\ \text { EMG } & \text { Eletromiografia/ Eletromiógrafo/ Eletromiograma } \\ \text { END } & \text { Escala Numérica de Dor } \\ \text { VAS } & \text { Escala Analógica de Dor } \\ \text { M } & \text { Músculo } \\ \text { Mass E } & \text { Músculo masseter esquerdo } \\ \text { Mass D } & \text { Músculo masseter direito } \\ \text { Orb Sup } & \text { Músculo orbicular dos lábios seguimento superior } \\ \text { Orb Inf } & \text { Músculo orbicular dos lábios seguimento inferior. } \\ \text { RMS } & \text { Root Mean Square } \\ \text { SEMG } & \text { Eletromiografia de Superfície } \\ \text { Supra E } & \text { Músculos supra-hioideos esquerdo } \\ \text { Supra D } & \text { Músculos supra-hioideos direito }\end{array}$


LISTA DE SÍMBOLOS

$\begin{array}{ll}\mathrm{dB} & \text { Decibel } \\ \mathrm{Hz} & \text { Hertz } \\ \mathrm{KHz} & \text { Kilohertz } \\ \mathrm{mV} & \text { Microvolts }\end{array}$




\section{LISTA DE SIGLAS}

$\begin{array}{ll}\text { AAOP } & \text { American Academy of Orofacial Pain } \\ \text { CAPPesq } & \text { Comissão de Ética para Análise de Projetos de Pesquisa } \\ & \text { do HCFMUSP } \\ \text { ISEK } & \text { International Society of Eletrophisiology and Kinesiology } \\ \text { SENIAM } & \text { European Recommendations of } \\ & \text { Electromyography } \\ \text { TCLE } & \text { Termo de Consentimento Livre e Esclarecido }\end{array}$




\section{LISTA DE FIGURAS}

Figura 1 - Vista lateral dos músculos faciais ..................................... 4

Figura 2 - Anatomia normal da ATM e músculos da mastigação ........... 8

Figura 3 - Movimentos orais com os lábios e bochechas realizados durante a avaliação eletromiográfica .................................... 29

Figura 4 - Eletromiógrafo ADS 1200............................................... 30

Figura 5-Eletrodos de superfície para detecção de sinais de eletromiografia do tipo bipolares .......................................... 31

Figura 6 - Eletrodo terra, unipolar ................................................... 31

Figura 7 - Vista anterior dos eletrodos aderidos à pele, conectados aos fios elétricos, mostrando os respectivos músculos 32

Figura 8 - Vista lateral dos eletrodos conectados à pele, conectados aos fios elétricos, mostrando os respectivos músculos. 32

Figura 9 - Registro dos movimentos 35

Figura 10 - Tela do computador mostando o registro de um tipo de movimento e a delimitação da contração 36

Figura 11 - Dados da contração delimitada entre T1 e T2 e utilizados os dados em RMS 37

Figura 12 - Posição de repouso no grupo de dor muscular mastigatória (GMM) e grupo controle (GC) 
Figura 13 - Pressão de um lábio contra o outro (apertamento) no grupo de dor muscular mastigatória (GMM) e grupo controle (GC) . 44

Figura 14 - Protrusão dos lábios no grupo de dor muscular mastigatória (GMM) e grupo controle (GC) 45

Figura 15 - Inflar as bochechas no grupo de dor muscular mastigatória (GMM) e grupo controle (GC) 47

Figura 16 - Sorriso aberto no grupo de dor muscular mastigatória (GMM) e grupo controle (GC) 48

Figura 17 - Sorriso fechado no grupo de dor muscular mastigatória (GMM) e grupo controle (GC) 49 


\section{LISTA DE TABELAS}

Tabela 1 - Distribuição dos pacientes do grupo de dor muscular mastigatória por faixa etária

Tabela 2 - Distribuição dos sujeitos do grupo controle por faixa etária ... 27

Tabela 3 - Período do dia em que os pacientes com dor muscular mastigatória relataram sentir dor 40

Tabela 4 - Distribuição dos pacientes com dor muscular mastigatória, quanto à intensidade de dor segundo a escala numérica de dor, no momento da avaliação

Tabela 5 - Distribuição dos pacientes com dor muscular mastigatória quanto à tonicidade dos órgãos fonoarticulatórios, segundo a avaliação clínica fonoaudiológica 


\section{RESUMO}

POLIDO A. Eletromiografia de superfície dos músculos orbicular da boca, bucinador, supra-hióideos e masseteres de pacientes com disfunção temporomandibular durante exercícios miofuncionais [dissertação]. São Paulo: Faculdade de Medicina, Universidade de São Paulo; 2009. 104 f.

O objetivo deste estudo foi avaliar a atividade elétrica dos músculos da mímica de pacientes com dor muscular mastigatória utilizando eletromiografia de superfície. Foram avaliadas 15 mulheres com dor muscular mastigatória (idade média de 33.4, variando de 22-44), grupo de estudo (GMM) e 21 mulheres (idade média de 28.5, variando de 21-45), do grupo controle (GC) Foram realizadas avaliação clínica fonoaudiológica e eletromiográfica (eletromiógrafo ADS 1200, da Lynx Tecnologia Eletrônica Ltda, eletrodos de disco de prata, descartáveis, gel condutor, auto-adesivos com 10mm de diâmetro por HAL Ind. e Com. LTDA) dos músculos: orbicular dos lábios, bucinador, supra-hióideos e masseter em repouso e nos movimentos: protrusão dos lábios, apertamento dos lábios, inflar bochechas, sorriso fechado e sorriso aberto. Houve diferença significativa entre os grupos: os valores da eletromiografia de repouso foram inferiores para o músculo masseter direito $(p=0.012)$ e esquerdo $(p=0.019)$; nos movimentos, os valores eletromiográficos foram superiores no grupo controle durante os movimentos: protrusão dos lábios - bucinador esquerdo $(p=0.005)$; suprahióideo esquerdo $(\mathrm{p}=0.011)$; apertamento dos lábios - bucinador esquerdo 
( $p=0.005)$; bucinador direito $(p=0.007)$; supra-hióideo esquerdo $(p=0.046)$; supra-hióideo direito $(p=0.039)$; orbicular superior $(p=0.042)$; inflar as bochechas - masseter esquerdo $(p=0.021)$; bucinador esquerdo $(p=0.007)$; bucinador direito $(p=0.002)$; orbicular superior $(p=0.039)$; sorriso fechado masseter esquerdo $(p=0.004)$; masseter direito $(p=0.019)$; bucinador esquerdo ( $p=0.013)$; supra-hióideo esquerdo $(p=0.046)$ e no sorriso aberto masseter esquerdo $(p=0.030)$. Desta forma, o músculo de maior atividade eletromiográfica foi o orbicular da boca. No repouso, os valores foram inferiores para o masseter e superiores para os demais músculos e nos movimentos, os valores foram superiores em todos os músculos para o grupo de estudo.

Keywords: Dor orofacial; Articulação temporomandibular; Eletromiografia. 


\section{SUMMARY}

POLIDO A. Surface electromyography of the orbicularis oris muscle of the mouth, buccinator, masseter and supra-hyoid in patients with temporomandibular desorders during orofacial myofunctional [dissertation]. São Paulo: Faculdade de Medicina, Universidade de São Paulo, 2009. 104 f.

The objective this study is assess the electric activity of mimic muscles in patients with masticatory muscle pain using surface electromyography (EMG). Was evaluated 15 women with masticatory muscle pain (mean age 33.4, ranging between $22-44$ years old), study group (GMM) and 21 women (mean age 28.5, ranging between $21-45$ years old), control group (CG). Clinical phonoaudiological and electromyographic assessments were performed (electromyograph ADS 1200 of Lynx Tecnologia Eletrônica Ltda, $10 \mathrm{~mm}$ disposable pregelled self-adhesive silver disk electrodes of HAL Ind. e Com. LTDA) in the muscles: orbicularis oris, buccinator, suprahyoid and masseter, both at rest and in movement: lip protrusion, lip contraction, cheek inflation, close smile and open smile. There was significant difference between the groups: the values of the electromyography at rest were lower for the right and left masseter muscle ( $p=0.012$ and $p=0.019$, respectively); in movement, the eletromyographic values were higher in the group control during movement: lip protrusion - right buccinator $(p=0.005)$; left suprahyoid $(p=0.011)$; lip contraction - left buccinator $(p=0.005)$; right buccinator $(p=0.007)$; left suprahyoid $(p=0.046)$; right suprahyoid $(p=0.039)$; orbicularis 
oris $(p=0.042)$; cheek inflation - left masseter $(p=0.021)$; left buccinator $(p=0.007)$; right buccinator $(p=0.002)$; orbicularis oris $(p=0.039)$; closed smile - left masseter $(p=0.004)$; right masseter $(p=0.019)$; left buccinator $(p=0.013)$; left suprahyoid $(p=0.046)$; open smile - left masseter $(p=0.030)$. Thus, the orbicularis oris muscle presented the highest EMG activity. At rest, the values were lower for the masseter and higher for the other muscles and, in movement, the values were higher for all the muscles in the study group.

Keywords: Orofacial Pain, Temporomandibular Disorders, electromyography 
"Feliz aquele que transfere o que sabe e aprende o que ensina. $O$ saber se aprende com os mestres. A sabedoria, só com o corriqueiro da vida."

\section{Cora Coralina}




\section{INTRODUÇÃO}

Tanto as articulações temporomandibulares como os músculos da mastigação e da mímica, fazem parte do sistema estomatognático, que juntos são responsáveis, pelas funções orais de sucção, mastigação, deglutição, respiração e fala. Havendo um desequilíbrio em uma das estruturas desse sistema, podem ocorrer dor ou distúrbios mandibulares.

A American Academy of Orofacial Pain (AAOP) define distúrbio temporomandibular (DTM) como problemas clínicos que envolvem a musculatura mastigatória, a articulação temporomandibular e as estruturas associadas (De Leeuw, 2008).

Os distúrbios temporomandibulares são divididos em subgrupos, dependendo da área comprometida, podendo afetar a articulação temporormandibular (ATM) propriamente dita ou os músculos mastigatórios.

Dentre as afecções que afetam os músculos, podemos destacar as dores musculares mastigatórias, as quais ocorrem no aparelho locomotor mastigatório. Podem causar dor aguda ou crônica da musculatura facial; ser unilateral, bilateral ou do tipo migratória e podem ser espontâneas ou desencadeadas e/ou agravadas pela mastigação ou por movimentos mandibulares.

Nestes casos, uma ferramenta muito importante para a avaliação da atividade elétrica de um músculo, durante uma visualização dinâmica dos mesmos, é a eletromiografia (EMG). Quando o músculo se contrai, a EMG capta e amplia o potencial de ação desse músculo. Uma das indicações para o uso da EMG é a pesquisa clínica. 
Para a captação do sinal eletromiográfico pode ser utilizado eletrodos de agulha ou de superfície.

Os eletrodos de agulha são inseridos na musculatura a ser avaliada e enviam sinais elétricos ao eletromiógrafo, registrando a atividade de unidades motoras isoladas em repouso ou em atividade.

Os eletrodos de superfície são aderidos à pele e capazes de registrar, de forma mais generalizada, a atividade de um número maior de fibras musculares, ativadas em condições de esforço mínimo, médio e máximo. É um método não invasivo, proporciona conforto e facilidade na colocação.

$\mathrm{Na}$ literatura científica, são comuns estudos utilizando a EMG para avaliar o repouso, rigidez, flacidez, fadiga e espasmos musculares, principalmente dos músculos mastigatórios, porém, estudos que avaliam os músculos da mímica, são escassos. Uma vez que estes músculos fazem parte do sistema estomatognático e que a dor muscular mastigatória afeta a musculatura facial como um todo, é de suma importância a avaliação desses músculos também.

Desta forma, neste trabalho a EMG foi utilizada para avaliar o comportamento dos músculos da mímica em pacientes com dores músculoesqueléticas mastigatórias, uma vez que a literatura científica relata que, pontos dolorosos nesses músculos, também causam dor difusa ocasionando alteração da atividade elétrica do músculo. 


\section{OBJETIVOS}

Este estudo teve como objetivo avaliar a atividade elétrica dos músculos orbicular dos lábios, bucinador, supra-hióideos e masseter, em indivíduos com dor muscular mastigatória. A avaliação ocorreu em duas fases: durante o repouso e em mobilidade destes músculos, por meio de eletromiografia de superfície. 


\section{REVISÃO DA LITERATURA}

A revisão da literatura abordará três enfoques. Primeiramente será apresentada uma explanação sobre a anatomia dos músculos da face e da articulação temporomandibular. Em seguida, serão abordadas questões referentes às dores orofaciais. Por fim, o enfoque será dado aos estudos e avanços tecnológicos em relação à técnica utilizada neste estudo, a eletromiografia.

\subsection{Anatomia e fisiologia do sistema estomatognático}

Faz-se necessário uma breve explicação sobre a anatomia e o funcionamento dos músculos faciais que serão estudados nesta pesquisa, bem como da articulação temporomandibular.

\subsubsection{Músculos da face}

O aparelho estomatognático é composto por vários músculos. Dentre eles, destacaremos somente os músculos estudados nesta pesquisa (Figura 1).

Figura 1 - Vista lateral dos músculos faciais

m. masseter

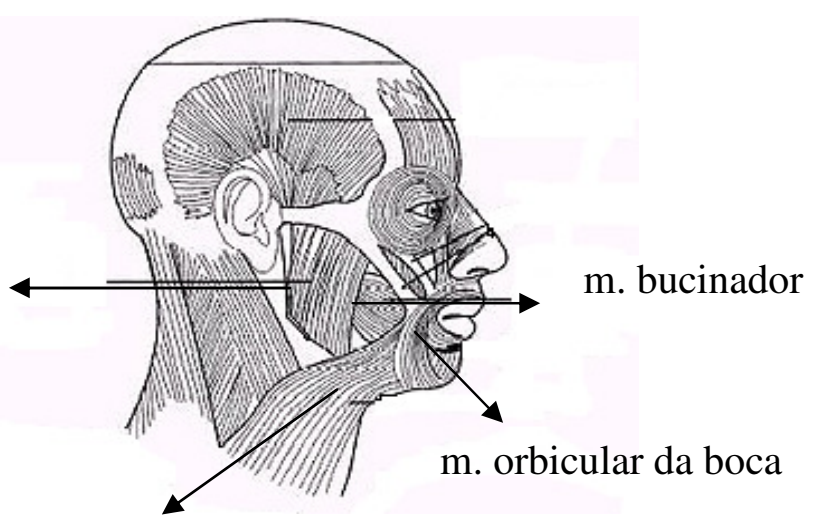

região de supra-hióideos 
O músculo orbicular da boca é o principal músculo que atua sobre os lábios. É ímpar, formado por um anel oval de fibras que circunda completamente a rima da boca. Este músculo é um esfíncter e, quando se contrai, fecha a boca e enruga os lábios. Como o seguimento inferior do lábio depende dos movimentos mandibulares para sua atuação, ele é mais móvel e mais rápido que o seguimento superior (Zemlin, 2000).

As bochechas são compostas externamente por pele e, internamente, por mucosa e, entre estas camadas, encontram-se músculos faciais, músculos da mastigação, tecido glandular e um corpo adiposo subcutâneo. Dentre esses músculos, os principais são o bucinador e o risório (Zemlin, 2000).

O músculo bucinador é o mais profundo da musculatura facial; suas fibras têm trajeto horizontal para frente e para medial, para mesclarem com as fibras musculares dos lábios superior e inferior. Devido a essa complicada organização, o músculo bucinador pode comprimir os lábios e as bochechas contra os dentes e direcionar os ângulos da boca lateralmente. O músculo risório é horizontal e suas fibras são paralelas e superficiais ao bucinador, quando contrai ajuda a direcionar o ângulo da boca lateralmente (Zemlin, 2000).

O músculo masseter é um dos músculos responsáveis pela mastigação. Tem forma de quadrilátero e é composto por duas porções ou feixes: um ântero-lateral ou superficial e outro póstero-medial ou profundo (Zemlin, 2000).

Os músculos supra-hióideos são músculos que se estendem da base do crânio ou da mandíbula em direção ao osso hióide e são todos simétricos e são 
formados por vários músculos sendo: digástrico, estilo-hióideo, milo-hióideo e geni-hióideo (Morales, 1999).

Os músculos faciais possuem uma característica especial, pois se contraem tanto voluntariamente quanto por controle emocional. As funções orofaciais emocionais frequentemente, não requerem uma contração isolada de músculos individuais, envolvem muitos músculos, principalmente os músculos orbicular superior e inferior (Lapatki et al 2003).

Os músculos da face, especialmente os da expressão facial, não possuem bainhas de facias características dos músculos esqueléticos. Muitas de suas fibras musculares inserem-se na pele da face, permitindo as diversas combinações de expressão facial (Zemlin, 2000).

A contração muscular é provocada pela mudança relativa de posição de várias moléculas ou filamentos no interior do arranjo muscular. O deslizamento dos filamentos é desencadeado por um fenômeno elétrico conhecido como potencial de ação. Este resulta da mudança no potencial da membrana que existe entre o interior e o exterior da célula muscular. Se um número suficiente de fibras musculares contraírem, a atividade elétrica pode ser detectada na superfície da pele (Bérzin, 2004; Zemlin, 2000; Guyton; Hall, 2006).

A contração pode ser isométrica ou isotônica. A contração isométrica ocorre quando o músculo não encurta durante a contração, portanto desenvolve tensão sem modificação do tamanho da fibra muscular; a isotônica quando encurta a fibra muscular, mas sua tensão permanece constante por toda a contração, ou seja, ocorre tensão acompanhada de modificação do tamanho da fibra muscular (Marchesan, 2002; Guyton; Hall, 2006). 
Para Hannam (2000) nenhum músculo se contrai de forma isolada nem unilateralmente, assim as tensões produzidas por um músculo durante uma função fazem parte de um conjunto de vetores funcionais que atuam na mandíbula, nos dentes e nas articulações temporomandibulares.

\subsubsection{Articulação temporomandibular}

As articulações temporomandibulares (ATM) fazem parte do sistema estomatognático. São compostas de estruturas ósseas, cartilaginosas e ligamentos, e são ativados por ação da musculatura associada (Bianchini, 2005). Relacionam o osso temporal à mandíbula e estão localizadas entre a região distal e superior da mandíbula e a região inferior e lateral do osso temporal, referida como complexo craniomandibular (Cabezas, 1997; Maciel; Turell, 2003). Tais articulações são bilaterais e, juntamente com os músculos, são responsáveis pelos movimentos mandibulares (Bianchini, 2005; Leandro; Nunes, 2000).

Estão entre as articulações mais especializadas e diferenciadas do organismo, possibilitando a realização das múltiplas funções estomatognáticas, como a sucção, mastigação, deglutição, fonação e respiração (Leandro; Nunes, 2000; Bianchini, 2005).

A Figura 2 mostra a localização da ATM e os músculos da mastigação. 
Figura 2 - Anatomia normal da ATM e músculos da mastigação

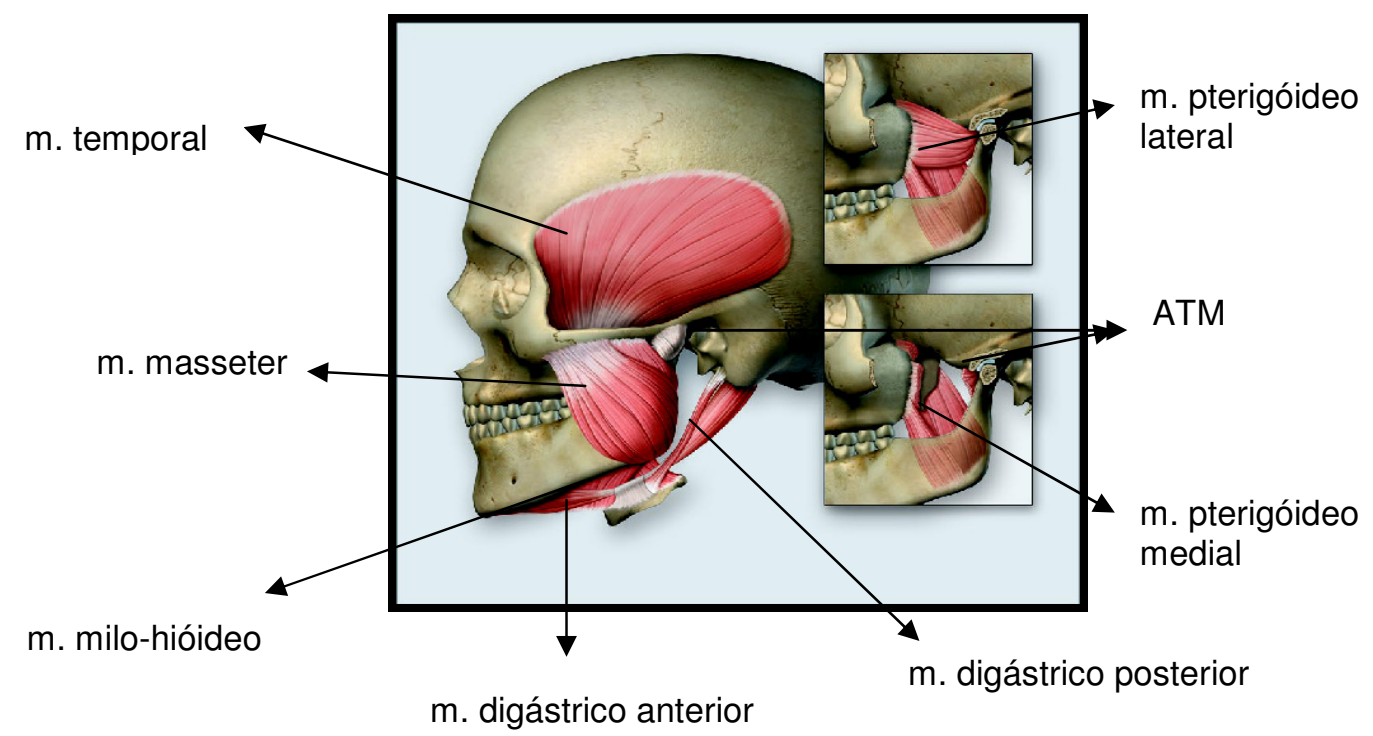

Fonte: Scrivani, 2008

A ATM suporta e acomoda adaptações oclusais, musculares e cervicais sendo que, qualquer condição desfavorável, pode desencadear alterações nos movimentos mandibulares. Neste sentido, o estudo da ATM e de seus distúrbios passa a ser fundamental também para a área fonoaudiológica (Bianchini, 2000).

\subsection{Dor orofacial}

Dor orofacial é um termo genérico que se refere às dores relacionadas às estruturas da cavidade oral e da face propriamente dita, podendo ter origem no crânio, na face ou em outras partes do corpo humano.

Segundo a American Academy of Orofacial Pain (AAOP), a dor orofacial inclui as condições álgicas decorrentes dos diferentes tecidos da cabeça, do pescoço e das estruturas que formam a cavidade oral. O diagnóstico diferencial 
abrange grande número de doenças ou afecções que comprometem, primária ou secundariamente, essas estruturas (De Leeuw, 2008). Desta forma, a dor pode ser o principal sintoma de diversas doenças que acometem diretamente as estruturas orofaciais, mas também pode ser o sintoma de doenças das regiões da cabeça e do pescoço ou do tórax e abdômen, quando provocam dores referidas (Okeson, 2006; Nobrega et al, 2007).

A dor orofacial assim como qualquer dor, geralmente é o resultado de um tecido danificado, ativando assim, os nociceptores que transmitem o estimulo doloroso ao cérebro (Vickers; Cousins, 2000). A multiplicidade das fontes potenciais de dores orofaciais aliadas à complexidade ao sistema trigeminal, realçam as dificuldades clínicas de diagnóstico e tratamento dessas dores (Sharav, 1994; Sessle, 2000; Conti et al, 2003; Siqueira et al, 2004; Okeson, 2006; De Leeuw, 2008).

A dor pode ser aguda ou crônica. As dores agudas apresentam ocorrência comum e normalmente estão relacionadas às doenças que afetam primária ou secundariamente a face, são associadas a condições clínicas recentes e cessam com o tratamento da causa. As dores crônicas têm diferentes níveis de complexidade, com diferentes origens, e nem sempre cessam com a eliminação da causa (Merskey; Bogduk, 1994; Ren; Dubner, 2002; Sessle, 2005, Camparis; Siqueira, 2006).

O Dr. Wedden Bell, proporcionou uma enorme contribuição ao campo da dor orofacial (Okeson, 2006). Ele contribuiu para os conceitos recentes, como sobre a origem da dor orofacial que pode ser neuropática, neurovascular ou músculo-esquelética (Conti et al, 2003). 
A possibilidade de a dor orofacial ser de origem muscular deve ser levada em consideração em todas as queixas do paciente. Mesmo quando a causa primária não é muscular e os efeitos excitatórios centrais tendem a se expressar nos músculos (Okeson, 2006).

Em resumo, as potenciais fontes de dores orofaciais são: alvéolodentárias, músculo-esqueléticas, neuropáticas, neuro-vasculares e psiquiátricas/psicológicas. Neste estudo será dada ênfase às dores músculoesqueléticas, uma vez que é o objetivo desta pesquisa.

\subsubsection{Dor músculo-esquelética mastigatória}

Os músculos, fáscias musculares, articulações, ligamentos, tendões, periósteos, bursas sinoviais e enteses são ricamente inervados, justificando a ocorrência de dor quando sofrem lesões traumáticas, inflamatórias, isquêmicas, tumorais e/ou sobrecargas funcionais. A dor músculo-esquelética é, portanto, predominantemente resultante da ativação por estímulos físicos ou químicos intensos dos nociceptores presentes nessas estruturas (Teixeira et al, 2007).

As dores músculo-esqueléticas são as causas mais comuns de desconforto na região da cabeça e do pescoço (Okeson, 2006).

A dor muscular emana dos músculos esqueléticos, tendões e das fascias musculares. Alguns autores sugerem que a origem da dor muscular está relacionada à vasoconstrição das artérias e ao acúmulo de produtos metabólicos nos tecidos musculares (Okeson, 2006). 


\subsubsection{Distúrbios temporomandibulares}

Em 1934, um otorrinolaringologista, Dr. James Costen descreveu o "distúrbio funcional da articulação temporomandibular", o qual recebeu o nome de "Síndrome de Costen". Ele acreditava que a causa deste distúrbio e da dor facial era a má-oclusão e a posição incorreta da mandíbula. O tratamento baseava-se nas alterações da oclusão dentária (Costen, 1934).

Através dos anos este nome foi substituído por "síndrome da ATM", "síndrome de dor-disfunção da ATM", "síndrome de dor-disfunção mandibular", e "síndrome craniomandibular", porém eram cometidos os mesmos erros de diagnóstico e tratamento (Laskin, 2008).

Atualmente, segundo a American Academy of Orofacial Pain (AAOP) os distúrbios temporomandibulares (DTM) são um termo coletivo que se refere aos problemas clínicos que envolvem a musculatura mastigatória, a articulação temporomandibular e as estruturas associadas. Por sua vez, é um subgrupo dos problemas músculo-esqueléticos faciais (De Leeuw, 2008).

A dor decorrente dos distúrbios temporomandibulares localiza-se frequentemente na face e ou cabeça, particularmente na região pré-auricular, dos músculos da mastigação, têmporas, nuca, fundo de olho, de um ou dos dois lados da face. A dor pode aparecer repentinamente ou progredir com flutuação na freqüência e intensidade por meses ou anos. Os sintomas são mais freqüentes pela manhã, principalmente nos sujeitos que apresentam apertamento ou bruxismo do sono (Camparis; Siqueira, 2006). Podem ocorrer ruídos como click ou crepitação, sensação de ouvido tapado e limitar ou desviar a mandíbula durante os movimentos de abertura, fechamento e 
mastigação (Dworkin et al, 1990; Cabezas, 1997; Felício, 1999; Okeson, 2006; De Leeuw, 2008; Scrivani, 2008).

Estudos epidemiológicos mostram que determinar uma causa única para DTM, pode ser complexo e difícil, uma vez que raramente estes distúrbios tem origem unifatorial (Biasotto-Gonzales, 2005).

A prevalência da DTM na população mostra que 40 a $75 \%$ dos indivíduos apresentam algum sinal (ruídos articulares ou movimentos anormais da mandíbula), 33\% tem pelo menos um sintoma (dor facial ou articular), e destes, de 3,6 a $7 \%$ requerem tratamento (De Leeuw, 2008).

Este problema é encontrado com maior freqüência em mulheres jovens. Em relação à idade, pode ocorrer em qualquer faixa etária, mas é mais comum dos 21 aos 40 anos (Bianchini, 2000; Berretin-Felix et al, 2005, Sarlani; Greenspan, 2005; Biasotto-Gonzales, 2005).

Em estudo realizado no Hospital São Paulo por Bove et al (2005) constatou-se que a maioria dos pacientes que procurou o serviço de Odontologia Especializado em Distúrbio Temporomandibular e Dor Orofacial foi do sexo feminino (85\%), sendo $3 \%$ menores de 14 anos, $11 \%$ entre 15 e 20 anos, $45 \%$ com idade entre 21 e 40 anos, $31 \%$ entre 41 e 60 anos e $11 \%$ com mais de 60 anos.

Helkimo foi pioneiro no desenvolvimento de índices para mensurar a gravidade dos distúrbios temporomandibulares, bem como as dores delas decorrentes. Em estudo epidemiológico, ele desenvolveu um índice subdividido em anamnésico, disfunção clínica e oclusal. Através desse índice ele procurou avaliar, de forma individual e na população em geral, a prevalência e o grau de 
gravidade da DTM de pacientes com sintomas derivados de dores mandibulares e instabilidade oclusal (Lima et al, 1999).

Dentre os pacientes com DTM, muitos apresentam alterações do sistema estomatognático, ou seja, alterações das funções orais (mastigação, deglutição, respiração e fala) e de postura, tonicidade e mobilidade dos órgãos fonoarticulatórios (lábios, língua, bochechas) (Felício, 1999).

Quanto às alterações dos lábios, podemos encontrar flacidez labial, ocorrendo esforço no selamento labial, notando-se excessiva tensão do músculo mentual para auxiliar a elevação do lábio inferior, bem como do próprio músculo orbicular da boca. Pode ocorrer também a rigidez labial, onde os lábios encontram-se fortemente selados e estirados, com tensão (Felício, 1999; Bianchini, 2000).

Em relação às alterações fonoaudiológicas relacionadas à língua, também podemos encontrar flacidez ou rigidez, a qual se encontra em volume, tensão e posição alteradas. Por exemplo, o paciente com DTM pode queixar-se de falta de espaço para a língua, a qual pode estar comprimida na cavidade oral, apresentando marcas de dentes nas laterais e interposição entre os arcos dentários (Felício, 1999; Bianchini, 2000).

As bochechas apresentam um papel importante na mastigação, funcionando como um reservatório e reconduzindo os alimentos do vestíbulo para as faces oclusais. As alterações encontradas também podem ser de flacidez ou rigidez, podendo estar comprimidas na direção das faces oclusais dos dentes e acompanhadas de leve protrusão labial devido à dor na ATM, na tentativa de manter a mandíbula abaixada; retraídas, geralmente acompanhando a retração labial e apresentar marcas de dentes na parte 
interna. Podemos encontrar assimetria funcional das mesmas, necessitando assim uma avaliação individualizada para os lados direito e esquerdo (Felício, 1999; Bianchini, 2000).

A avaliação fonoaudiológica de pacientes com DTM consta de anamnese (levantamento de dados pessoas, queixa, histórico da doença, sintomas associados, tratamentos anteriores, achados de exames complementares, hábitos parafuncionais, dados comportamentais e outros) e exame clínico de antroposcopia, que se refere à avaliação visual do sistema estomatognático realizado pelo fonoaudiólogo. Durante a avaliação o paciente deve permanecer com a cabeça na posição habitual, com o perfil facial vertical, permitindo a comparação de estruturas bilaterais quanto ao nível, contorno e tamanho (Cattoni et al, 2003).

No exame de antroposcopia, além da avaliação das estruturas do sistema estomatognático, deve constar da avaliação dos movimentos mandibulares (abertura, fechamento, lateralização e protrusão), palpação da musculatura mastigatória e cervical, palpação e auscuta da ATM e exame da cavidade oral, dentição e oclusão (Cattoni et al, 2003; Scrivani, 2008), postura corporal habitual, tensões, respiração, mastigação, deglutição, fala e voz (Bianchini, 2005).

Felicio et al (1991), discorre sobre as DTM seguindo uma abordagem fonoaudiológica, enfocando a relação entre desequilíbrio muscular e esses distúrbios. A DTM é vista como resultado de estresse emocional e alterações no desempenho das funções de deglutição, mastigação e fala, uma vez que podem provocar modificações na dentição e nas forças que atuam sobre a 
ATM. Os autores propõem a realização de trabalho de reeducação da musculatura oral e das funções, para equilíbrio do sistema estomatognático.

Sob o ponto de vista fonoaudiológico, o tratamento de alguns casos de DTM, se dá por meio da terapia miofuncional orofacial, que consta de exercícios miofuncionais para adequação da postura, tonicidade e mobilidade dos músculos faciais e das funções estomatognáticas que estão alteradas e diminuição da dor. Os exercícios podem ser isométricos, isotônicos ou isocinéticos. Os exercícios isométricos são exercícios principalmente de contração mantida e de força muscular, e indicados para aumentar tônus muscular. Os isotônicos são exercícios principalmente de mobilidade e indicados para incentivar a oxigenação muscular, a coordenação da musculatura e o aumento da amplitude dos movimentos; já os isocinéticos são a junção de ambos (Marchesan, 2002).

\subsection{Eletromiografia (EMG)}

A EMG tem sido importante ferramenta no estudo dos músculos craniofaciais desde que foi introduzida na Ortodontia por Moyers em 1949. Após mais de cinqüenta anos de estudo, o exame eletromiográfico pode ser elemento fundamental para a avaliação da atividade elétrica do músculo (Bérzin, 2004).

Pode ser considerada como método de avaliação de alterações musculares (Bérzin et al, 2004). Envolve o estudo da velocidade da condução neural, da unidade motora e da morfologia do seu potencial de ação (Bérzin, 2004) 
A EMG é o registro da atividade elétrica do músculo, através da análise do sinal elétrico emanado durante a contração muscular (Malta et al, 2006), sendo especificamente útil na avaliação das posturas musculares em repouso (Lous et al, 1970; Rugh; Drago, 1981; Moreno, 2006); de rigidez muscular (quando a função muscular excede o necessário para cumprir seu papel); flacidez muscular (quando a função da musculatura é desempenhada de modo deficitário) (Sheikoleslam et al, 1982, Möller et al, 1984; Yemm, 1985; Felício, 1999), desequilíbrios, espasmos (Ramfjord, 1961; Möller et al, 1984; Lund; Widmer, 1989) e fadiga muscular (Bérzin et al, 2004) auxiliando no diagnóstico de diversas doenças que afetam a mastigação, deglutição, fala e articulação temporomandibular.

O uso de EMG é sugerido na documentação dos registros pré e pós intervenção terapêutica para evidenciar o sucesso do tratamento, no biofeedback sobre a consciência e controle dos hábitos parafuncionais diurnos e noturnos (Lund; Widmer, 1989).

O aparelho utilizado para a realização do exame é o eletromiógrafo, aparelho capaz de detectar as variáveis elétricas que ocorrem na célula no decorrer da transmissão nervosa e da contração muscular que são transformadas em sinais elétricos e, após amplificação, é registrado na tela do osciloscópio do aparelho, para serem posteriormente analisados (Sullivan; Schimitz, 2003).

Este sinal elétrico é, geralmente, muito pequeno, portanto, deve ser registrados, diferencialmente, entre dois eletrodos colocados próximos um ao outro, aderidos ao músculo. A diferença entre esses dois eletrodos ocorre pelo potencial de ação gerado pelo músculo. A EMG de superfície se dá pela ação 
das interferências das correntes elétricas das fibras musculares que estão localizadas sob os eletrodos (Junge, 1998).

Quanto ao processamento do sinal eletromiográfico em condições dinâmicas e voluntárias, a investigação qualitativa da amplitude do padrão de atividade muscular e suas relações entre diferentes músculos no domínio temporal pode ser processado como o valor RMS (Root Mean Square), raiz quadrada da média eletrônica dos quadrados da corrente ou da voltagem ao longo do ciclo, que nos fornece a energia instantânea do sinal (Winter, 1990).

Turker (1993), Soderberg e Cook (1994) e De Luca (1997) alertaram para a importância da padronização nos procedimentos da EMG a fim de não acarretar erros ou distorções nos resultados obtidos. Em função dessa preocupação, especialistas de várias partes do mundo, incluindo a International Society of Electrophysiology and Kinesiology (ISEK), se reuniram e determinaram regras a serem seguidas no estudo da EMG com o intuito de padronizar esses estudos. Surgiu então o documento denominado European Recommendations for Surface Electromyography (SENIAM), publicado originalmente em 1999 (Merletti, 1999).

Diversas variáveis podem interferir na validade e na precisão de qualquer medida eletromiográfica. Esse processo inclui a colocação do eletrodo, a distância entre eles, o tamanho dos mesmos, temperatura da pele, fatores biológicos (idade, sexo, morfologia esqueletal, espessura do tecido adiposo etc), fatores psicológicos, preparação da pele para minimização da impedância entre outros (Basmajian; De Luca, 1985; Lund et al, 1995; Lund, 1995; Tassinary et al, 1989; Klasser; Okeson, 2006). 
Esses parâmetros devem ser controlados em todos os estudos que utilizam a EMG de superfície como técnica de mensuração da atividade muscular. Esta técnica ainda pode ser influenciada por fatores que não podem ser controlados durante a coleta dos sinais, como por exemplo, a freqüência de disparo das unidades motoras que podem variar de um dia para o outro ou até mesmo entre medidas. Dessa forma, mesmo que se controlem todas as variáveis, ainda assim existiria certa variabilidade que é inerente à medida eletromiográfica (Turker, 1993; Basmajian; De Luca, 1985; Lund et al, 1995; Ervilha et al, 1998; Klasser; Okeson, 2006).

Para que a medida seja apropriada, são necessários processos adequados de normalização e quantificação dos sinais que podem ser realizados de diferentes formas (Basmajian; De Luca, 1985; Turker, 1993; Ervilha et al, 1998; Mirka, 1991; Soderberg; Knutson, 2000).

Normalizar um sinal significa uma tentativa de minimizar as diferenças entre indivíduos, necessária para que se possam fazer comparações. A normalização do sinal eletromiográfico vem sendo considerada muito importante para que se possam fazer as devidas comparações entre os sujeitos, dias de medidas, músculos e intensidade dos sinais eletromiográficos (Basmajian e Luca, 1985; Kelly et al, 1996; Ervilha et al, 1998; Lapatki et al, 2003, Stefani, 2008).

Em pesquisa realizada por Ervilha et al (1998), para verificar a eficácia da normalização do sinal eletromiográfico, concluíram que a normalização é necessária para que se possam comparar valores obtidos de diferentes sujeitos e em dias diferentes. Os valores do pico da amplitude e da média do sinal 
obtido em tarefas cíclicas mostraram-se valores adequados para este procedimento de normalização.

Em estudos envolvendo pacientes com dor e disfunção mastigatória, é frequentemente utilizado a eletromiografia de superfície (SEMG), por utilizar eletrodos aderidos à pele e proporcionar conforto, facilidade na colocação e não ser um método invasivo (Soderberg; Cook,1994; Bérzin et al, 2004; Bérzin, 2004). São comuns os estudos de SEMG envolvendo o comportamento dos músculos mastigatórios frente à dor muscular mastigatória. Poucos estudos são realizados com os músculos da mímica. Goldreich et al (1994) encontraram diminuição na atividade EMG do músculo masseter após três semanas de ativação ortodôntica. Segundo tais autores, a dor nos músculos mastigatórios tem efeito sobre a atividade muscular desses músculos.

$\mathrm{Na}$ dor miofascial causada por pontos dolorosos, em geral o sintoma é referido. Na região de cabeça e pescoço, o paciente pode queixar-se de cefaléia, dor de dente, dor nos seios da face ou na ATM, embora a avaliação clínica dessas áreas possa não proporcionar nenhuma evidência de alteração patológica local (Jaeger et al, 2005).

Dworkin et al (1988) monitoraram a expressão facial de pessoas com dor crônica na ATM depois do exame clinico envolvendo palpação dos músculos mastigatórios, cervicais e ATM. Concluíram que as pessoas com dor demonstram-na por expressão facial. Em outro estudo Dworkin; LeResche (1992) filmaram 36 mulheres com DTM crônica comparando com 35 mulheres com inicio de DTM em um teste de estímulos de dor (cold pressor test) e palpação digital dos músculos mastigatórios e ATM. Encontraram que os níveis de expressão facial induzidas pela dor eram significativamente maiores em 
sujeitos com DTM crônica. Isto pode contaminar os resultados causando aumento na atividade muscular (EMG).

Schroeder et al (1991) realizaram um estudo com 30 pacientes com dor e disfunção mandibular e 25 do grupo controle e analisaram a atividade muscular espontânea do músculo masseter. Observaram que a dor crônica pode aumentar a atividade elétrica dos músculos adjacentes aos músculos da mastigação. Da mesma forma, Maillou e Cadden (1997) relataram em seu estudo que, após a aplicação de estímulos nocivos em estruturas somáticas profundas, pode aumentar a EMG nos músculos mastigatórios. Jensen (1999), em seu estudo, afirmou que houve aumento na atividade eletromiográfica de superfície nos músculos mastigatórios e cervicas em pacientes com cefaléia primária do tipo-tensão. Wang et al (2004) afirmou que a dor decorrente de desarranjos internos na ATM causa um aumento da EMG de superfície nos músculos mastigatórios.

O "modelo de adaptação à dor" proposto por Lund et al (1991), sugere que a dor crônica não é mantida por alguma forma de hiperatividade muscular. Nas condições de dor, a atividade dos músculos agonistas é frequentemente reduzida pela dor. Por outro lado, a dor provoca pequenos aumentos no nível de atividade do antagonista. Como conseqüência dessas mudanças, a produção e a velocidade do movimento da área atingida pela dor, são muitas vezes reduzidas. Para explicar como essas mudanças acontecem no comportamento, os autores propuseram um modelo baseado na neurofisiologia da modulação da excitação e interneurônios inibitórios oferecidos pelo alto limiar de aferências sensoriais. Sugeriram que a "disfunção" que ocorre por dor crônica é uma adaptação e proteção normal e não é a causa de dor. 
Tsai et al (2002) realizaram EMG de superfície nos músculos da mastigação e aplicaram a Escala Analógica de Dor (VAS), durante estresse emocional em indivíduos de uma Universidade nos Estados Unidos. Observaram que a atividade elétrica desses músculos aumentou sob estresse e que o resultado da VAS também foi maior sob esta condição.

Sarlani e Greenspan (2005) compararam as diferenças de respostas, através da Escala Analógica de Dor (VAS), em indivíduos com DTM e mulheres e homens saudáveis. Verificaram que a somação temporal da dor foram maiores nos indivíduos com DTM do que nos indivíduos saudáveis. Segundo os autores, isso sugere uma hiperexcitabilidade do sistema nocicepitivo central, o que contribui para o desenvolvimento ou manutenção da dor crônica na DTM.

A expressão facial das pessoas com dor resulta em um aumento do sinal EMG provenientes dos músculos faciais (Lund et al, 1991). Esta contaminação pode levar a uma confusão quanto à verdadeira origem do aumento da atividade muscular (Klasser; Okeson, 2006).

Moreno (2006) avaliou 46 mulheres, com idade entre 19 a 40 anos de idade, sendo 28 com DTM e 18 assintomáticas. O objetivo do seu estudo foi verificar a presença e intensidade dos sintomas de dor, atividade eletromiográfica nos principais músculos mastigatórios e qualidade de vida em mulheres com DTM miogênica. Concluiu que pacientes com DTM miogênica apresentam sintomas com maior intensidade de dor e maior atividade eletromiográfica em repouso dos músculos masseteres, temporal anterior e trapézio posterior e pior qualidade de vida, quando comparadas com o grupo assintomático. 
Nieberg (1960), Marx (1963; 1965) encontraram atividade eletromiográfica no músculo orbicular dos lábios durante o contato labial em repouso em muitas crianças com oclusão normal, ao passo que Essenfelder e Vitti (1977), Sales e Vitti (1979), Tosello et al (1998) não observaram tais atividades no mesmo músculo também em posição de repouso dos lábios, em estudo realizado com indivíduos com má-oclusão e normoclusão.

Lous et al (1970) estudaram a atividade muscular de repouso do masseter e temporais anterior e posterior, em 39 indivíduos com DTM e em 45 indivíduos assintomáticos. Em média, a atividade postural dos indivíduos com DTM foi significativamente maior, quando comparada a do grupo controle. Esse aumento limitou-se, na maioria dos casos, a um único músculo, e sua localização diferiu entre os pacientes. A maior atividade do músculo temporal associou-se à sensibilidade à palpação. A grande atividade postural do masseter foi associada a dor no pescoço e à sensibilidade na porção mais profunda deste músculo. Os autores sugerem que a variação individual dos resultados EMG esteja relacionada à etiologia diferenciada dos distúrbios temporomandibulares.

Com o propósito de avaliar o conceito de posição de repouso clinico, Rugh e Drago (1981), selecionaram um grupo de 10 indivíduos assintomáticos, e realizaram um estudo EMG. Os autores encontraram diferença estatisticamente significante entre a posição de repouso clínico e a abertura mandibular de menor atividade muscular. Os resultados sugerem que a posição de repouso clínico e a posição fisiológica de repouso, não configuram realmente estado de completo repouso. 
Tosello et al (1999) realizaram estudo durante o enrugamento e a compressão dos lábios, nos músculo orbicular da boca e mentual em três grupos de indivíduos: a) com normoclusão; b) com má-oclusão (classe II, divisão I de Angle) e competência labial e c) com má-oclusão (classe II, divisão I de Angle) e incompetência labial.

Durante o enrugamento dos lábios, os pesquisadores observaram que as atividades eletromiográficas dos músculos mentual e orbicular da boca foram semelhantes nos três grupos, com exceção do orbicular da boca no segmento inferior dos indivíduos do grupo com má-oclusão e incompetência, o qual teve atividade eletromiográfica maior. Durante a compressão dos lábios contra os dentes, a atividade muscular foi maior no músculo orbicular da boca segmento superior nos indivíduos com má-oclusão, sendo mais evidente no grupo com incompetência labial; já o segmento inferior do mesmo músculo apresentou atividade moderada nos três grupos.

Cecere et al (1996) realizaram estudo EMG de superfície comparando os músculos masseter e temporal anterior de pessoas saudáveis após realizar atividades de mastigação e mordida, três vezes durante o mesmo dia (no período da manhã, uma hora e sete horas após a primeira gravação). Seus resultados indicaram que houve diferença estatisticamente significativa nas atividades elétricas de tais músculos entre as EMG iniciais e as realizadas sete horas mais tarde. Os autores fundamentaram que esta discrepância estava relacionada com o intervalo entre as sessões, devido a alterações das condições psicológicas, resultando em variações fisiológicas da atividade muscular ou pela impedância da pele dos indivíduos. 
Ruf et al (1997) em estudo para avaliar a atividade EMG dos músculos mastigatórios durante função sob estresse induzido em 15 sujeitos, constataram aumento da atividade EMG durante repouso e atividade muscular funcional. No entanto, nem todos os indivíduos seguiram este padrão. Algumas pessoas neste estudo apresentaram diminuição na atividade EMG. Esta diferença pode ser explicada pela variação individual de cada pessoas ou de cada músculo a responderem a estímulos específicos.

Neely e Pomerantz (2002) realizaram estudo cujo objetivo geral foi o de medir a força dos músculos da mímica. Os objetivos específicos do estudo foram: determinar se a medida dos músculos da mímica era exequível; determinar os valores de força gerados pelos músculos de olhos e boca e determinar quais técnicas seriam mais confiáveis. Os resultados mostraram que: a) a parte superior da face (fechamento dos olhos e elevação das sobrancelhas) foi mais forte do que os movimentos da parte inferior (sorriso e protrusão de lábios); b) a medida de força dos músculos é exeqüível; c) o método mais confiável é o de eletrodos adesivos.

Root e Stephens (2003) estudaram três expressões faciais básicas: o sorriso, a expressão triste e o olhar de terror e, para comparação, estudaram três expressões planejadas, que não tinham significado subjetivo. Os registros foram feitos com seis pares de músculos faciais do lado esquerdo da face: orbicular da boca e zigomático para o sorriso; corrugador e depressor do ângulo de boca para tristeza e frontal e mentual para horror. Para as expressões planejadas, os músculos estudados foram: frontal e zigomático; frontal e depressor do ângulo de boca e frontal e orbicular. Foram examinados oito sujeitos em cada uma das seis expressões. Os resultados obtidos pela 
EMG durante o sorriso foram significativamente maiores do que de qualquer outra expressão. Não houve diferenças significativas entre as outras expressões.

Stefani (2008) realizou estudo eletromiográfico do padrão de contração muscular da face de 31 sujeitos, com idades entre 18 e 45 anos. O objetivo do estudo foi avaliar os músculos orbicular da boca, masseter, bucinador e suprahióideos durante oito movimentos faciais, comparando a atividade eletromiográfica de cada um dos músculos ao longo dos movimentos. O estudo concluiu que o músculo orbicular da boca foi o que apresentou maior atividade eletromiográfica e o músculo bucinador foi mais ativo nos movimentos de sorriso fechado e aberto. 


\section{MÉTODOS}

\subsection{Amostra}

Os pacientes que participaram deste estudo foram triados pelos professores da Disciplina de Traumatologia Maxilo-Facial do Departamento de Cirurgia, Prótese e Traumatologia Maxilo-Faciais da Faculdade de Odontologia da Universidade de São Paulo. Todos receberam o diagnóstico de Distúrbio Temporomandibular de origem muscular, segundo critérios clínicos.

Este estudo foi aprovado pela CAPPesq - Comissão de Ética para Análise de Projetos e Pesquisa do Hospital das Clínicas da Faculdade de Medicina da Universidade de São Paulo (FMUSP) (Anexo C) e pelo Comitê de Ética e Pesquisa da Faculdade de Odontologia da Universidade de São Paulo (Anexo D). Todos os participantes consentiram em participar do estudo e assinaram o Termo de Consentimento Livre e Esclarecido (Anexo A)

Foram avaliados 36 indivíduos do gênero feminino com idades variando entre 20 e 45 anos, subdivididos em dois grupos: grupo de estudo -composto por 15 sujeitos, com dor muscular mastigatória (GMM) com idade média de 33,4 (24-44) anos (Tabela 1), sem transtornos internos da articulação temporomandibular e com oclusão clinicamente normal (classe I de Angle) e grupo controle (GC), formado por 21 indivíduos, com idade média de 28,5 (2145) anos (Tabela 2), sem sinais e sintomas de DTM ou fonoaudiológicos e com oclusão clinicamente normal (classe I de Angle). 
Tabela 1 - Distribuição dos pacientes do grupo de dor muscular mastigatória por faixa etária

\begin{tabular}{lc}
\hline \hline \multicolumn{1}{c}{ Faixas etárias } & $\mathbf{n ~ ( \% )}$ \\
\hline 20 a 30 anos & $6(40 \%)$ \\
31 a 40 anos & $5(33,7 \%)$ \\
41 a 45 anos & $4(26,3 \%)$ \\
\hline Total & $15(100 \%)$ \\
\hline \hline
\end{tabular}

Tabela 2 - Distribuição dos sujeitos do grupo controle por faixa etária

\begin{tabular}{lc}
\hline \hline \multicolumn{1}{c}{ Faixas etárias } & $\mathbf{n}(\%)$ \\
\hline 20 a 30 anos & $14(66,7 \%)$ \\
41 a 40 anos & $5(23,8 \%)$ \\
\hline a 45 anos & $2(9,5 \%)$ \\
\hline \hline
\end{tabular}

\subsection{Critérios de exclusão}

Os critérios de exclusão para os indivíduos com dor muscular mastigatória foram: ausência de mais de três dentes na boca; ausência de dois dentes antagonistas; uso de fármacos relaxantes musculares; má-oclusão; problemas musculares de origem neurológica; uso de placas mio-relaxantes.

Para os indivíduos do grupo controle, os critérios de exclusão foram: alterações fonoaudiológicas, má-oclusão, ausência de mais de três dentes na boca; ausência de dois dentes antagonistas, histórico de doenças neurológicas. 


\subsection{Avaliações realizadas}

Após a triagem realizada na Disciplina de Traumatologia Maxilo-Facial do Departamento de Cirurgia, Prótese e Traumatologia Maxilo-Faciais da Faculdade de Odontologia da Universidade de São Paulo, os participantes do estudo realizaram as avaliações fonoaudiológica e eletromiográfica.

\subsubsection{Avaliação fonoaudiológica}

A avaliação fonoaudiológica constou de uma anamnese e exame clínico do sistema estomatognático (Anexo B).

A anamnese constou de questões relacionadas à DTM (dor, ruído, bruxismo, tratamentos realizados), problemas de saúde e uso de medicamentos. Foi utilizada a escala numérica de dor (END), a qual é representada por números de 0 a 10 , onde 0 é ausência de dor e 10 é a dor máxima. O sujeito deveria apontar para a condição de dor no momento do exame.

O exame clínico do sistema estomatognático foi realizado em acordo com critérios já descritos (Felicio, 1999). As estruturas do sistema estomatognático avaliadas foram: lábios, língua e bochechas, quanto à postura de repouso, tônus e mobilidade, tomando-se como parâmetro os padrões de normalidade. Este exame é realizado por meio de observação visual e pela palpação dos músculos. 


\subsubsection{Avaliação eletromiográfica}

Foram realizados registros da atividade elétrica simultânea dos músculos orbicular da boca, bucinador e masseter,e das regiões supra-hióidea, de ambos os lados.

Esses registros foram obtidos em repouso e durante uma seqüência de cinco tipos de movimentos orais: protrusão dos lábios (bico); pressão de um lábio contra o outro (apertamento dos lábios); inflar bochechas; sorriso com lábios fechados e sorriso com os lábios entreabertos (Figura3).

Figura 3 - Movimentos orais com os lábios e bochechas realizados durante a avaliação eletromiográfica
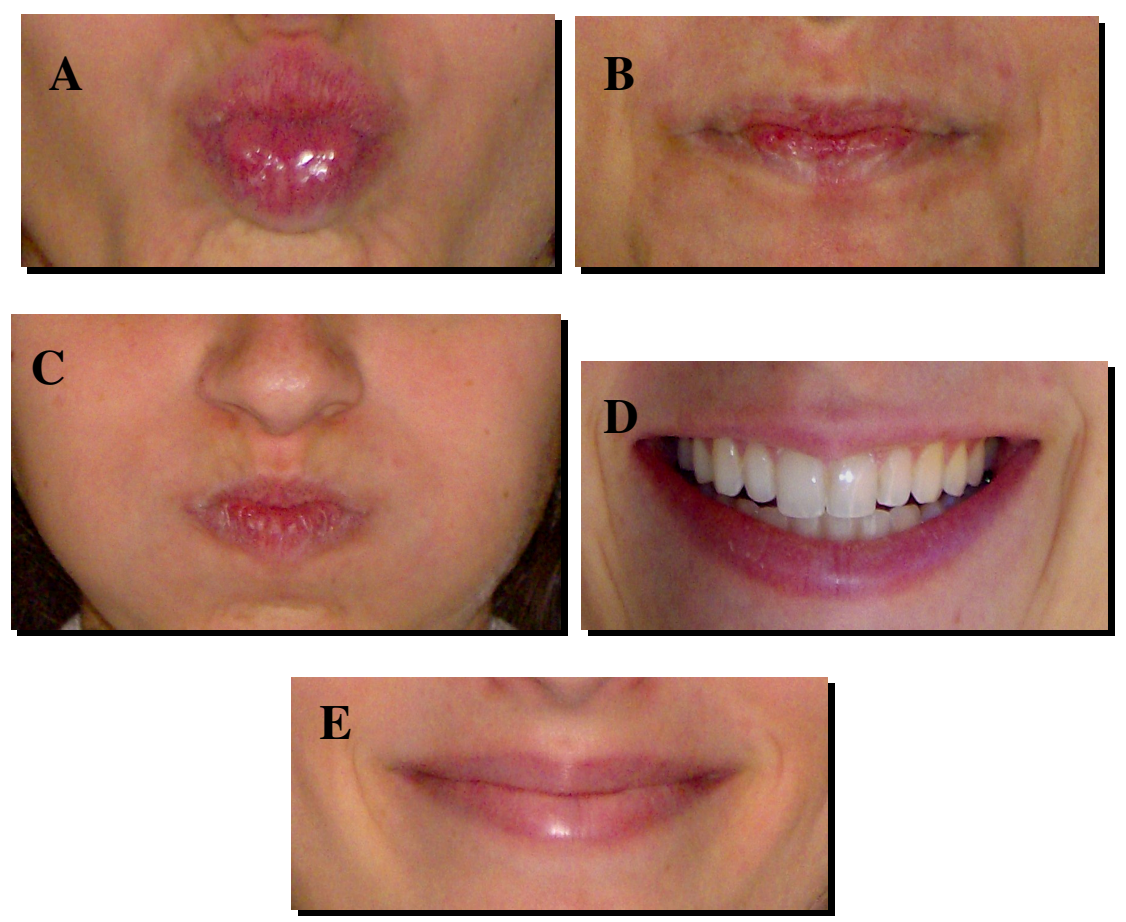

A - protrusão de lábios (bico); B - pressão de um lábio contra o outro (apertamento); C - inflar bochechas;

D - sorriso aberto; E sorriso fechado 
Para realizar os registros eletromiográficos foram utilizados os seguintes equipamentos: a) eletromiógrafo ADS 1200; b) eletrodos bipolares Hall e eletrodos terra Hall.

\subsubsection{Eletromiógrafo}

O eletromiógrafo utilizado foi o amplificador ADS 1200, com o programa Biolnspector, versão 1.8.7, fabricado pela Lynx Tecnologia Eletrônica Ltda, de oito canais, que apresentou as seguintes configurações: faixas de entrada de +/- $1 \mathrm{mV}$ a $10 \mathrm{mV}$; rejeição de sinais $>100 \mathrm{~dB}$ em $60 \mathrm{~Hz}$, filtro passa-alta de $1^{\mathfrak{a}}$. ordem entre $0,1 \mathrm{~Hz}$ a $20 \mathrm{~Hz}$; filtro passa-baixo de $4^{\mathrm{a}}$. ordem entre $100 \mathrm{~Hz}$ e $2 \mathrm{KHz}$ (ambos selecionáveis); taxa de aquisição de 4000 amostras/segundo por canal (Figura 4).

Figura 4 - Eletromiógrafo ADS 1200

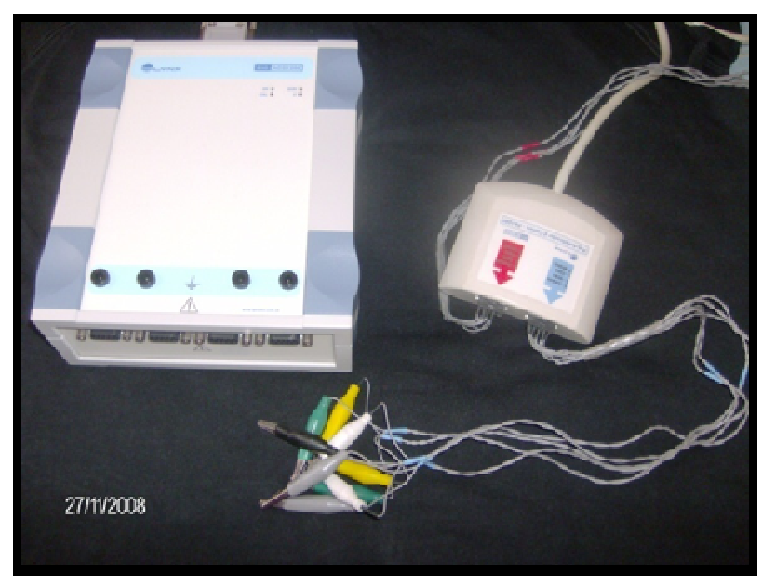

As configurações foram selecionadas ao inicio das coletas, de acordo com o fabricante. Os dados coletados foram em RMS automaticamente, segundo o software padrão AqAnalysis $^{R}$, do mesmo fabricante do EMG. O EMG foi conectado a um microcomputador HP Pavillon 6000. 


\subsubsection{Eletrodos}

Para a detecção dos sinais EMG foram utilizados eletrodos do tipo disco de prata/cloreto de prata, bipolares, descartáveis, com gel condutor, autoadesivos com 10mm de diâmetro (Figura 5), conforme recomendado pelo ISEK (Merletti, 1998), fabricados por HAL Industria e Comércio LTDA. Os eletrodos terra diferem apenas por serem unipolares (Figura 6).

Figura 5 - Eletrodos de superfície para detecção de sinais de eletromiografia do tipo bipolares

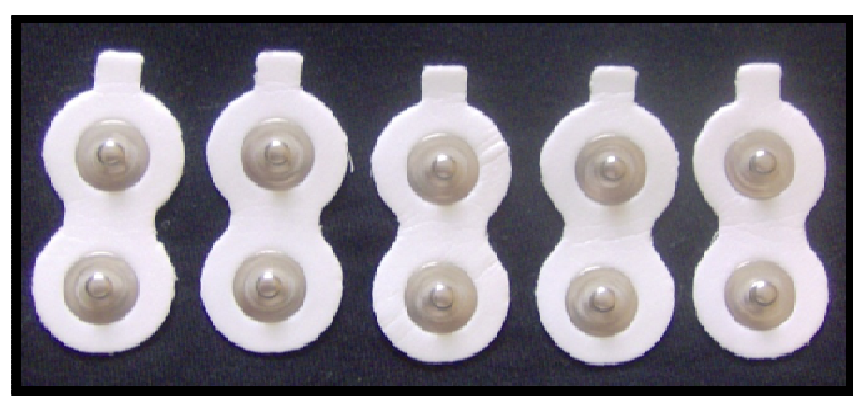

Figura 6 - Eletrodo terra, unipolar

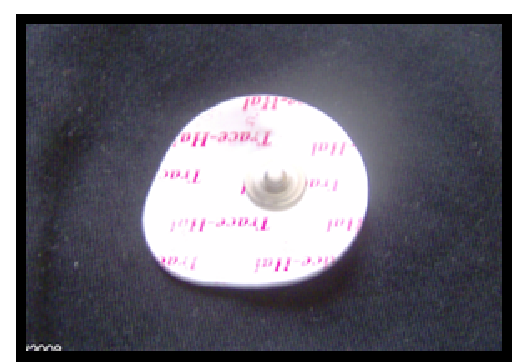

Os eletrodos de superfície foram conectados ao amplificador EMG por meio de fios elétricos (Figuras 7 e 8). 
Figura 7 - Vista anterior dos eletrodos aderidos à pele, conectados aos fios elétricos, mostrando os respectivos músculos

m. orbicular

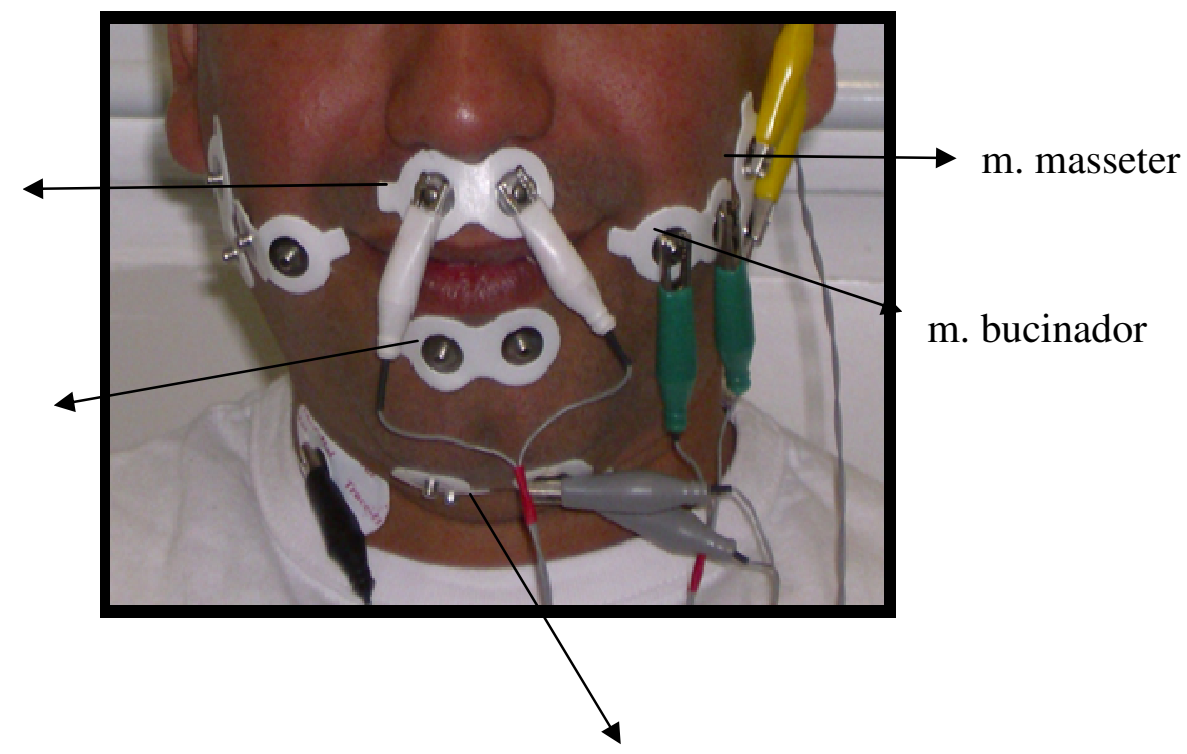

região de supra-hióideos

Figura 8 - Vista lateral dos eletrodos conectados à pele, conectados aos fios elétricos, mostrando os respectivos músculos

m. orbicular superior

m. orbicular inferior

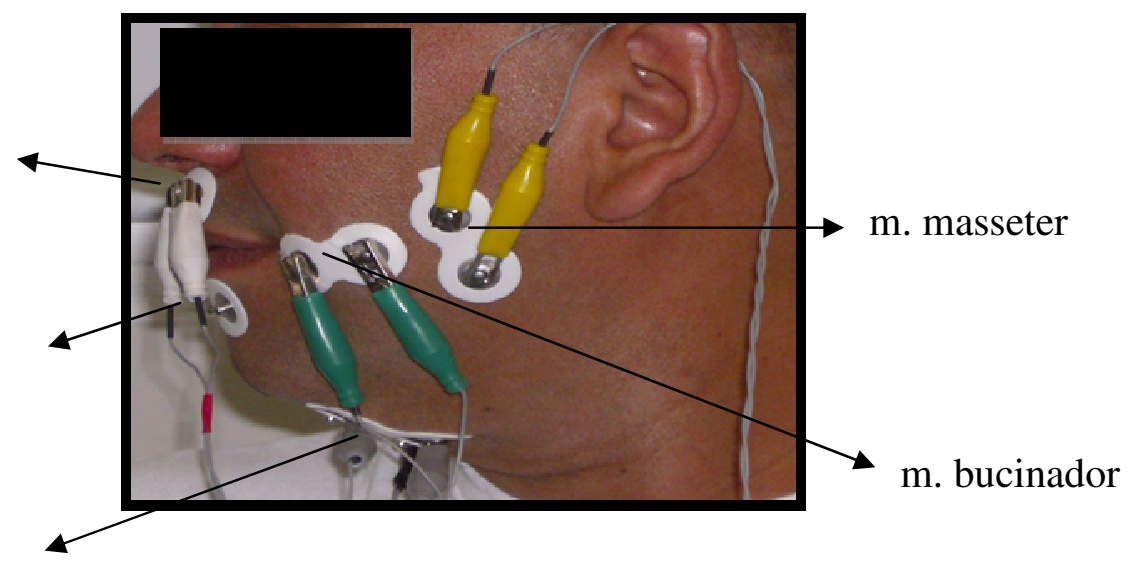

região de supra-hióideos 


\subsection{Procedimentos}

Como pré-requisito para a realização dos exames eletromiográficos, os sujeitos da pesquisa permaneciam em jejum por duas horas, para evitar alterações nos músculos da mastigação, como fadiga ou cansaço. Metais e roupas de lã na região de cabeça e pescoço foram removidos.

A sala em que foi realizada a avaliação eletromiográfica era silenciosa, com piso de borracha, iluminação natural e sem instrumentos eletrônicos ou elétricos ligados nas proximidades da sala.

Os sujeitos da pesquisa sentavam-se confortavelmente em posição de $90^{\circ}$, com os pés apoiados no chão em cadeira sem apoio de cabeça.

Antes da colocação dos eletrodos, a superfície da pele era limpa com gaze embebida em álcool 96\%. O eletrodo terra era então colocado sobre o músculo esternocleido-mastoideo direito.

O local exato para a colocação dos eletrodos na superfície foi determinado conforme recomendação do ISEK (Merletti, 1999).

\subsection{Coleta}

A figura 9 mostra a sequência dos eventos realizados por cada sujeito.

Após a colocação dos eletrodos, os sujeitos permaneceram em repouso por 10 minutos para diminuir a impedância da pele. Após esse período, ao comando do examinador, iniciava-se o registro eletromiográfico. Inicialmente foi registrado o repouso por 30 segundos. A seguir, o individuo iniciava o primeiro tipo de movimento. Cada tipo de movimento tinha a duração de 3 segundos e entre cada movimento havia um repouso de 3 segundos. Cada tipo de 
movimento foi repetido por cinco vezes, com duração total de 30 segundos cada (Figura 9b e 10).

Após o término da sequência de cada tipo de movimento, os indivíduos tinham um intervalo de quatro minutos, em que permaneciam em repouso, antes de começarem o próximo tipo.

O tempo total de registro foi de 3 minutos por paciente. Os registros foram realizados em dias diferentes, conforme a disponibilidade dos pacientes.

A sequência dos tipos de movimentos para o registro dos dados foi: repouso, protrusão de lábios, pressão de um lábio contra o outro (apertamento), inflar as bochechas, sorriso aberto e sorriso fechado. 
Figura 9 - Registro dos movimentos

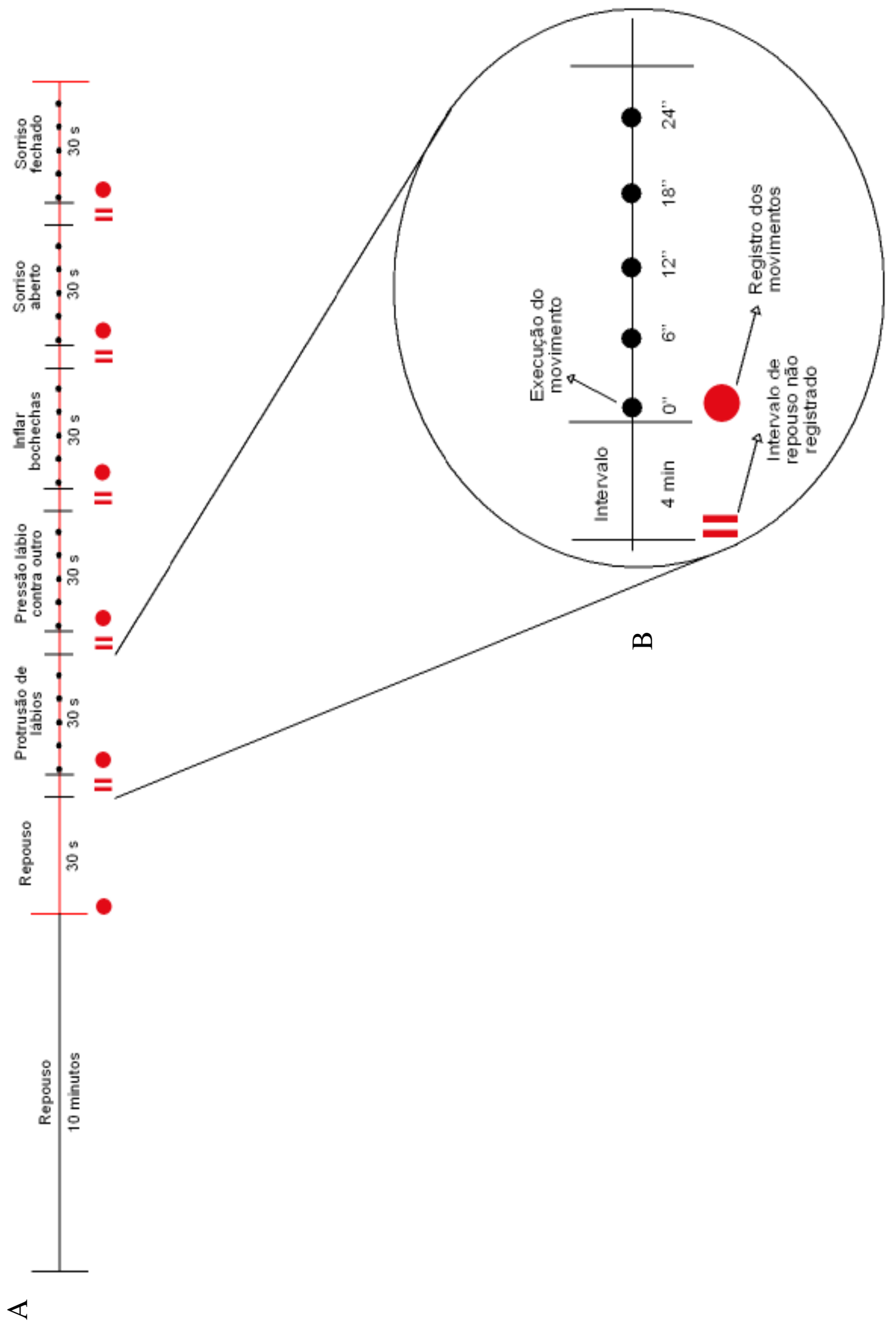


Após a coleta dos dados, os mesmos eram apresentados na tela do computador e as contrações eram delimitadas (T1 e T2) (Figura 10).

Figura 10 - Tela do computador mostando o registro de um tipo de movimento e a delimitação da contração

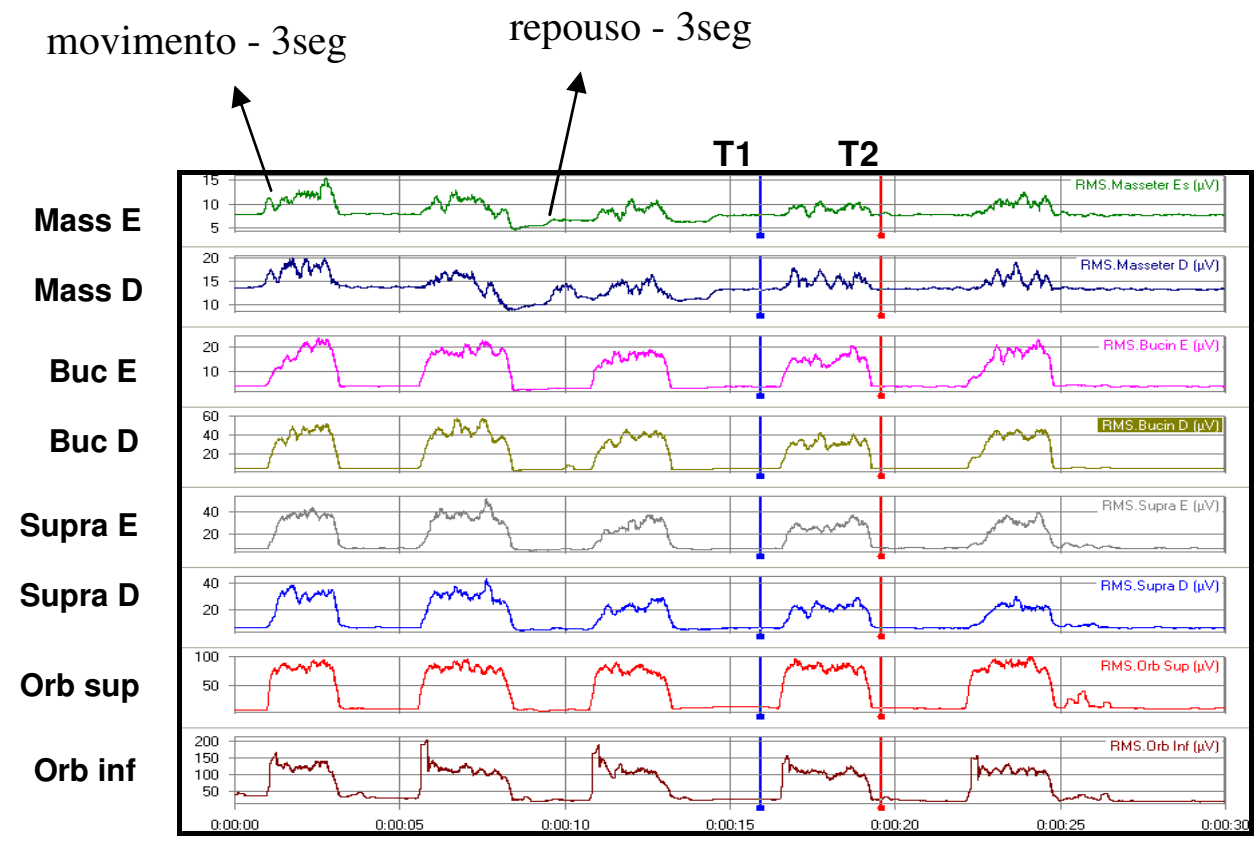

Mass E - músculo masseter esquerdo; Mas D - músculo masseter direito; Buc E - músculo bucinador esquerdo; Buc D - músculo bucinador direito; Suprs E - músculos supra-hióideos esquerdo; Supra D músculos supra-hióideos direito; Orb sup - músculo orbicular superios; Orb inf - músculo orbicular inferior; T1 e T2 - áreas selecionadas para análise

A área selecionada era apresentada em forma de tabela, realizada pelo próprio softwear e expressos em números. Os valores utilizados eram os representados em RMS (Root Mean Square) (Figura 11). 
Figura 11 - Dados da contração delimitada entre T1 e T2 e utilizados os dados em RMS

\begin{tabular}{|c|c|c|c|c|c|c|c|c|}
\hline & |RMS Masseter E: & PMS Masseter D & AMS.Bucin E & AMS Bucin D & AMS.SupraE & AMMS.Supra D & RMS Oib Sup & RMS. Oblat \\
\hline I & 60 & (6V) & (uv) & $(4 \mathrm{~V})$ & $\begin{aligned}\mu \mathrm{V}) \\
\end{aligned}$ & $(j M)$ & (j) & $6 \mathrm{OM}$ \\
\hline Anostes: & 3500 & 350 & $\$ 550$ & $\$ 650$ & 3650 & 3650 & 3550 & $3 \times 50$ \\
\hline Masumo & 10.5591 & 18.0054 & 20.2332 & 43.1824 & 37,4756 & 29.2053 & 96.3745 & 158.783 \\
\hline Mirimo & 7,23667 & 13,1836 & 3,96729 & 5,00460 & 6.5918 & 6.68335 & 10,1624 & 22,9187 \\
\hline Mbx - Min & 3,32542 & 4,82178 & 16.2659 & 38,1775 & 30,8008 & 22,522 & 08,2122 & 135,004 \\
\hline Médis & 8,71138 & 14,7711 & 11,7001 & 24.2215 & 21,2867 & 17,2979 & 51,3583 & 85,4435 \\
\hline Detvio Padbo & 0.844217 & 1,24557 & 5,0003 & 12.233 & 9.516 & 7,14615 & 30.5943 & 39,0779 \\
\hline Bien & 312005 & 5320013 & $42 \mathrm{~min}$ & 98.4024 & 272788 & $53.1 \times 5$ & 223982 & 31184 \\
\hline FMS & 8.75121 & $148 \div 19$ & 12.7236 & 27.1352 & 23,3857 & 18.7156 & 68.5715 & 93.9548 \\
\hline
\end{tabular}

Todos os dados foram armazenados no microcomputador em pastas individuais para cada paciente, para posterior análise dos dados. 


\section{ANÁLISE DOS DADOS}

Os dados foram coletados, analisados e comparados em tabelas (Apêndice).

Para a análise da posição de repouso, o delimitador T1 foi posicionado no inicio da coleta e T2 no final dos 30 segundos. Já para delimitar cada contração, durante os tipos de movimentos, foi utilizado o delimitador T1, no início da contração, e o T2, no final da mesma (Tabela 10), delimitando-se assim, a contração. Desta forma, das cinco contrações registradas em cada tipo de movimento, foram selecionadas as três contrações intermediárias, tendo sido descartadas a primeira e a última. A análise estatística foi realizada com as médias dessas três contrações.

Após delimitar a contração, a área selecionada era apresentada em forma de tabela. Os valores utilizados eram os representados em RMS (Figura 11). Em seguida, este valor era selecionado e colocado em uma tabela no programa Excel, para cada contração.

Esse procedimento foi realizado para as três contrações medianas selecionadas. Em seguida, foi realizada a media em RMS de cada tipo de movimento, realizado em todos os sujeitos, chegando-se ao número representativo da média de contração de cada músculo.

As medidas de dados qualitativos foram representadas e analisadas em termos de proporções e porcentagem de cada característica, em relação a amostra dos pacientes com dor muscular mastigatória. As medidas de dados quantitativos deram origem às medidas de tendência central (média e mediana) para a descrição da amostra. 
Para a normalização dos dados eletromiográficos, as médias das contrações de cada músculo em RMS, em cada tipo de movimento, foi dividida pelo valor de repouso do mesmo individuo.

Com estes valores finais é que foram realizados os testes estatísticos. Para a análise estatística na comparação dos dados durante o repouso, foi utilizado o teste não-paramétrico de Mann-Whitney e para a análise dos dados em movimento foi utilizado o teste não-paramétrico de Friedman.

O nível de significância foi de $5 \%$. 


\section{RESULTADOS}

\subsection{Avaliação fonoaudiológica}

A avaliação fonoaudiológica constou de anamnese e exame clínico do sistema estomatognático.

\subsubsection{Anamnese}

Dos 15 pacientes com dor muscular mastigatória avaliados, todos foram do gênero feminino com idade média de 33,4 (variando entre 20 e 45).

Quanto ao período do dia que os pacientes com dor muscular mastigatória sentiam mais dor, podemos observar que 4 pacientes $(26,6 \%)$ apresentaram dor o dia todo, 4 pacientes $(26,6 \%)$ apresentaram dor pela manhã, 2 pacientes $(13,4 \%)$ apresentaram dor no período da tarde e $5(33,4 \%)$ apresentaram dor no período da noite (Tabela 3).

Tabela 3 - Período do dia em que os pacientes com dor muscular mastigatória relataram sentir dor

\begin{tabular}{ccl}
\hline \hline Período do dia & $\mathrm{N}$ & $(\%)$ \\
\hline dia todo & 4 & $(26,6)$ \\
manhã & 4 & $(26,6)$ \\
à tarde & 2 & $(13,4 \%)$ \\
à noite & 5 & $(33,4 \%)$ \\
\hline TOTAL & 15 & $(100 \%)$ \\
\hline \hline
\end{tabular}


Em relação à escala numérica de dor (END) (média de 5,41; desvio padrão de 3,70 , variando de 0 a 10), dois pacientes (13,33\%) relataram não apresentar dor no momento do exame, a mesma quantidade relatou apresentar dor grau 2; dois pacientes (13,33\%) apresentaram dor grau 3; um paciente $(6,68 \%)$ relatou apresentar dor grau 4 ; também um paciente $(6,68 \%)$ relatou dor grau 6; dois pacientes $(13,33 \%)$ relataram dor grau 7 ; um paciente $(6,68 \%)$ dor grau 1 e quatro pacientes $(26,66 \%)$ relataram apresentar dor grau 4 no momento do exame (Tabela 4).

Tabela 4 - Distribuição dos pacientes com dor muscular mastigatória, quanto à intensidade de dor segundo a escala numérica de dor, no momento da avaliação

\begin{tabular}{cc}
\hline \hline Grau da dor & $\mathrm{N}(\%)$ \\
\hline 0 & $2(13,33)$ \\
2 & $2(13,33)$ \\
3 & $2(13,33)$ \\
4 & $1(6,68)$ \\
6 & $1(6,68)$ \\
7 & $2(13,33)$ \\
8 & $1(6,66)$ \\
10 & $4(26,66)$ \\
\hline TOTAL & $15(100)$ \\
\hline \hline
\end{tabular}




\subsubsection{Exame clínico do sistema estomatognático}

A alteração fonoaudiológica tanto de tonicidade quanto de mobilidade foi um dos critério de exclusão no GC. Portanto, nestes itens, o GC foi normal.

Nos pacientes com dor muscular mastigatória, quanto a tonicidade de lábios observamos que 6 pacientes (40\%) apresentaram tonicidade normal, seis sujeitos (40\%) apresentaram tonicidade tipo flácido 1 e três $(20 \%)$ apresentaram tonicidade tipo flácido 2. Quanto a tonicidade de língua, quatro pacientes $(26,67 \%)$ apresentaram tonicidade normal, nove (60\%) apresentaram tonicidade tipo flácido 1 e dois pacientes (13,33\%) apresentaram tonicidade tipo flácido 2. Quanto a tonicidade de bochechas, dez pacientes $(66,67 \%)$ apresentaram tonicidade normal e cinco pacientes $(33,33 \%)$ apresentaram tonicidade tipo flácido 1 (Tabela 5).

Tabela 5 - Distribuição dos pacientes com dor muscular mastigatória quanto à tonicidade dos órgãos fonoarticulatórios, segundo a avaliação clínica fonoaudiológica

\begin{tabular}{cccc}
\hline \hline & \multicolumn{3}{c}{ Orgãos fonoarticulatõrio } \\
\cline { 2 - 4 } Tonicidade & Lábios & Língua & Bochechas \\
& $\mathrm{N}(\%)$ & $\mathrm{N}(\%)$ & $\mathrm{N}(\%)$ \\
\hline normal & $6(40)$ & $4(26,67)$ & $10(66,67)$ \\
flácido 1 & $6(40)$ & $9(60)$ & $5(33,33)$ \\
flácido 2 & $3(20)$ & $2(13,33)$ & 0 \\
\hline TOTAL & $15(100)$ & $15(100)$ & $15(100)$ \\
\hline \hline
\end{tabular}

Quanto à mobilidade dos mesmos órgãos, o GMM apresentou adequação. 


\subsection{Eletromiografia}

Quanto ao repouso, podemos observamos que o GC apresentou diferenças estatisticamente significantes em relação aos músculos masseteres esquerdo e direito, comparado ao GMM. Não houve diferenças significantes em relação aos demais músculos.

Os dados da atividade EMG na posição de repouso dos dois grupos, podem ser observados na figura 11.

Figura 12 - Posição de repouso no grupo de dor muscular mastigatória (GMM) e grupo controle (GC)

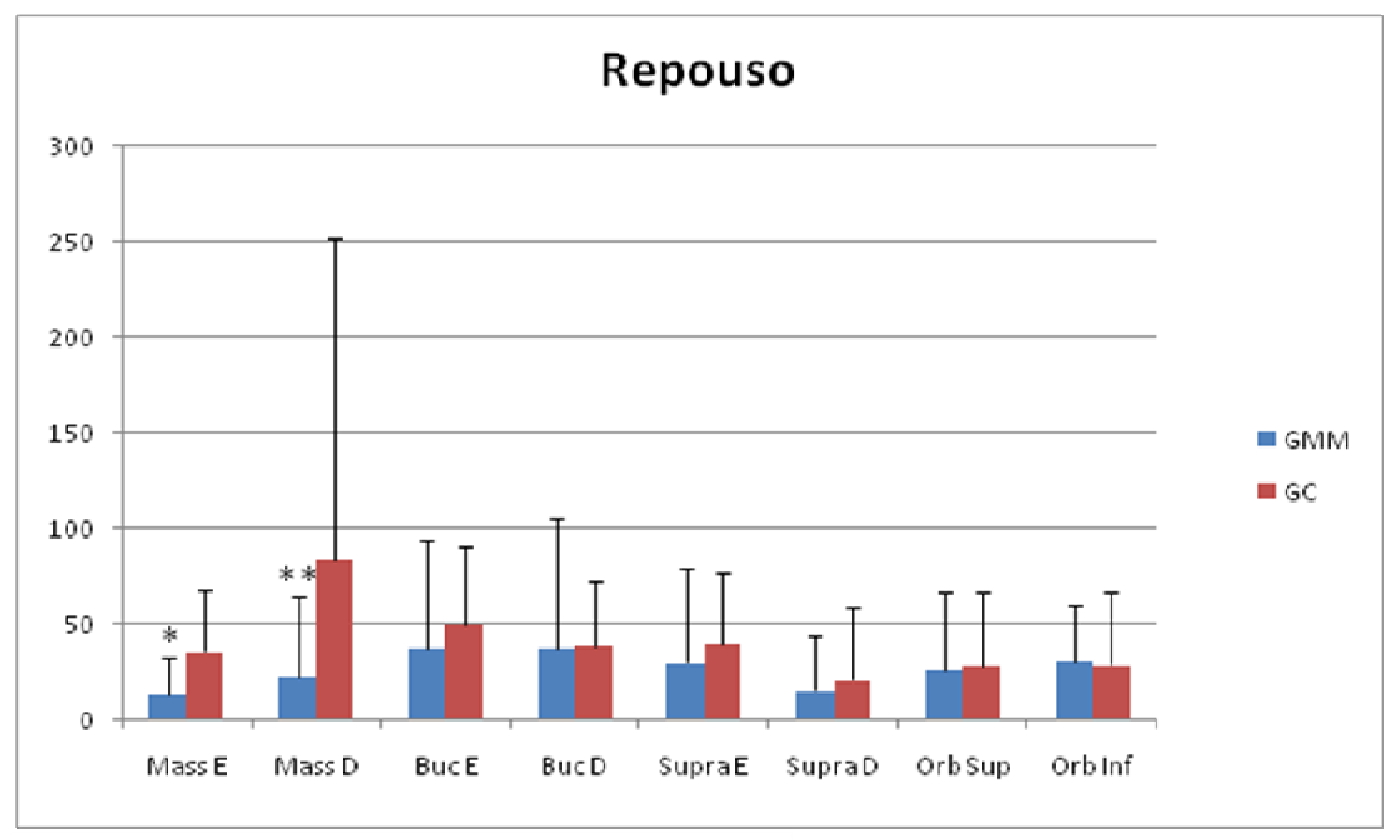

${ }^{*} \mathrm{p}=0.019{ }^{* *} \mathrm{p}=0.012$

Quanto à atividade EMG no movimento de apertamento dos lábios no GMM, podemos observar que o músculo orbicular superior apresentou valor significativamente maior que os músculos masseteres esquerdo e direito e supra-hióideo esquerdo. O músculo orbicular inferior apresentou valor significativamente maior que o músculo masseter direito. 
Quanto à atividade EMG, do GC, temos que os músculos orbiculares superior e inferior apresentaram valores significativamente maiores que os músculos masseteres esquerdo e direito, bucinadores esquerdo e direito e supra-hióideo direito. O músculo orbicular inferior apresentou valor significativamente maior que o supra-hióideo esquerdo.

Comparando-se os dois grupos, temos que o GMM e o GC diferiram quanto aos músculos bucinadores esquerdo e direito, supra-hióideos esquerdo e direito e orbicular superior. O GMM apresentou valor significativamente maior que o grupo GC, em todos os músculos.

Os dados da atividade EMG, no movimento de apertamento dos lábios dos dois grupos, podem ser observados na figura 12.

Figura 13 - Pressão de um lábio contra o outro (apertamento) no grupo de dor muscular mastigatória (GMM) e grupo controle (GC)

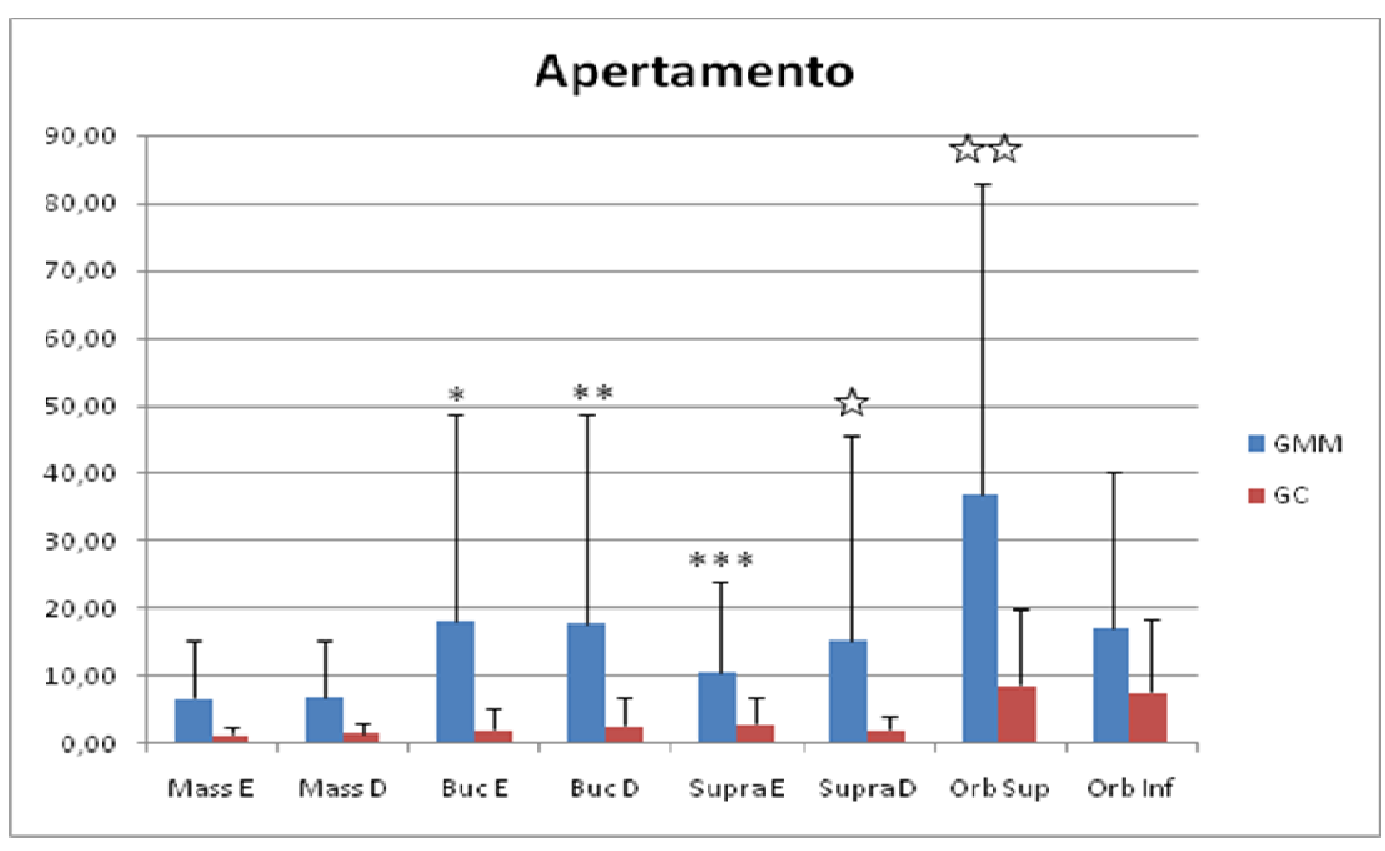

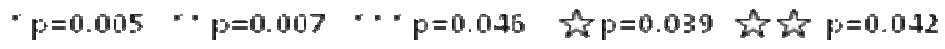


Quanto à atividade EMG no movimento de protrusão dos lábios no GMM, podemos observar que os músculos orbiculares superior $e$ inferior apresentaram valores significativamente maiores que os músculos masseteres esquerdo e direito e o supra-hióideo esquerdo. O músculo orbicular superior, ainda difere significativamente dos músculos bucinador esquerdo e suprahióideo direito, apresentando valor significativamente maior.

Quanto à atividade EMG do GC, os músculos orbiculares superior e inferior apresentaram valores significativamente maiores que os músculos masseteres esquerdo e direito, bucinadores esquerdo e direito, supra-hióideos esquerdo e direito.

Comparando-se os dois grupos, observamos que o GMM difere o GC nos músculos bucinador esquerdo e supra-hióideo esquerdo. O GMM apresentou valor significativamente maior do que o grupo de GC em todos os músculos.

Os dados da atividade EMG, no movimento de protrusão dos lábios dos dois grupos, podem ser observados na Figura 13.

Figura 14 - Protrusão dos lábios no grupo de dor muscular mastigatória (GMM) e grupo controle (GC)

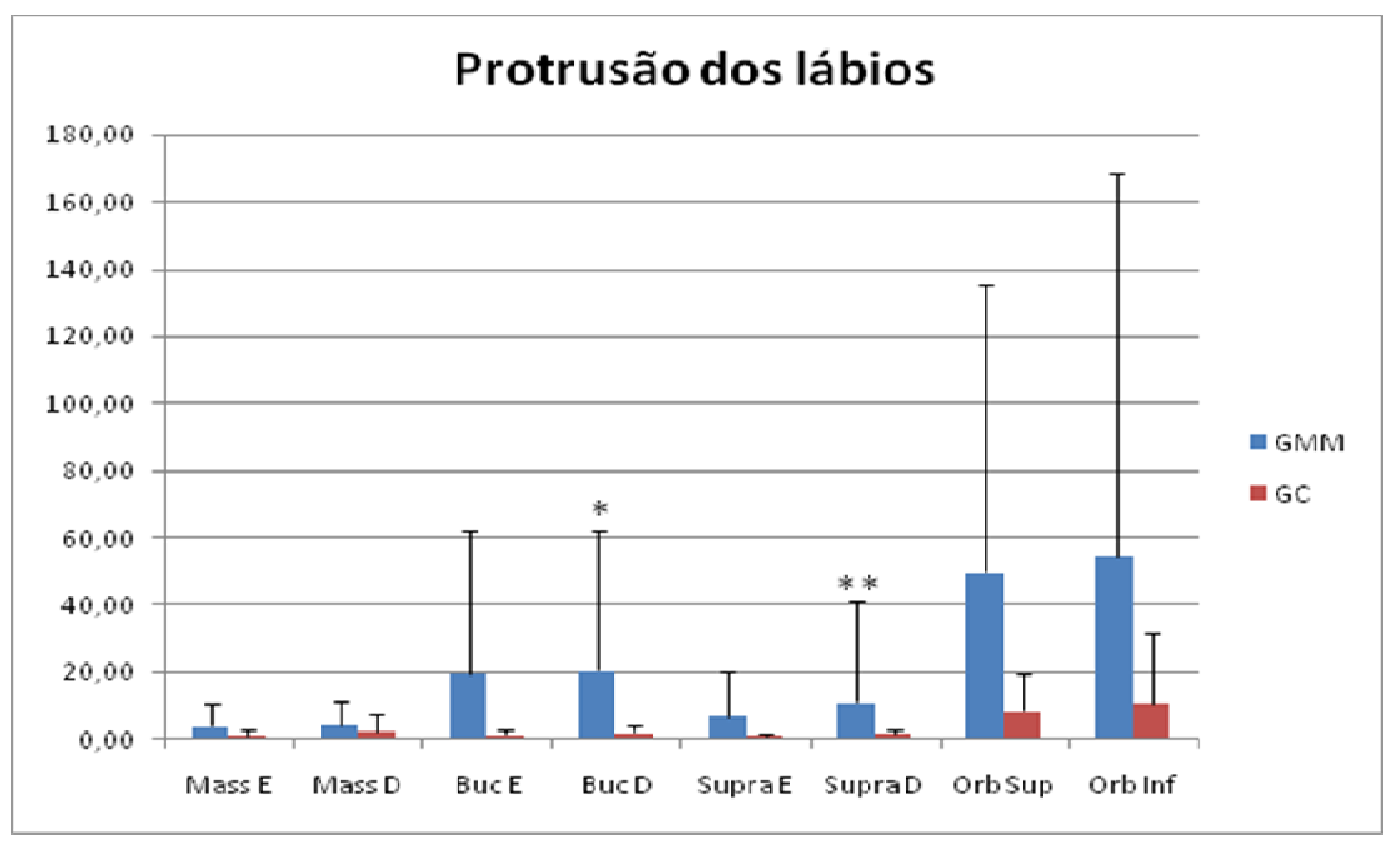

$p=0.005 \cdots p=0011$ 
Quanto à atividade EMG no movimento de inflar as bochechas no GMM, podemos observar que o músculo orbiculares superior e inferior apresentou valores significativamente maiores que os músculos masseteres esquerdo e direito e supra-hióideo direito. O músculo orbicular superior ainda difere significativamente do músculo supra-hióideo esquerdo, apresentando valor significativamente maior.

Quanto à atividade EMG do GC, podemos observar que o músculo orbicular superior e inferior apresentou valores significativamente maiores que os músculos masseteres esquerdo e direito, bucinadores esquerdo e direito e supra-hióideos esquerdo e direito.

Comparando-se os dois grupos, observamos que ambos os grupos diferem quanto ao músculo masseter esquerdo, bucinadores esquerdo e direito e o orbicular superior. O GMM apresenta valor significativamente maior do que o grupo de GC, em todos os músculos.

Os dados da atividade EMG, no movimento de inflar as bochechas dos dois grupos, podem ser observados na Figura 14. 
Figura 15 - Inflar as bochechas no grupo de dor muscular mastigatória (GMM) e grupo controle (GC)

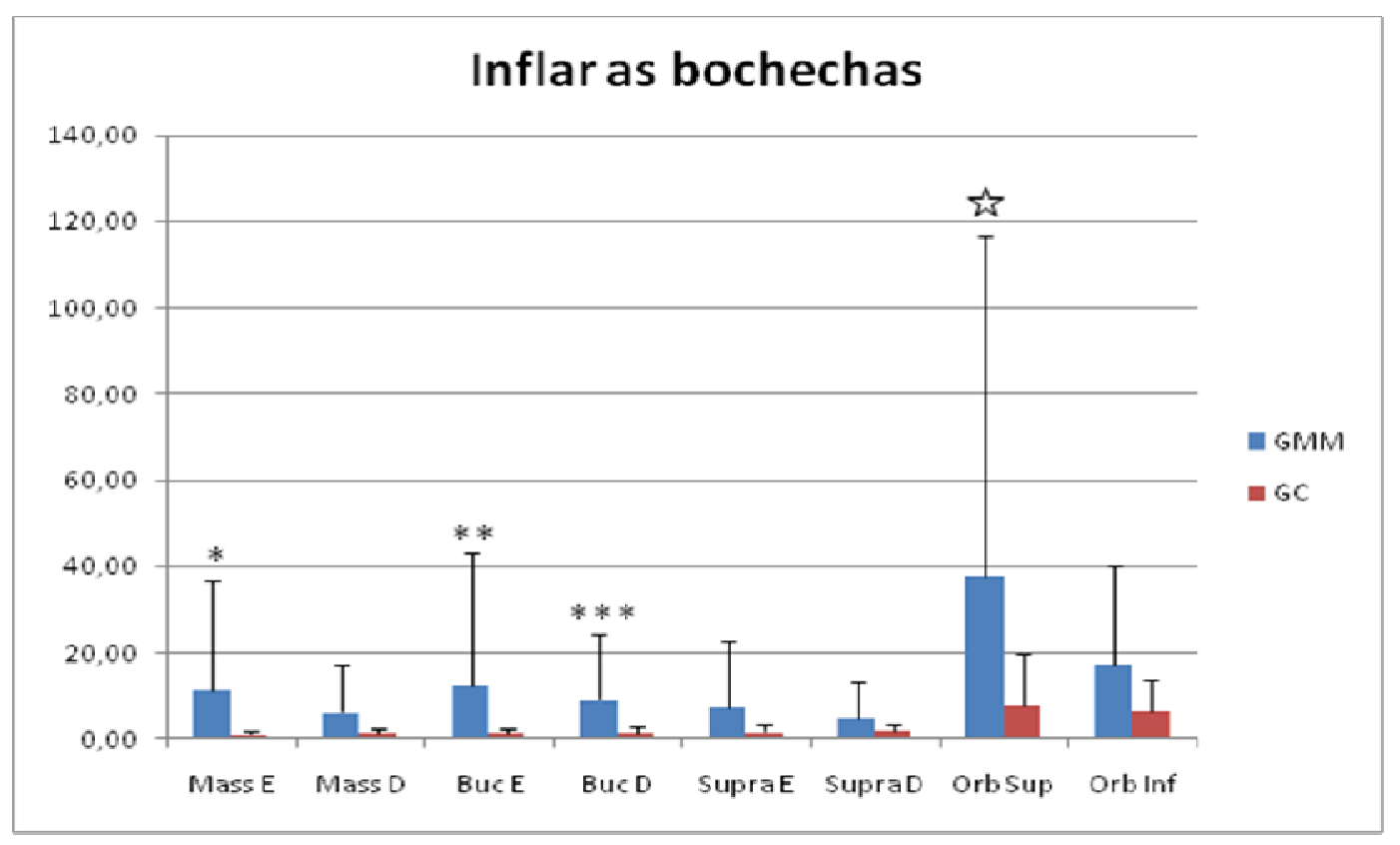

${ }^{*} p=0.021 \cdots p=0.007 \cdots p=0.002$ 낭 $p=0.039$

Quanto à atividade EMG no movimento de sorriso aberto no GMM, podemos observar que o músculo masseter direito apresentou valor significativamente menor que o músculo orbicular inferior.

Quanto à atividade EMG do GC, podemos observar que os músculos orbiculares superior e inferior apresentaram valores significativamente menores que os músculos masseteres esquerdo e direito e os supra-hióideos esquerdo e direito.

Comparando-se os dois grupos, observamos que ambos diferem quanto ao músculo masseter esquerdo. O GMM apresentou valor significativamente maior do que o grupo de GC, em todos os movimentos.

Os dados da atividade EMG no movimento de sorriso aberto dos dois grupos, podem ser observados na Figura 15. 
Figura 16 - Sorriso aberto no grupo de dor muscular mastigatória (GMM) e grupo controle (GC)

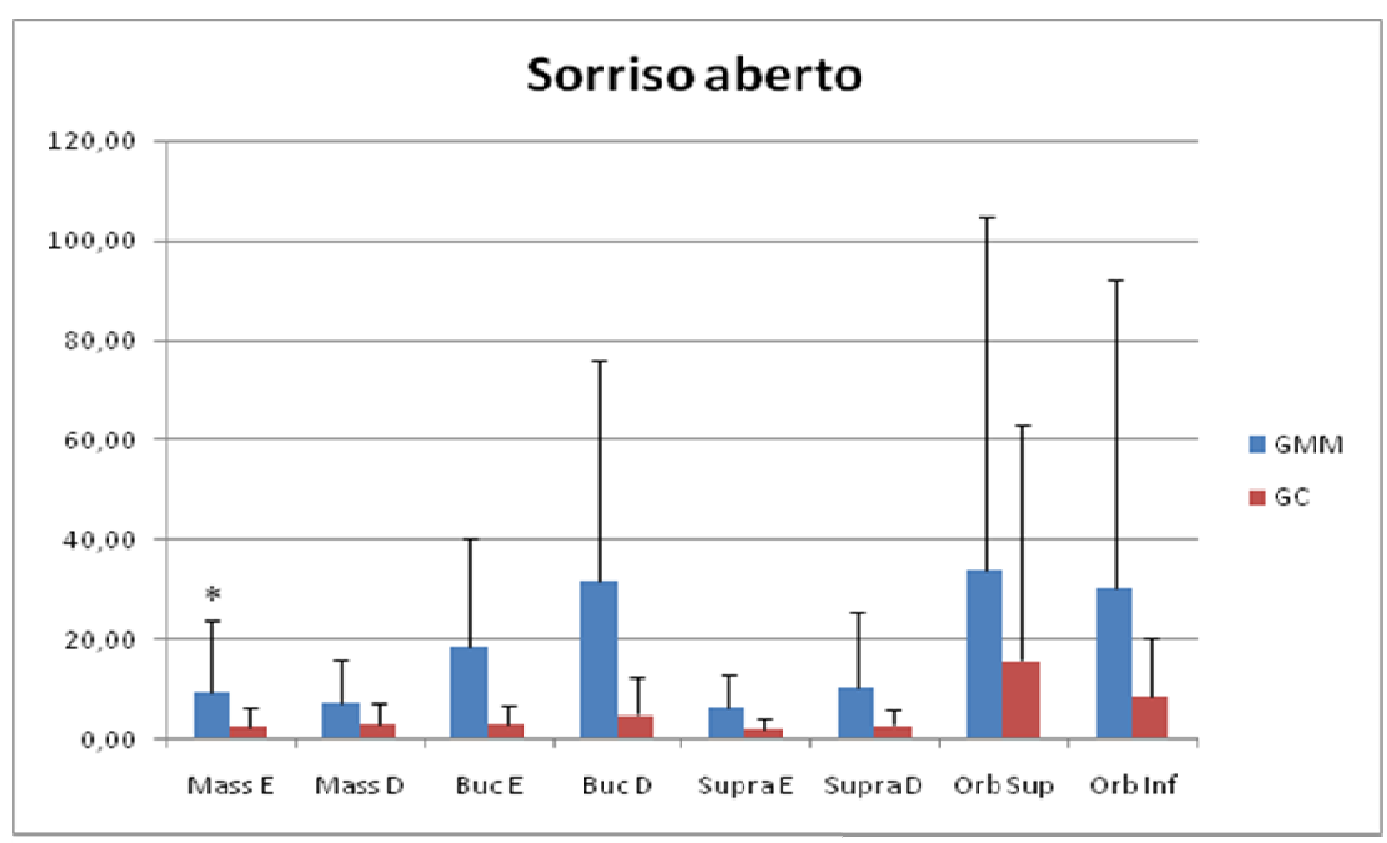

${ }^{*} p=0.030$

Quanto à atividade EMG no movimento de sorriso fechado no GMM, podemos observar que o músculo supra-hióideo direito apresentou valor significativamente menor que os músculos bucinadores esquerdo e direito.

Quanto à atividade EMG do GC, podemos observar que o músculo suprahióideo esquerdo apresentou valor significativamente menor que os músculos bucinador direito e os orbicurares superior e inferior.

Comparando-se os dois grupos, observamos que ambos diferem quanto aos músculos masseteres esquerdo e direito, bucinadores esquerdo e o suprahióideo esquerdo. O GMM apresenta valor significativamente maior do que o grupo de GC, em todos os músculos.

Os dados da atividade EMG no movimento de sorriso fechado dos dois grupos, podem ser observados na Figura 16. 
Figura 17 - Sorriso fechado no grupo de dor muscular mastigatória (GMM) e grupo controle (GC)

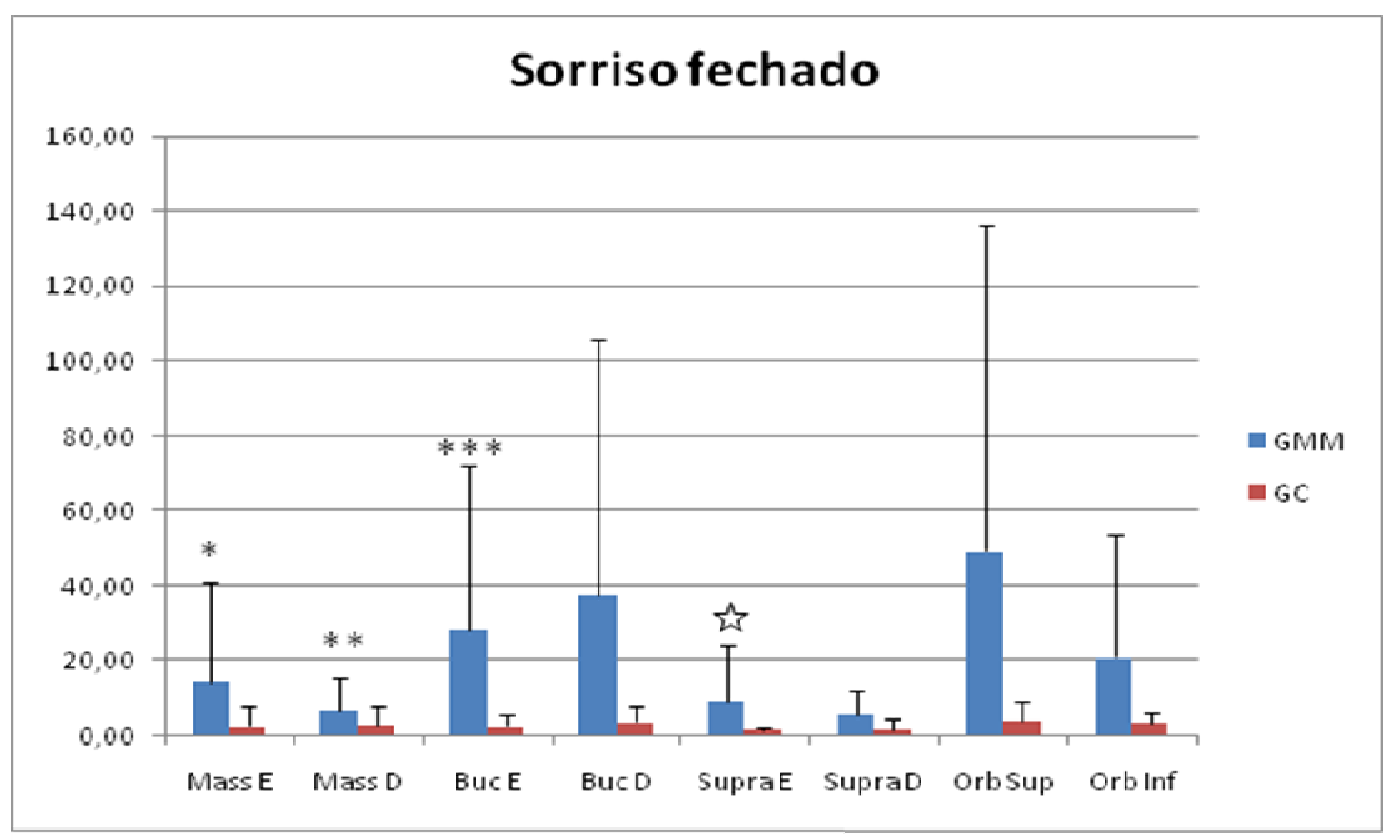

$* \mathrm{p}=0.004$ ** $\mathrm{p}=0.019 * * * \mathrm{p}=0.013$ 药 $\mathrm{p}=0.046$ 


\section{DISCUSSÃo}

Embora a importância da eletromiografia de superfície seja questionada quanto à sua aplicação no diagnóstico e tratamento de pacientes com dor e distúrbios temporomandibulares e não tenha sido demonstrado ser ela superior ou mesmo semelhante aos métodos diagnósticos atuais, que se baseiam na história clínica e no exame minucioso dos músculos da mastigação e da articulação temporomandibular, o mesmo não se aplica quando se trata de pesquisa clínica, pois quando os estudos eletromiográficos são realizados em condições apropriadas e devidamente monitoradas, o que é muito mais difícil em termos de rotina clínica, eles podem trazer subsídios para a melhor compreensão dessa afecção álgica (Kasser; Okeson, 2006).

Até o presente momento, existem muitos estudos sobre os músculos da mastigação, porém, ainda são escassos os estudos sobre o comportamento dos músculos da mímica em pacientes com queixas de dor muscular mastigatória, embora a literatura científica documente que pontos dolorosos nesses músculos também causam dor difusa (Jaeger et al, 2005).

A EMG tem permitido tanto a investigação neuromuscular como a cinesiológica e a biomecânica, dependendo do tipo de técnica empregada. No presente estudo, a técnica eletromiográfica através de eletrodos de superfície foi escolhida por ser menos invasiva (Bérzin, 2004). Seguramente ela tem limitações e os dados deste estudo não podem ser ampliados a todos os pacientes, principalmente quando realizados fora de condições padronizadas que minimizem as distorções. 
Vários fatores influenciam o resultado da EMG de superfície, como sexo, idade, condição morfológica da face, as características da pele dos indivíduos (Basmajian e De Luca, 1985; Lund et al, 1995; Tassinary et al, 1989; Klasser; Okeson, 2006) e o próprio ambiente em que é realizado o exame, o que motivou o pareamento da presente amostra.

\subsection{Intensidade de dor}

A dor é uma experiência desagradável, em alguns casos limitantes. Sua função é de proteção, levando o indivíduo a procurar tratamento. Tem diferentes significados para cada indivíduo e para cada situação (Bianchini, 2000).

Neste estudo, a intensidade de dor dos pacientes com dor muscular mastigatória foi em média moderada $(E N D=5,4)$, o que coincide com a literatura a respeito, que mostra que pacientes com queixas de dor, apresentam intensidade variando de leve a moderada (Dworkin et al, 1990). Parece não existir predileção por período do dia para a dor (Cabezas, 1997; Felício, 1999; Okeson, 2006; De Leeuw, 2008), como também foi observado neste estudo, embora pacientes com dor muscular por bruxismo relatem mais freqüência de dor ao acordarem pela manhã (Camparis; Siqueira, 2006). Entretanto, bruxismo não foi avaliado no presente estudo. Vários mecanismos estão envolvidos na dor crônica, como sensibilização central, neuroplasticidade, disfunção do sistema inibitório descendente e anormalidades psicossocias (Sessle, 2005) e a intensidade relatada pelo paciente depende da somatória de fatores avaliados. Sarlani; Greenspan, 2005, compararam as diferenças de respostas, através da Escala Analógica de 
Dor (VAS), em pacientes com DTM, comparativamente a mulheres e homens saudáveis. Verificaram que a somação temporal da dor foi maior nos pacientes com DTM do que nos indivíduos saudáveis, fato que sugere uma hiperexcitabilidade do sistema nocicepitivo central, o que contribui para o desenvolvimento ou manutenção da dor crônica em DTM.

\subsection{Dor no sexo feminino}

A dor muscular mastigatória é mais prevalentes em mulheres, e por essa razão optou-se por uma amostra feminina, para reduzir as possíveis influências do gênero nos resultados da EMG.

Estudos relatam que pelo fato da mulher apresentar vários fatores, inclusive hormonais, que a diferenciam dos homens, as tornam mais susceptíveis à dor crônica (Bianchini, 2000; Berretin-Felix et al, 2005, Bove et al em 2005, Sarlani; Greenspan, 2005).

\subsection{Alterações fonoaudiológicas}

O sistema estomatognático é constituído por estruturas que trabalham harmonicamente, com o objetivo de desempenhar as funções orais. As alterações que possam ocorrer nesse sistema podem gerar desequilíbrios, impedindo o desempenho adequado das funções (Bianchini, 2000).

As maiores alterações fonoaudiológicas encontradas neste estudo foram do tipo flacidez dos lábios, língua e bochechas. Segundo Felício (1999) e Bianchini (2000), essas alterações são as mais comumente encontradas quando se trata de pacientes com DTM. 
Os desequilíbrios musculares em pacientes com DTM, principalmente na dor muscular mastigatória, são comuns, uma vez que esses desequilíbrios acometem as funções orais de mastigação e deglutição, sendo que estas funções são importantes para manter a tonicidade muscular de lábios, língua e bochechas. Desta forma, é importante o restabelecimento do equilíbrio miofuncional de tais órgãos, por meio de terapia fonoaudiológica e consequentemente das funções orais (Felício, 1999; Bianchini, 2000).

Nesta amostra não foram encontradas alterações de mobilidade desses órgãos, porém essas alterações podem ser observadas devido à alteração de tonicidade, dificultando os movimentos.

\subsection{Eletromiografia no repouso}

A relação entre dor muscular e hiperatividade muscular tem sido defendida por muitos autores (Goldreich et al, 1994; Dworkin et al,1988; Tassinary et al, 1989; Sarlani; Greenspan, 2005), entretanto essa relação é complexa e até o presente momento não existe comprovação de relação causa-efeito (Lund; Widmer 1989; Lund et al 1995, Lund 1995). Dor que não envolve diretamente os músculos da mastigação, podem também afetar a atividade desses músculos (Kasser \& Okeson, 2006).

Esses autores realçaram, em excelente revisão da literatura sobre função motora mastigatória e dor. Por exemplo, que a atividade dos masseteres reduz após ativação ortodôntica, devido à dor na estrutura paradental desencadeada por esse procedimento (Goldreich et al, 1994), além disso, dor crônica em estruturas adjacentes aos músculos da mastigação pode aumentar a atividade destes durante registros eletromiográficos (Schroeder et al, 1991), da mesma 
forma como ocorre após a aplicação de estímulos nocivos em estruturas somáticas profundas (Maillou e Cadden, 1997), na articulação temporomandibular (Wang et al, 2004), em pacientes com cefaléia primária do tipo-tensão (Jensen, 1999) ou em pacientes com dores cervicais (Wang et al, 2004). Por outro lado, a existência de dor nos músculos da mastigação causa redução da atividade desses músculos e do movimento mandibular (Lund et al, 1991).

No presente estudo, houve redução da atividade eletromiográfica no repouso, comparativamente com o controle, dado que pode coincidir com o que é formulado pelo "modelo de adaptação à dor" de Lund $(1991 ; 1995)$, em que a presença de dor nos músculos da mastigação pode provocar adaptação funcional desses mesmos músculos, reduzindo sua atividade e demonstrando o papel inibitório da dor como proteção ao segmento afetado, como já foi discutido no parágrafo anterior.

Estudos de EMG com indivíduos saudáveis submetidos a estresse mostram sua influência nos músculos da mastigação e na posição mandibular (Cecere et al, 1996; Ruf et al, 1997; Tsai et al, 2002). Na posição de repouso observamos diferença significativa no masseter dos pacientes com dor muscular mastigatória, portanto não se pode desconsiderar a influência da condição emocional dos pacientes nos presentes resultados. De qualquer modo, essa seria uma resposta da própria condição de cronicidade da dor, a qual não se pode facilmente separar em um estudo desta natureza.

Outro aspecto interessante, ainda no que diz respeito à EMG em repouso do masseter, é que pessoas com dor demonstram sua dor por expressão facial. Isto foi evidenciado por Dworkin et al (1988) que monitoraram a expressão 
facial de pessoas com dor crônica na ATM depois do exame clinico envolvendo palpação dos músculos mastigatórios e cervicais e da ATM. Em outro estudo Dworkin; LeResche (1992) filmaram 36 mulheres com DTM crônicos comparando com 35 mulheres com DTM agudos em um teste de estímulos de dor (cold pressor test) e palpação digital dos músculos mastigatórios e ATM. Encontraram que os níveis de expressão facial induzidas pela dor eram significativamente maiores em sujeitos com DTM crônica. Isto pode contaminar os resultados causando aumento momentâneo na atividade do músculo e também não pode ser descartada sua possibilidade nos resultados do presente estudo.

\subsection{Eletromiografia dos músculos da mímica}

As alterações eletromiográficas observadas neste estudo, durante os movimentos dos músculos da mímica, ocorreram predominantemente no grupo de estudo. Como os músculos da mímica, encontram-se na região afetada, embora inicialmente não estejam diretamente envolvidos na atividade dos músculos mastigatórios, esses dados poderiam estar em acordo com o envolvimento de cadeias musculares adjacentes à região afetada, como já foi discutido anteriormente. Até o presente momento, a maioria dos estudos correlaciona dores orofaciais ou cefaléias com músculos pericraniais, mastigatórios ou cervicais, mas são escassos ou inexistem estudos, como o atual, relacionando-os com os músculos da mímica.

Pode-se especular que, os valores superiores encontrados na EMG dos músculos da mímica no grupo de pacientes com dor muscular mastigatória, poderiam decorrer da dor emanada dessas estruturas profundas, como ocorre 
com os músculos cervicais (Wang et al, 2004) ou após ativação de aparelho ortodôntico (Goldreich et al, 1994), em relação aos músculos mastigatórios.

Nos movimentos de pressão de um lábio contra o outro (apertamento), protrusão dos lábios e inflar as bochechas o músculo que apresentou maior atividade EMG foi o orbicular dos lábios, tanto no GC como no GMM. Os dados encontrados neste estudo corroboram com os encontrados por Stefani (2008), a qual observou que o músculo orbicular da boca foi o que apresentou maior atividade elétrica nos movimentos de pressão de um lábio contra o outro, protrusão labial e lateralização dos lábios.

Zemlin (2000) afirma que o lábio inferior é menos variável na geração de um nível de força estática do que o superior, porém o lábio superior é mais estável que o inferior. Em uma pesquisa realizada por Neely e Pomerantz (2002) observou-se que o lábio inferior gerou o dobro de força, em Newtons, que o lábio superior.

Para tais movimentos (apertamento dos lábios, protrusão dos lábios e inflar as bochechas), é necessário o vedamento labial para que ocorra a pressão negativa intra oral e, consequentemente a realização do movimento. Por ser o músculo orbicular da boca o principal músculo dos lábios e, uma vez contraído, fecha a boca e enruga os lábios (Zemlin, 2000) é justificável a participação mais ativa deste músculo durante esses movimentos.

Os músculos das bochechas, principalmente os músculos risório e bucinador foram mais ativos no movimento de sorriso fechado, nos dois grupos avaliados. Para a realização do movimento de sorriso fechado, temos o direcionamento do ângulo de boca lateralmente. O músculo bucinador é o mais profundo da musculatura facial e as fibras do músculo risório são paralelas e 
superficiais ao bucinador, sendo que a função principal destes músculos é o direcionamento lateral do ângulo de boca (Zemlin, 2000). Stefani (2008) também encontrou que o músculo bucinador foi mais ativo no movimento de sorriso, porém tanto aberto quanto fechado.

\subsection{Normalização dos dados}

Muitos pesquisadores relatam a existência de variáveis que podem interferir na validade e na precisão de qualquer medida eletromiográfica (Turker, 1993; Basmajian e De Luca, 1985; Lund et al, 1995; Tassinary et al, 1989; Klasser; Okeson, 2006). Desta forma, faz-se necessário o controle dessas variáveis, para a confiabilidade nos resultados obtidos.

Em muitos estudos que utilizam a eletromiografia de superfície é utilizada a normalização dos dados com o objetivo de minimizar as diferenças na comparação dos valores EMG obtidos nos mesmos músculos em diferentes sujeitos, ou em diferentes músculos no mesmo sujeito ou ainda no mesmo sujeito e músculo, porém em dias diferentes (Basmajan, De Luca, 1985; Kelly et al, 1996; Ervilha et al, 1998; Lapatki et al, 2003).

As técnicas de normalização utilizam a conversão de valores eletromiográficos absolutos em valores relativos. A atividade elétrica de um músculo durante uma determinada tarefa é comparada com um valor de referência muscular (Mirka, 1991). Porém é controversa a técnica utilizada mais recomendada. Em estudos na área de ortopedia e fisioterapia, a técnica mais empregada é a comparação da contração máxima com o movimento isométrico de um músculo pré-determinado. 
Segundo estudo realizado por Ervilha et al, 1998, a normalização de um sinal EMG de superfície pode ser realizada pelo pico ou média do sinal eletromiográfico ou pela contração máxima do músculo. Em seus resultados, os autores observaram que o coeficiente de variabilidade $(\mathrm{CV})$, que é o quociente entre o desvio padrão e a média, foi menor quando utilizado o procedimento de normalização pela média ou pelo pico do sinal EMG, tornando os dados mais confiáveis. Em nosso estudo, a normalização foi realizada dividindo-se as médias das contrações de cada músculo em RMS, em cada tipo de movimento pelo valor de repouso do mesmo individuo, seguindo a recomendação de Ervilha et al 1998.

\subsection{Importância e limitações do estudo}

Em conjunto, os dados do presente estudo contribuem para melhor compreensão do papel dos músculos da mímica em pacientes com diagnóstico de dor muscular mastigatória. Embora tenha aumentado o número de estudos com registros eletomiográficos, esses estudos não são realizados em amostras homogêneas e dificultam a comparação.

A despeito das limitações deste estudo, como número da amostra e presença de dor com suas inúmeras variáveis, seus resultados podem ser considerados preliminares e podem indicar alterações específicas nos músculos da mímica que estariam em consonância com as teorias atuais sobre a relação entre dor muscular e atividade muscular segmentar. Certamente novos estudos prospectivos são necessários para compreendermos melhor essa relação entre os músculos da mímica e os músculos da mastigação em pacientes que apresentam dor muscular mastigatória. 


\section{CONCLUSÕES}

Em repouso, o registro EMG dos músculos masseteres foram maiores no grupo controle.

Em todos os tipos de movimentos, os registros EMG dos músculos da mímica, foram maiores no grupo de pacientes com dor muscular mastigatória do que no grupo controle.

O músculo que apresentou maior atividade EMG durante os tipos de movimentos foi o orbicular da boca (seguimentos superior e inferior), principalmente nos movimentos de apertamento dos lábios, protrusão dos lábios e inflar as bochechas. 


\section{ANEXOS}

ANEXO A - Termo de consentimento livre e esclarecido

HOSPITAL DAS CLÍNICAS

FACULDADE DE MEDICINA DA UNIVERSIDADE DE SÃO PAULO

I - DAdOS DE IDENTIFICAÇÃo DO SUJEITO DA PESQUISA OU RESPONSÁVEL LEGAL

Nome do paciente

RG №

Sexo: $M() F(~)$

DN: $. / \ldots \ldots . . . . . . . .$.

№

Endereço Cidade:

Bairro: Telefone:

CEP:

\section{II - DADOS SOBRE A PESQUISA CIENTÍFICA}

\section{Título do protocolo de pesquisa}

Eletromiografia de superfície dos músculos orbicular da boca, bucinador, suprahióideos e masseteres de pacientes com disfunção temporomandibular durante exercícios miofuncionais orofaciais.

\section{Dados do Pesquisador}

Pesquisador Executante: Aline Polido

Cargo/função: Fonoaudióloga

CRFa. № $8204 /$ SP

Unidade do HCFMUSP: Fisiopatologia Experimental

Endereço: Av. Prof. Lineu Prestes, 2227 - Depto. de Cirurgia - Faculdade de Odontologia - CEP: 05508-900

Telefone: 30917887 
$\mathrm{Eu}$

$\mathrm{RG} \quad \mathrm{n}^{\circ}$

concordo em participar da pesquisa de

"Eletromiografia de superfície dos músculos orbicular da boca, bucinador, supra-hióideos e masseteres de pacientes com disfunção temporomandibular durante exercícios miofuncionais orofaciais" de livre e espontânea vontade. Esta pesquisa tem por objetivo verificar se os músculos faciais das pessoas que tem problemas na articulação temporomandibular funcionam como o das pessoas que não tem tais problemas. Minha participação nesta pesquisa consiste em preencher um questionário, realizar uma avaliação fonoaudiológica dos músculos faciais e, em seguida, realizar o exame de eletromiografia (avaliação do funcionamento dos músculos faciais), durante exercícios com os lábios, língua e bochechas. Os benefícios desta pesquisa é contribuir para futuros trabalhos nesta área, bem como, analisar o funcionamento dos meus músculos faciais. Este exame não causa riscos psicológicos nem físicos. O sigilo será total.

Declaro que, após convenientemente esclarecido pelo pesquisador e ter entendido o que me foi explicado, consinto em participar do presente Protocolo de Pesquisa.

São Paulo, de de 200 


\section{ANEXO B - Avaliação fonoaudiológica}

\section{ANAMNESE}

\section{Dados Pessoais}

\section{Nome:}

D.N.:

Idade:

Profissão:

Data:

\section{$\underline{\text { Questões }}$}

1. Você tem algum problema de saúde? Qual(is)?

2. Toma algum medicamento? Qual?

3. Você sente dores na face, mandíbula, têmporas, na frente das orelhas ou nas orelhas? Quando?

4. Como são essas dores?

5. Você já foi a um médico, dentista, terapeuta ou outro profissional da saúde por causa da dor facial? Quando? Qual o tratamento realizado? Qual o resultado do tratamento?

6. Se você sente dor, que nota você daria para a sua dor facial, em uma escala de 0 a 10, no presente momento, se 0 for "sem dor" e 10 for "a pior dor que você já sentiu":

$\begin{array}{lllllllllll}0 & 1 & 2 & 3 & 4 & 5 & 6 & 7 & 8 & 9 & 10\end{array}$

7. Você já ficou com sua mandíbula travada ou de tal forma que fosse impossível abrir a boca?

8. Sua mandíbula estala ou faz qualquer ruído quando você abre ou fecha sua boca ou enquanto mastiga?

9. Alguém já Ihe falou que você range ou aperta os dentes enquanto dorme à noite?

10. Durante o dia, você range ou aperta os dentes?

11.Você sente dor ou cansaço nos músculos da face? Qual o período do dia que dói mais? 
2. AVALIAÇÃO DOS ÓRGÃOS FONOARTICULATÓRIOS

Lábios (mm. orbicular dos lábios)

$\begin{array}{lllll}\text { Tônus: } & \text { Rígido } & 1 & 2 & 3 \\ & \text { Normal } & & 0 & \\ & \text { Flácido } & 1 & 2 & 3\end{array}$

Mobilidade: Normal

Alterada

Língua

$\begin{array}{lllll}\text { Tônus: } & \text { Rígido } & 1 & 2 & 3 \\ & \text { Normal } & & 0 & \\ & \text { Flácido } & 1 & 2 & 3 \\ \text { Mobilidade: } & \text { Normal } & & & \\ & \text { Alterada } & & & \end{array}$

Bochechas (mm. bucinador)

$\begin{array}{lllll}\text { Tônus: } & \text { Rígido } & 1 & 2 & 3 \\ & \text { Normal } & & 0 & \\ & \text { Flácido } & 1 & 2 & 3\end{array}$

Mobilidade: Normal

Alterada 


\section{ANEXO C - Parecer do Comitê de Ética do Hospital das Clínicas da Faculdade de Medicina da Universidade de São Paulo}

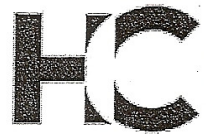

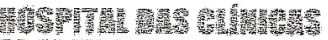

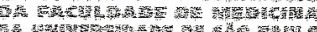

A

Área de Fisiópátólogia Experimental

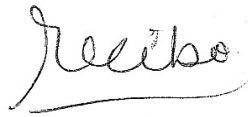

\section{O Presidente da Comissão de Ética para Análise}

de Projetos de Pesquisa - CAPPesq da Diretoria Clínica do Hospital das Clínicas e da Faculdade de Medicina da Universidade de São Paulo, em 13.11.08, tomou ciência da execução do Protocolo de Pesquisa n 1001/08, intitulado: "ElETROMIOGRAFIA DOS MÚSCULOS ORBICULAR DA BOCA, BUCINADOR E MENTAL DE SUJEITOS COM DISFUNÇĀO TEMPORO-MAMDIBULAR DURANTE EXERCÍCIOS MIOFUNCIONAIS OROFACIAIS".

\footnotetext{
- No que tange sua parte empírica está sendo
} desenvolvido na FACULDADE DE ODONTOLOGIA DA USP, tendo o seu Comitê de Ética aprovado o estudo em 20.04.07.

Pesquisador Responsável: PROF. DR. JOSÉ TADEU TESSEROLI DE SIQUEIRA Pesquisador Executante: ALINE POLIDO

Encaminhe-se à CPG-FMUSP para as devidas providéncias. S.P. $27,11,08$

Cece Prof. Dra. Elia Garcia Caldin Pós-Graduaça em cièncias suplente de Coordenador
CAPpesq, 13 de novembro de 2008.

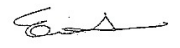

PROF. DR. EDUARDO MASSAD

Presidente da Comissāo Ética para Análise de Projetos de Pesquisa

Comissão de Ética para Análise de Projetos de Pesquisa do HCFMUSP e da FMUSP

Diretorio Clínica do Hospital das Clínicas da Faculdade de Medicina da Universidadé de São Paulo Rua Ovídio Pires de Campos. $225,5^{\circ}$ andar - CEP 05403010 - São Paulo - SP 
ANEXO D - Parecer do Comitê de Ética e Pesquisa da Faculdade de Odontologia da Universidade de São Paulo

\author{
UNIVERSIDADE DE SÃO PAULO \\ FACULDADE DE ODONTOLOGIA
}

\title{
PARECER DE APROVAÇÃO \\ Protocolo $163 / 06$
}

Com base em parecer de relator, o Comitê de Ética em Pesquisa APROVOU o protocolo de pesquisa "Eletromiografia dos músculos orbicular da boca, bucinador e mentual de sujeitos com disfunção temporomandibular durante exercícios miofuncionais orofaciais", de responsabilidade do Pesquisador Aline Polido, sob orientação da Professor(a) Doutor(a) Oswaldo Crivello Júnior.

Tendo em vista a legislação vigente, devem ser encaminhados a este Comitê relatórios anuais referentes ao andamento da pesquisa e ao término cópia do trabalho em "cd". Qualquer emenda do projeto original deve ser apresentada a este CEP para apreciação, de forma clara e sucinta, identificando a parte do protocolo a ser modificada e suas justificativas.

São Paulo, 20 de abril de 2007

Prof. Dr. Joẫ Gualberto de Cerqueira Luz Coordenador do CEP-FOUSP 


\section{REFERÊNCIAS BIBLIOGRÁFICAS}

Basmajian JV, De Luca CJ. Muscles alive: their function revealed by electromyography. 5th ed. Baltimore: Williams \& Wilkins; 1985.

Berretin-Felix G, Genaro KF, Trindade IEK, Trindade ASJ. Mastigatory function in temporomandibular dysfunction patients: eletromygrafic evaluation. $\mathrm{J}$ appl oral sci. 2005; 13(4):360-542.

Bérzin F, Pedroni CR, Borini CB. Electromyographic examination in temporomandibular disorders: evaluation protocol. Braz J Oral Sci. 2004;3:52629.

Bérzin F. Surface eletromiography in the diagnosis of syndromes of the craniocervical pain. Braz J Oral Sci. 2004;3(10):480-483.

Bianchini EMG. Articulação temporomandibular e fonoaudiologia. In: Ferreira LP e cols. Tratado de Fonoaudiologia. São Paulo: Roca; 2005. p. 315-29.

6. Bianchini EMG. Articulação temporomandibular: implicações, limitações e possibilidade fonoaudiológicas. Carapicuíba: Pró-Fono; 2000.

Bove SR, Guimarães AS, Smith RL. Caracterização dos pacientes de um ambulatório de disfunção temporomandibular e dor orofacial. Rev Latino-am Enfermagem. 2005;13(5):686-91.

Cabezas TN. Desordens temporomandibulares. in: Lopes Filho O, organizador. Tratado de fonoaudiologia. São Paulo: Roca; 1997. p.821-28.

Camparis CM, Siqueira JTT. Sleep bruxism: clinical aspects and characteristics in patients with and without chronic orofacial pain. Oral Surg Oral Med Oral Pathol Oral Radiol Endod. 2006;101:188-93. 
Cattoni DM, Fernandes FDM, Marchesan I. Q, Latorre MRDO. Medidas antropométricas faciais em crianças: segundo período de dentição mista. Rev CEFAC. 2003; 5(1):21-9.

Cecere $\mathrm{F}$, Ruf $\mathrm{S}$, Pancherz $\mathrm{H}$. Is quantitative electromyography reliable?. J Orofac Pain. 1996;10(1):38-47.

Conti PCR, Pertes RA, Heir GM, Nasri C, Cohen HV, Araújo CRP. Orofacial pain: basic mechanisms and implication for successful management. J Appl Oral Sci. 2003; 11(1): 1-7.

Costen JB. A syndrome of ear and symptoms dependent upon disturbed function of the temporomandibular joint. Ann Otol Rhinol Laryngol. 1934;43:115.

De Leeuw R. Orofacial pain: guidelines for assessment, diagnosis and management. 4th ed. Chicago: Quintessence Publishing; 2008.

De Luca CJ. The use of surface electromyography in biomechanics. J Appl Biomech. 1997; 13(2):135-63.

Dworkin SF, LeResche L, Derouen T. Reability of clinical measurement in temporomandibular disorders. Clin J Pain. 1988; 4(2):89-99.

Dworkin SF, Huggins KH, LeReche L, Von Korff M, Hooward J, Truellove E, Sommers E. Epidemiology of signs and symptons in temporomandibular disorders: clinical signs in cases and controls. J Am Dent Assoc. 1990; 120 (3):273-81 .

Dworkin SF, LeResche L. Research diagnostic criteria for temporomandibular disorders: review, criteria, examinations and specifications: critique. J Craniomandib Disord. 1992. 6(4):301-55.

Ervilha UF, Duarte M, Amadio AC. Estudo sobre procedimentos de normalização do sinal eletromiográfico durante o movimento humano. Rev Bras Fisiot. 1998; 3(1):15-20. 
Essenfelder LRC, Vitti M, Análise eletromiográfica dos músculos orbiculares oris em jovens portadores de oclusão normal. Ortodontia. 1977; 10(3):180-91. Felício CM, Silva MA, Nunes LJ. Síndrome dor-disfunção: uma abordagem fonoaudiológica. Odontol Mod. 1991. 18(5):26-8

Felício CM. Fonoaudiologia aplicada a casos odontológicos: motricidade oral e audiologia. São Paulo: Pró-fono; 1999. Cap. 3, p.92-125: Desordens tempomandibulares: diagnóstico fonoaudiológico e terapia.

Goldreich H, Gazit E, Lieberman MA, Rugh JD. The effect of pain from orthodontic arch wire adjustment on masseter muscle electromyographic activity. Am J Orthod Dentofacial Orthop 1994;106:365-70.

Guyton AC, Hall JE. Tratado de fisiologia médica. Rio de Janeiro: Elsevier; 2006. $72-83$

Hannam AG. Biomecânica musculoesquelética da mandíbula humana. In: Zarb GA, Carrlsson GE, Sessle BJ, Mohl ND. Disfunção temporomandibular e dos músculos da mastigação. 2a ed. São Paulo: Santos Livraria Editora; 2000.

Jaeger B, Simons DG, Simons L. Visão geral da cabeça e do pescoço. In: Simons DG, Travel JG, Simons LS. Dor e disfunção miofascial: manual dos pontos gatilhos. 2a ed. Porto Alegre: Artmed; 2005. v.1, 195-224.

Jensen R. Pathophysiological mechanisms of tension-type headache: a review of epidemiological and experimental studies. Cephalalgia. 1999;19:602-21.

Junge D. Oral sensorimotor function. Los Angeles: Medico Dental Media International; 1998.

Kelly BT, Kadrmas WR, Kirkendall DT, Speer KP. Optimal normalization tests for shoulder muscle activation: an electromyographic study. J Orthop Res. 1996;14(4):647-53

Klasser GD, Okeson JP. The clinical usefulness of surface electromyography in the diagnosis and treatment of temporomandibular disorders. J Am Dent Assoc. 2006; 137:763-771. 
Lapatki BG, Stegeman DF, Jonas IE. A surface EMG electrode for the simultaneous observation of multiple facial muscles. J Neurosci Methods. 2003;123:117-28.

Laskin DM. Temporomandibular disorders: a term past its time?. J Am Dent Assoc. 2008;139:124-8.

Leandro LFL, Nunes LJ. ATM. Diagnóstico e tratamento. São Paulo: Pancast; 2000.

Lima DR, Brunetti RF, Oliveira W. Estudo da prevalência de disjunção craniomandibular segundo o índice de Helkimo tendo como variáveis: sexo, faixa etária e indivíduos tratados ou não ortodonticamente. Rev Fac Odontol São José dos Campos. 1999;2(2):127-33.

Lous I, Sheikoleslam A, Moller E. Postural activity in subjects with functional disorders of the chewing apparatus. Scand J Dent Res. 1970;78:404-10.

Lund JP, Widmer CG. An evaluation of the use surface electromyography in the diagnosis, documentation and treatment of dental patients. J Craniomand Disord. 1989;3:125-37.

Lund JP, Donga R, Widmer CG, Stohler CS. The pain-adaptation model: a discussion of the relationship between chronic musculoskeletal pain and motor activity. Can J Physiol Pharmacol. 1991;69(5):683-94.

Lund JP, Widmer CG, Feine JS. Validity of diagnostic and monitoring test used for temporomandibular disorder. J Dent Res. 1995; 74(4):1133-43.

Lund JP. Pain and the control of muscles. In: Fricton JR, Dunber R, editors. Orofacial pain and temporomandibular disorders. New York: Raven; 1995. p. 103-15.

Maciel RN, Turell JCF. Anatomia da ATM. In: Maciel RN. ATM e dores craniomandibulares: fisiopatologia básica. São Paulo: Livraria Santos; 2003. Cap. 3, p.61-90. 
Maillou P, Cadden SW. Effects of remote deep somatic noxious stimuli on a jaw reflex in man. Arch Oral Biol. 1997;42:323-7.

Malta J, Campolongo GD, Barros TEP, Oliveira RP. Eletromiografia aplicada aos músculos da mastigação. Acta Ortop Bras. 2006;14:141-46.

Marchesan IQ. Fundamentos em fonoaudiologia: aspectos clínicos de la motricidad oral. Buenos Aires: Panamericana, 2002.

Marchiori SC, Vitti M. Estudo eletromiografico do músculo orbicular da boca. RGO. 1996;44(6):331-4.

Marx R. The circun-oral muscles and the incisor relationship an eletromyographic study. Trans Eur Orthod Soc. 1965;41:187.

Marx R. The use of integrators in eletromyographic investigation of orthodontic problems. Trans Eur Orthod Soc. 1963;39:318.

Merletti R. Standards for Reporting EMG data. J Electromyogr Kinesiol. 1999; 9(1):3-4 [citado 1 dez 2008]. Disponível em: https://www.isekonline.org/standards_emg.asp.

Merskey H, Bogduk N, editors. Classification of chronic pain. 2a ed. Seattle: IASP; 1994.

Mirka GA. The quantification of EMG normalization error. Ergonomics. 199;134:343-52.

Molina OF. Fisiopatologia craniomandibular. São Paulo: Pancast; 1989. 19-64: Aparelho estomatognático.

Möller E, Sheikholeslam A, Lous I. Response of elevator activity during astication to treatment of functional disorders. Scand J Dent Res.1984; 92(1):64-83

Morales RC. Terapia de regulação orofacial: conceito RCM. São Paulo: Memnon; 1999. 
Moreno BGD. Avaliação clínica, de qualidade de vida e atividade eletromiografica de indivíduos com disfunção temporomandibular [dissertação]. São Paulo: Faculdade de Medicina, Universidade de São Paulo; 2006.

Moyers RE. Temporomandibular muscle contraction patterns in angle class II, division I malocclusions: an electromyographic analysis. Am J Orthod. 1949;25:837-57.

Navarro JN. Avaliação comparativa por meio de eletromiografia de superfície do padrão de comportamento dos músculos masseter e temporal em pacientes parcialmente edentados antes e após a reabilitação com próteses parciais removíveis [tese]. São Paulo: Faculdade de Medicina, Universidade de São Paulo; 2007.

Neely JG, Pomerantz RG. Measurement of facial muscles strength in normal subjects. Laringoscope. 2002; 112(9):1562-8.

Nieberg IG. An eletromyographic and cephalometric radiography investigation of the orofacial muscular complex. Am J Orthod. 1960;46:627-8.

Nobrega JCM, Siqueira SRDT, Siqueira JTT, Teixeira MJ. Differential diagnosis in atypical facial pain: a clinical study. Arq Neuropsiquiatr. 2007; 65:256-61.

Okeson JP. Dores bucofaciais de Bell. 6a ed. São Paulo: Quintenssence; 2006. Pennacchio EA, Borg-Stein J, Keith DA. The incidence of pain in muscle of mastigation in patients whith fibromyalgia. J Mass Dent Soc. 1998; 47:8-12.

Portney L. Eletromiografia e testes de velocidade de condução nervosa. In: O'Sullivan SB. Fisioterapia: avaliação e tratamento. 2a ed. São Paulo: Editora Manole; 1993. p.183-223.

Ramfjord SP. Bruxism: a clinical and electromyographic study. J Am Dent Assoc. 1961; 62:21-44.

Ren K, Dubner R. Descending modulation in persistent pain: an update. Pain. 2002; 100:1-6. 
Root AA, Stephens JA. Organization of the central control of muscles of facial expression in man. J Physiol. 2003; 549(1):289-98.

Ruf S, Cecere F, Kupfer J, Pancherz H. Stress-induced changes in the functional electromyographic activity of the masticatory muscles. Acta Odontol Scand. 1997;55(1):44-8.

Rugh DJ, Drago CJ. Vertical dimension: a study on clinical rest position and jaw muscle activity. J Prosthet Dent. 1981;45(6):670-5.

Sales RD, Vitti M. Análise eletromiográfica dos músculos orbiculares oris em indivíduos portadores de maloclusão classe I, antes e pós submetidos a tratamento ortodôntico. Rev Assoc Paul Cir Dent. 1979;33(5):399-411.

Sarlani E, Greenspan JD. Why look in the brain for answers to temporomandibular disorder pain?. Cells Tissues Organs. 2005;180:69-75.

Schroeder H, Siegmund H, Santibanez G, Kluge A. Causes and signs of temporomandibular joint pain and dysfunction: an electromyographical investigation. J Oral Rehabil. 1991;18:301-10.

Scrivani SJ, Keith DA, Kaban LB. Temporomandibular disorders. N Engl J Med. 2008;359(25):2693-705.

Sessle BJ. Acute and chronic craniofacial pain: brainstem mechanisms of nociceptive transmission and neuroplasticity and their clinical correlates. Crit Rev Oral Biol Med. 2000; 11:57-91.

Sessle BJ. The neural basis of temporomandibular and masticatory muscle pain. J Orofacial Pain. 1999;13:238-45.

Sharav Y. Orofacial pain. In: Wall PD, Melsack R, editors. Textbook of pain. 3rd ed. Edinburgh: Churchill Livingstone; 1994. p.563-82.

Sheikholeslam A, Moller E, Lous I. Postural and maximal activity in elevators of mandible before and after treatment of functional disorders. Scand J Dent Res. 1982; 90(1):37-46. 
Siqueira JTT, Ching LH, Nasri C, Siqueira SRDT, Teixeira MJ, Heir G, Valle LBS. Clinical study of patients with persistent orofacial pain. Arq Neuropsiquiatr. $2004 ; 62: 988-96$.

Soderberg GL, Cook TM. Electromyography in biomechanics. Phys Ther. Alexandria. 1994; 64(12):1813-20.

Soderberg GL, Knustson LM. A guide for use and interpretation of kinesiologic electromyographic data. Phys Ther. 2000; 80(5): 485-498.

Stefani FM. Estudo eletromiográfico do padrão de contração muscular da face de adultos [tese]. São Paulo: Faculdade de Medicina, Universidade de São Paulo; 2008.

Sullivan SB; Schimitz TJ. Fisioterapia: avaliação e tratamento. São Paulo: Manole; 2003.

Tassinary LG, Cacioppo JT, Geen TR. A psychometric study of surface electrode placements for facial electromyographic recording: the brow and cheek region. Psychophysiology. 1989; 26(1):1-16.

Teixeira MJ, Yeng LT, Kaziyama HHS. Fisiopatologia da dor musculoesquelética. In: Teixeira MJ, Yeng LT, Kaziyama HHS, colaboradores. Sindrome dolorosa miofacial e dor músculo-esquelética. São Paulo: Roca; 2007. p.53-70.

Tosello DO, Vitti M, Berzin F. EMG activity of the orbicularis oris and mentalis muscles in children with maloclusion, incompetent lips and atypical swallowing: part I. J Oral Rehabil. 1998; 25(11):838-46.

Travell J, Simons D. Myofascial pain and dysfunction. Philadelphia: Williams \& Wilkins; 1983. 
Tsai CM, Chou SL, Gale EN, McCall WD Jr. Human masticatory muscle activity and jaw position under experimental stress. J Oral Rehabil. 2002;29(1):44-51.

Turker K.S. Electromyography: some methodological problems and issues. Phys Ther. 1993;73(10):698-710.

van Boxtel A, Goudswaard P. Changes in EMG power spectra during fatigue in muscle contraction and migraine headache patients. Headache. 1983;23:223-8. Vickers ER, Cousins MJ. Neuropathic orofacial pain, part 1: prevalence and pathophysiology. Aust Endod J. 2000; 26(1):19-26.

Wang K, Arendt-Nielsen L, Jensen T, Svensson P. Reduction of clinical temporomandibular joint pain is associated with a reduction of the jaw-stretch reflex. J Orofac Pain. 2004;18(1):33-40.

Winter DA. Biomechanics and motor control of human movement. 2a ed. New York: Jonh Wiley \& Sons; 1990. p.165-212.

Yemm R. A neurophysiological approach to the pathology and aetiology of temporomandibular dysfunction. J Oral Rehabil. 1985; 12:343-53.

Zemlin WR. Princípios de anatomia e fisiologia em fonoaudiologia. 4a ed. Porto Alegre: Artmed; 2000. 


\section{APÊNDICES}

Registro eletromiográfico da posição de repouso do GC

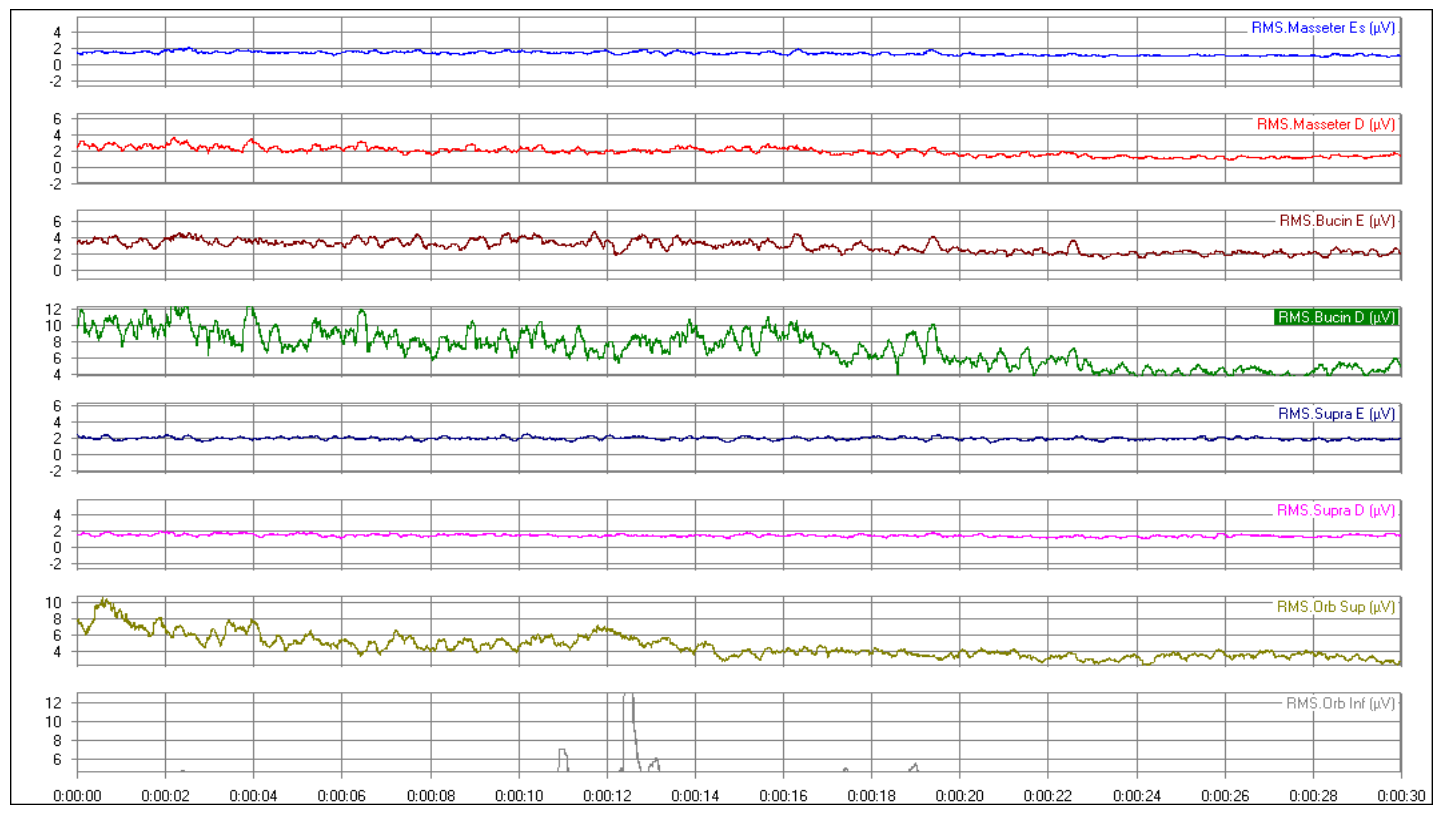

Registro eletromiográfico da posição de repouso do GMM

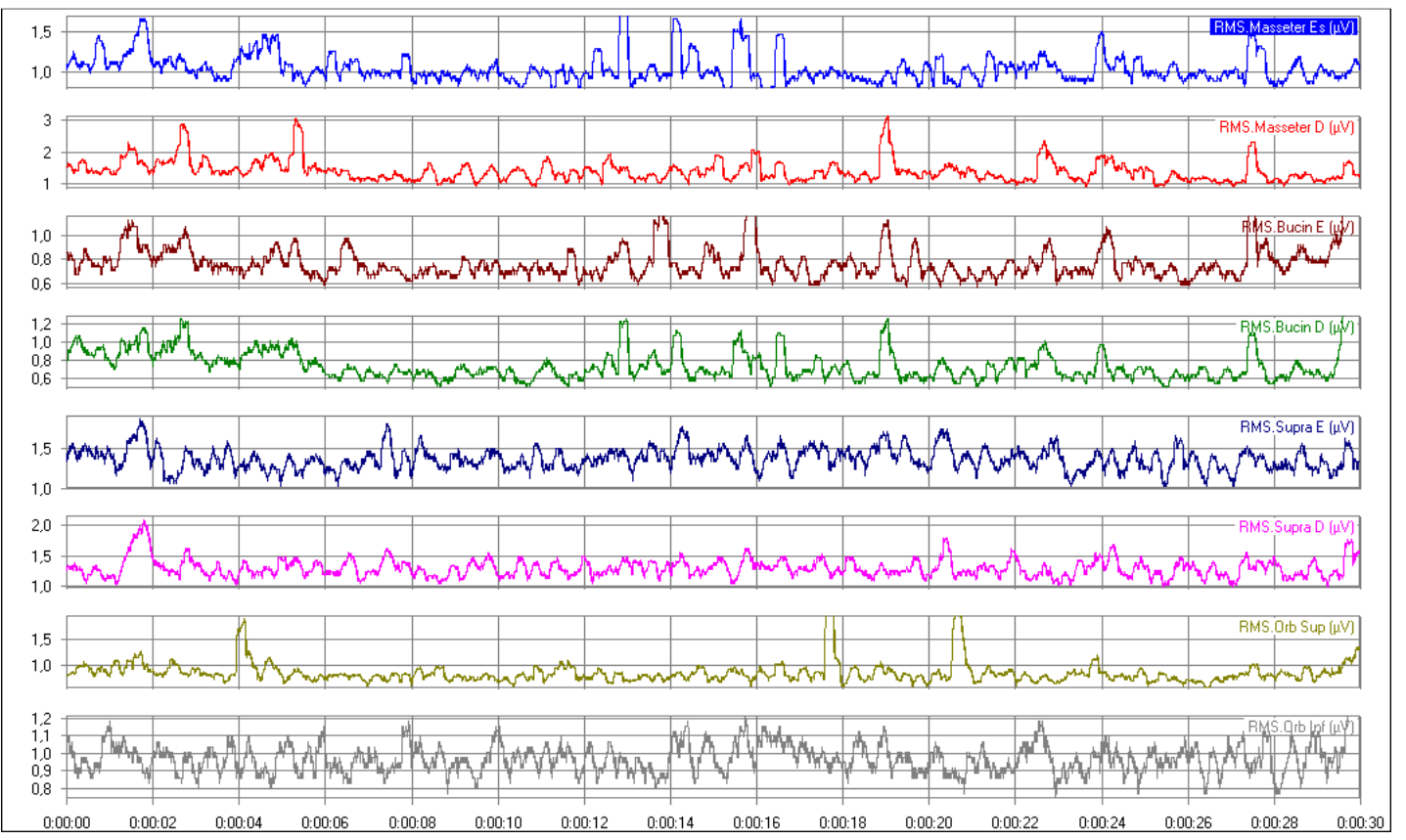


Registro eletromiográfico do movimento de apertamento dos lábios do GC

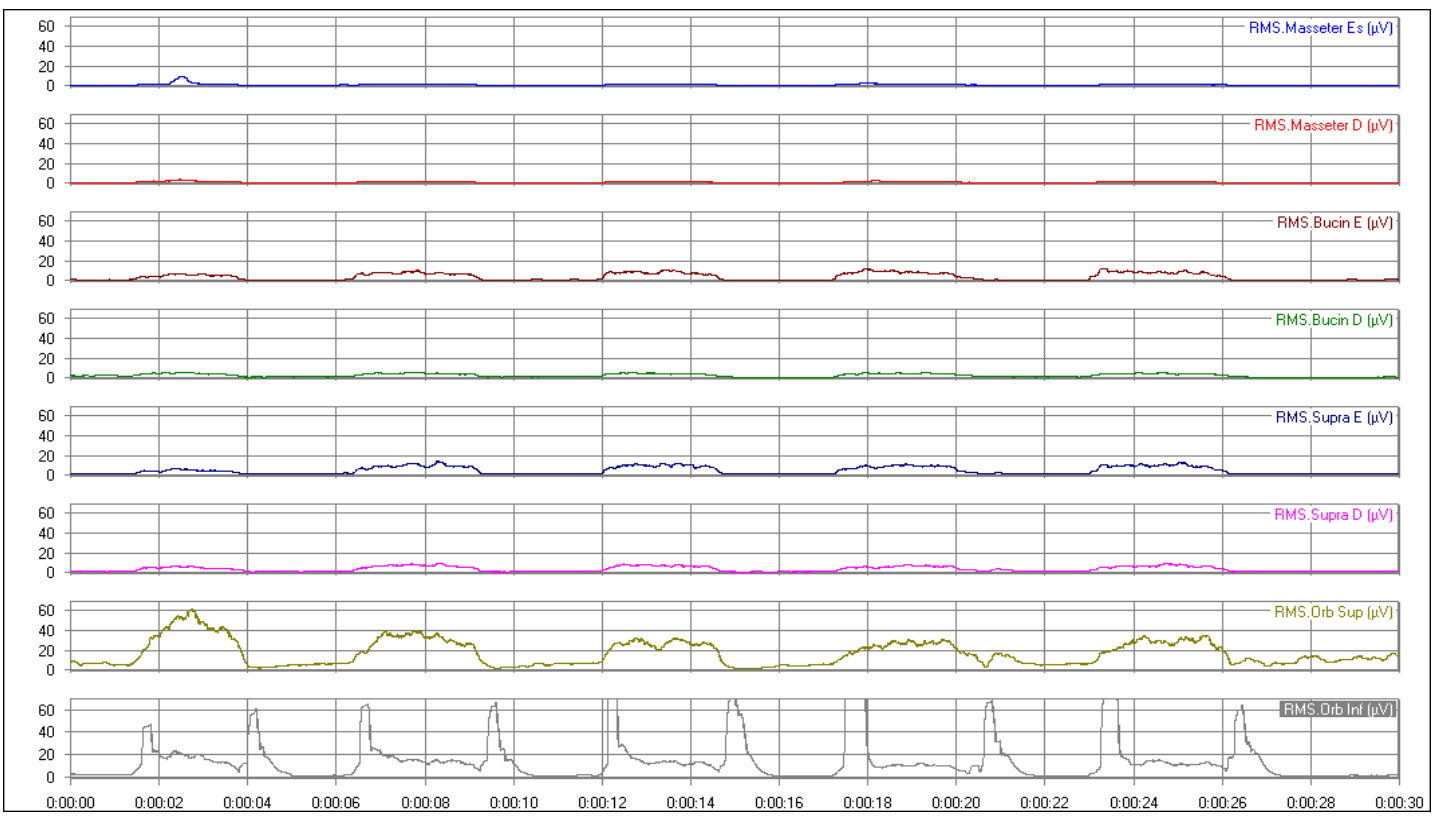

Registro eletromiográfico do movimento de apertamento dos lábios do GMM

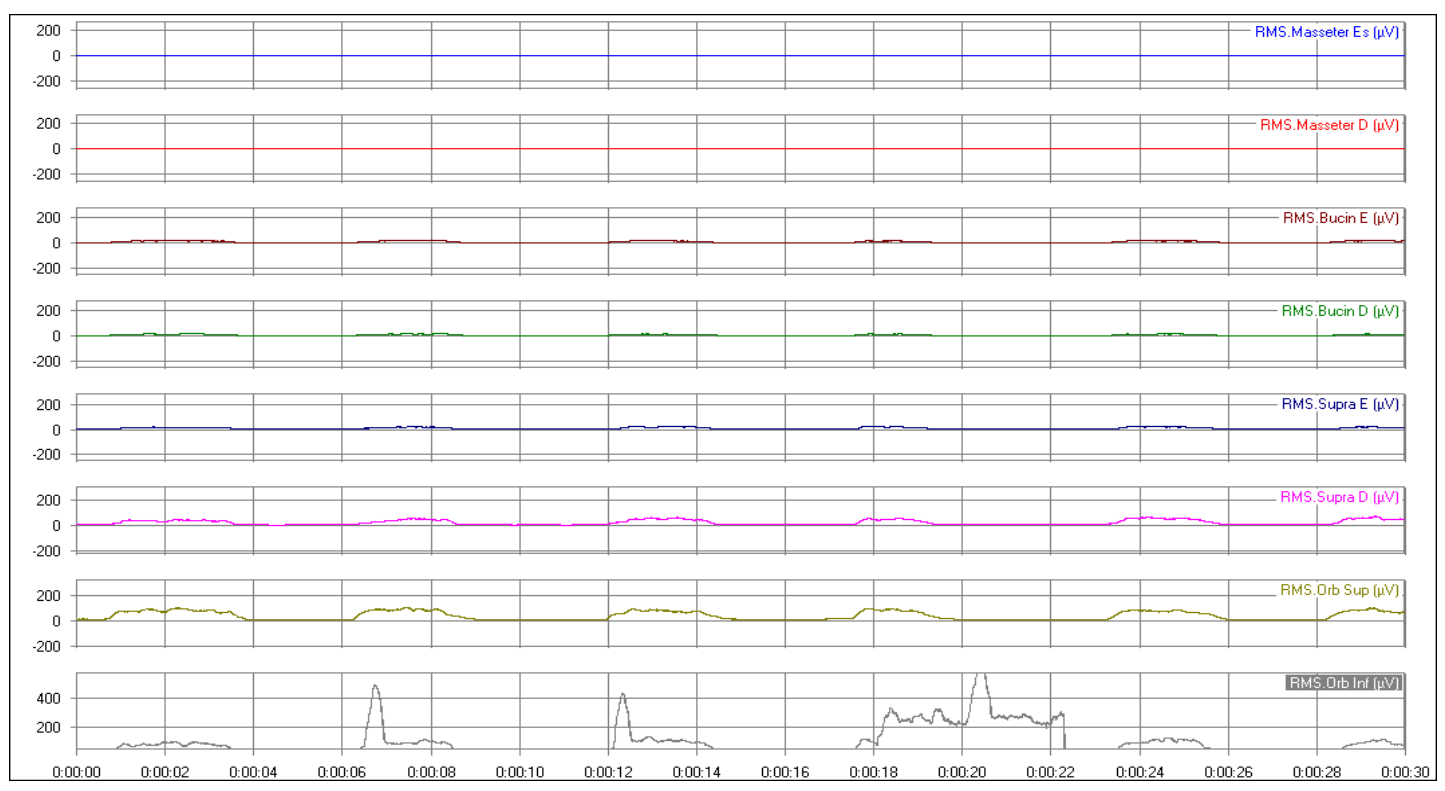


Registro eletromiográfico do movimento de protrusão dos lábios do GC

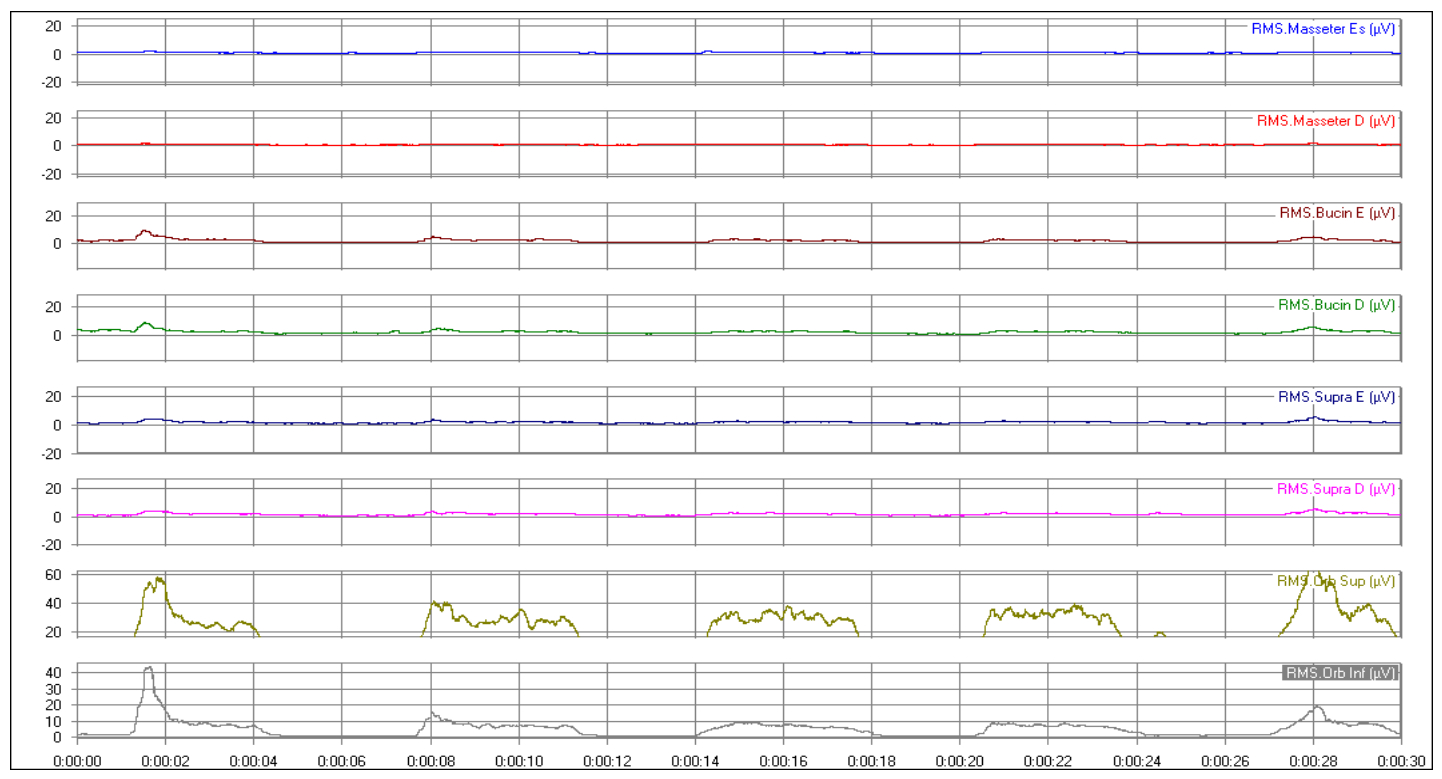

Registro eletromiográfico do movimento de protrusão dos lábios do GMM

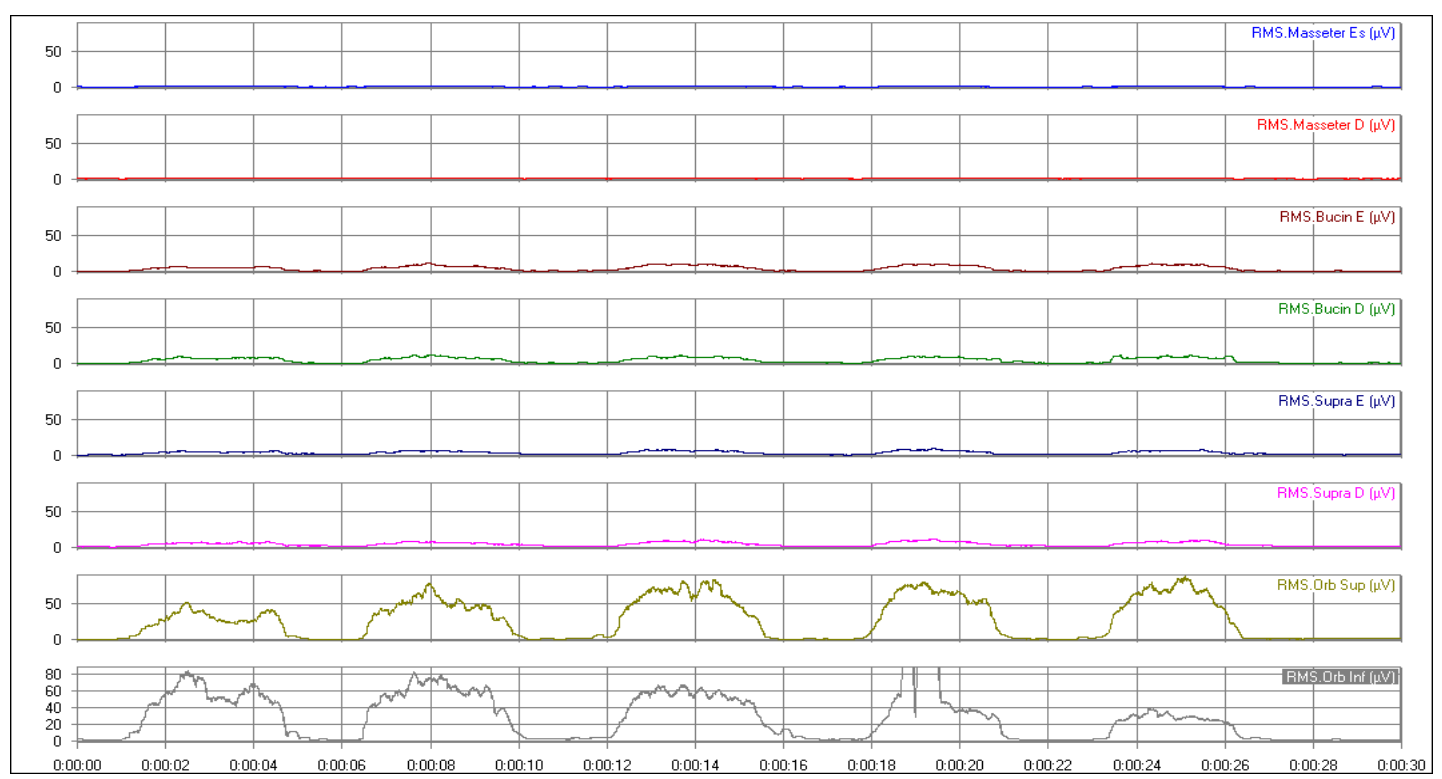


Registro eletromiográficos da posição de inflar as bochechas do GC

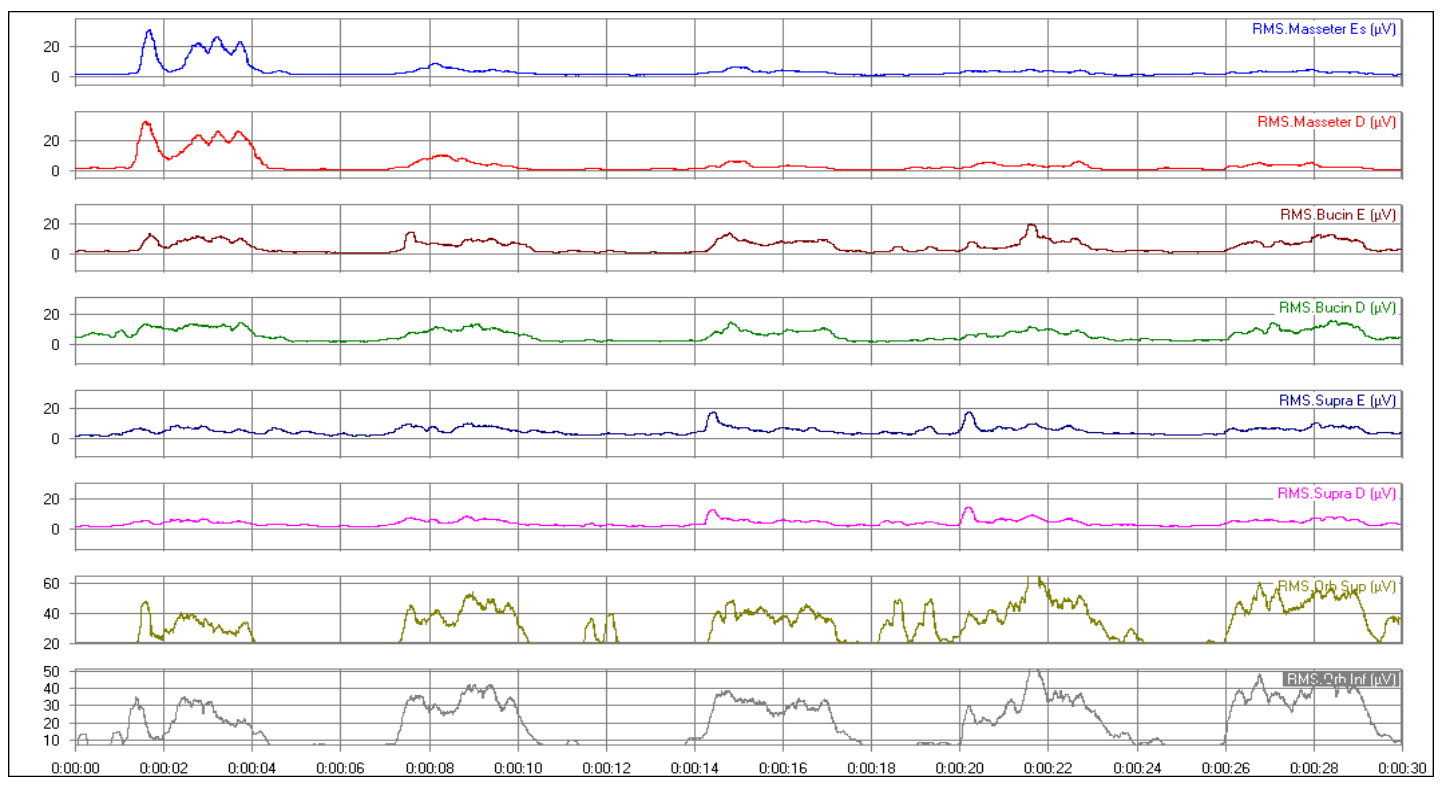

Registro eletromiográficos no movimento de inflar as bochechas do GMM

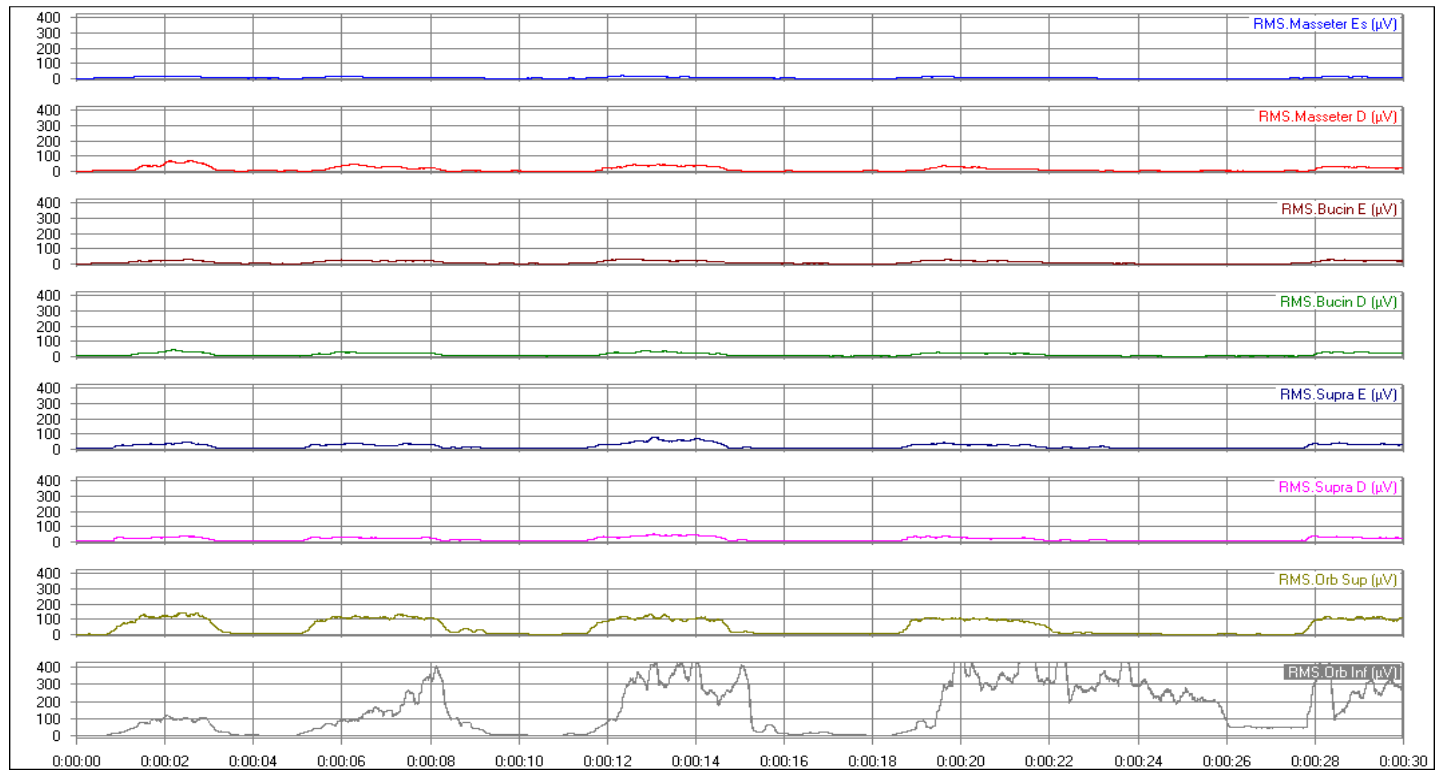


Registro eletromiográficos da posição de sorriso fechado do GC

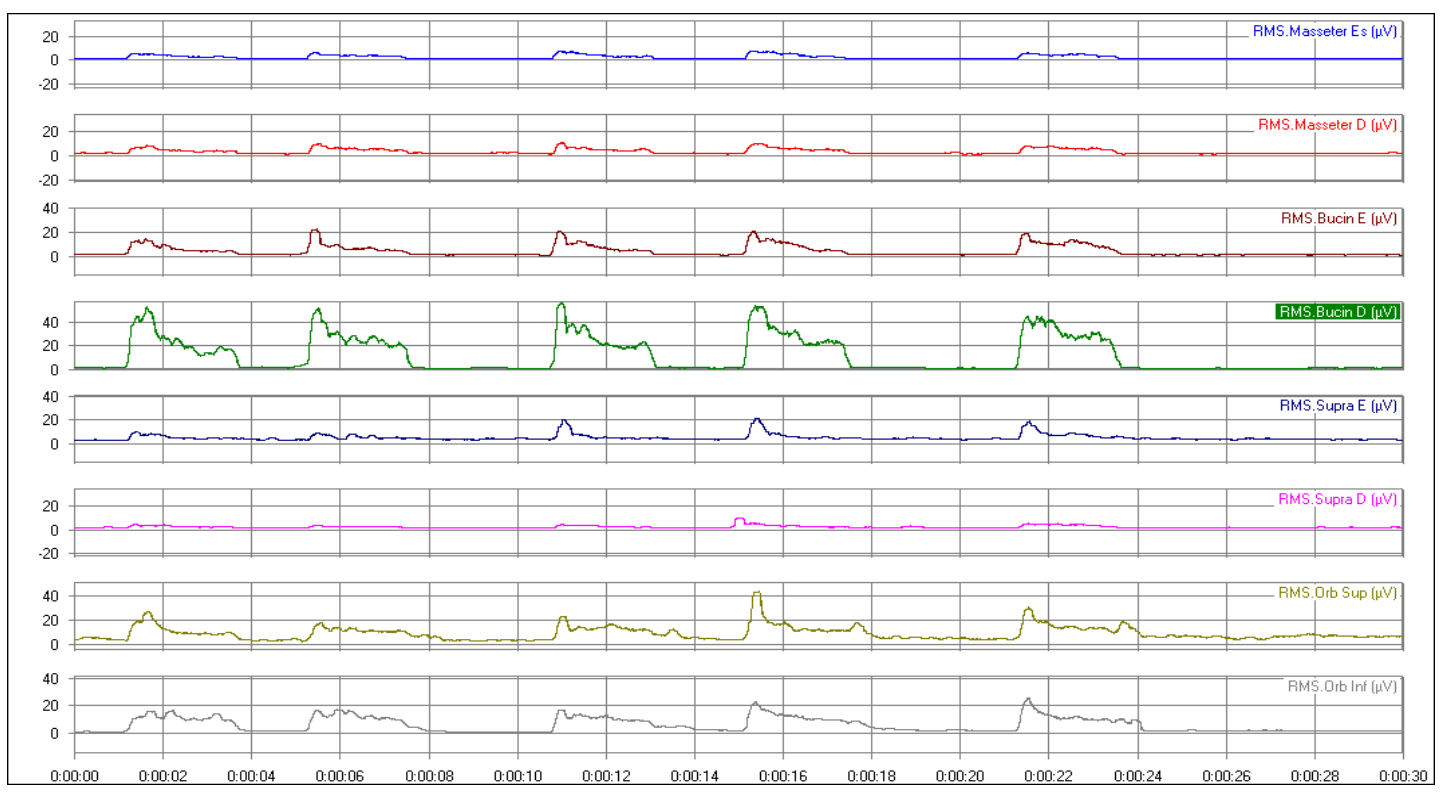

Registro eletromiográfico no movimento de sorriso fechado do GMM

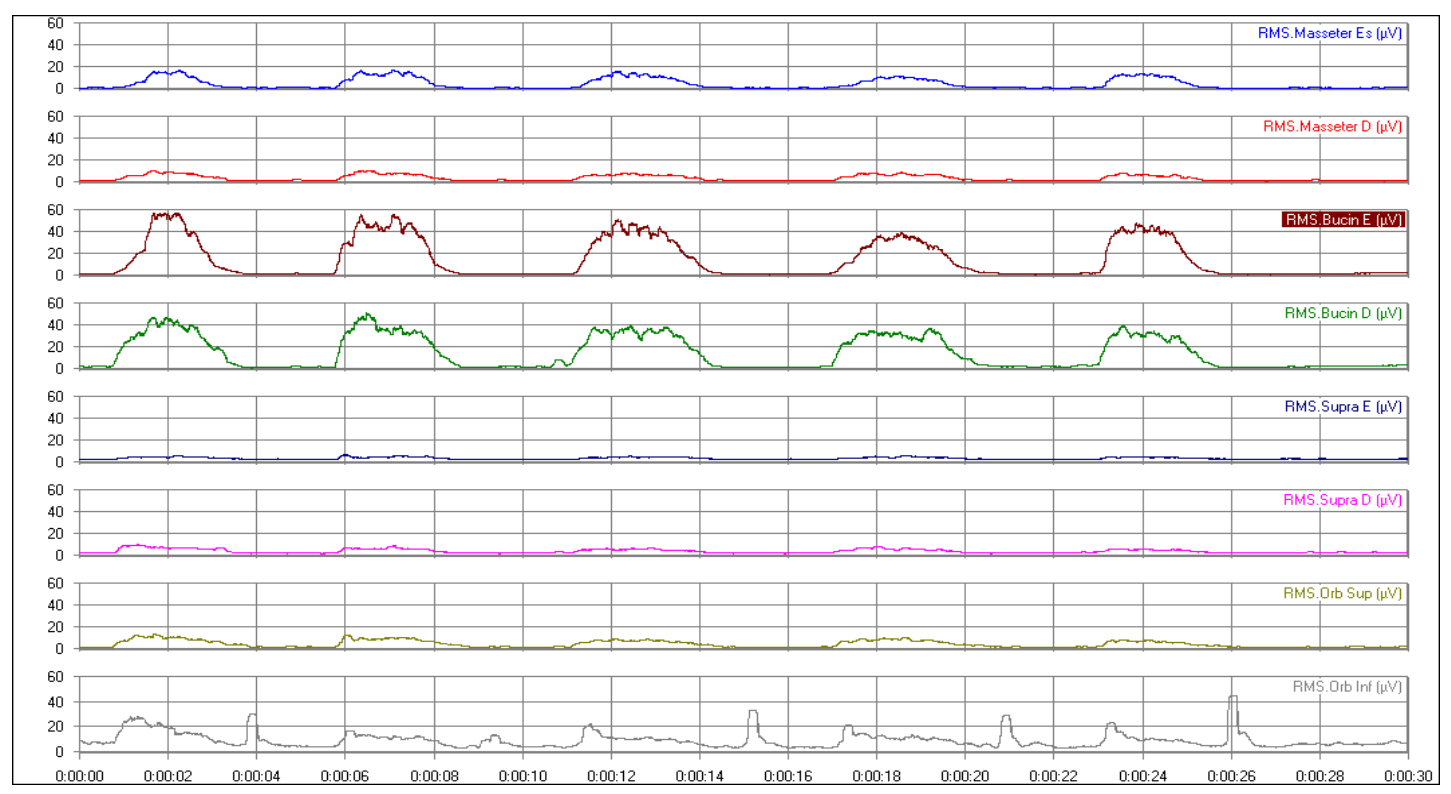


Registro eletromiográfico no movimento de sorriso aberto do GC

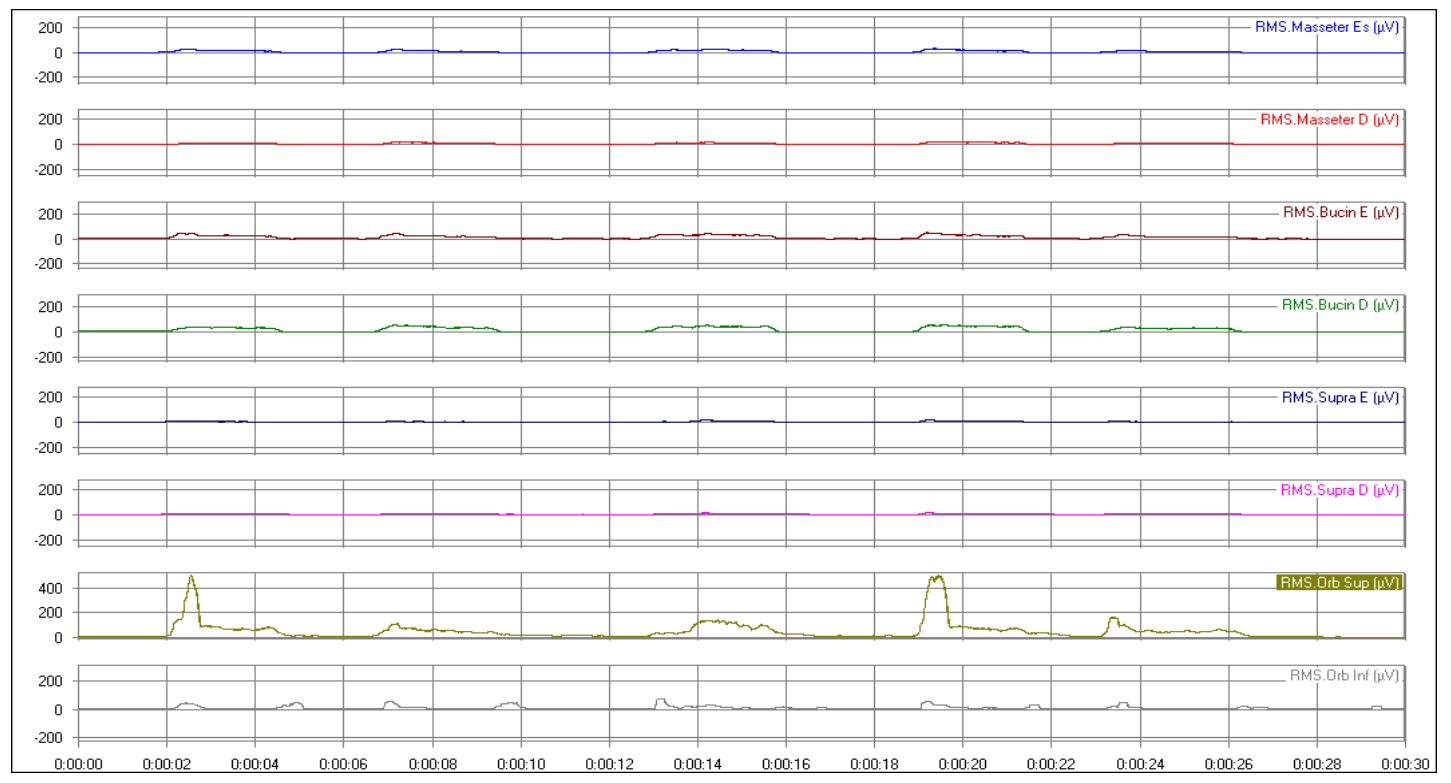

Registro eletromiográficos no movimento de sorriso aberto do GMM

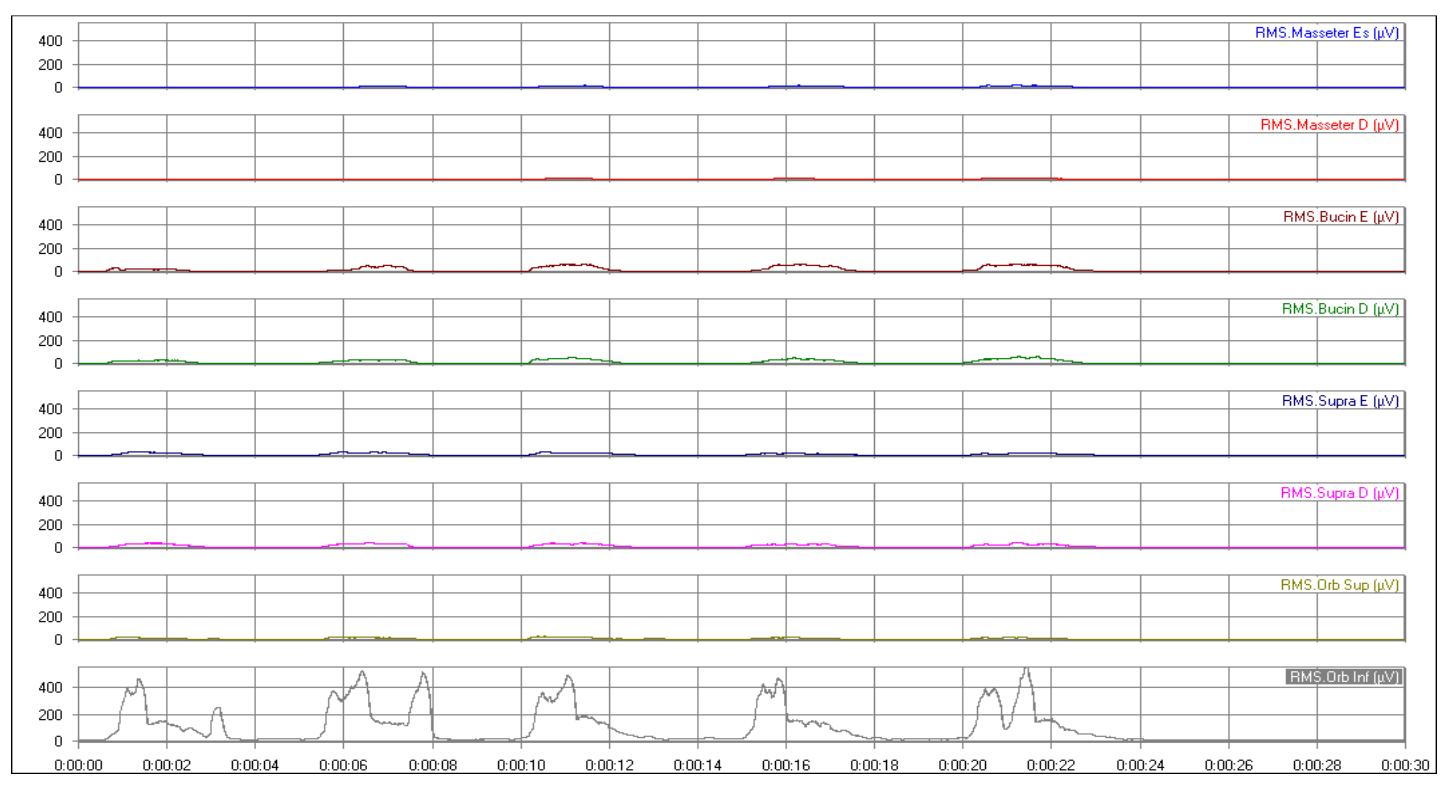


Valores de média, desvio-padrão, mínimo, máxima e mediana das variáveis mensuradas no repouso

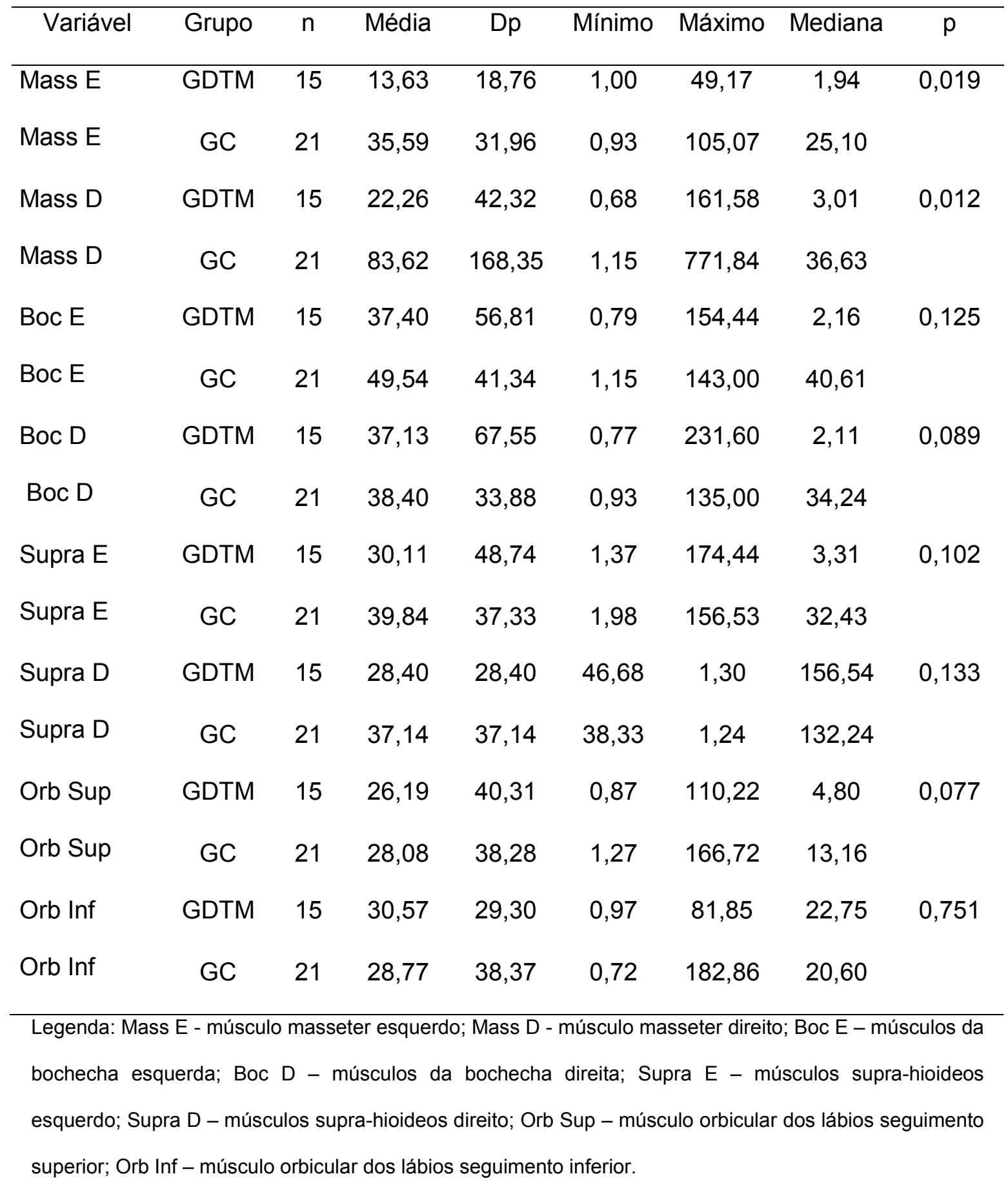


Valores de média, desvio-padrão, mínimo, máximo e mediana do movimento de apertamento dos lábios, segundo o grupo e o músculo avaliado

\begin{tabular}{|c|c|c|c|c|c|c|c|c|}
\hline Variável & Grupo & $\mathrm{n}$ & Média & $d p$ & Mínimo & Máximo & Mediana & $p$ \\
\hline Mass E & GDTM & 15 & 6,66 & 8,62 & 0,06 & 25,36 & 3,21 & 0,058 \\
\hline Mass E & GC & 21 & 1,39 & 1,01 & 0,53 & 5,00 & 1,08 & \\
\hline Mass D & GDTM & 15 & 6,72 & 8,55 & 0,02 & 29,22 & 1,91 & 0,072 \\
\hline Mass D & GC & 21 & 1,45 & 1,71 & 0,14 & 8,61 & 1,02 & \\
\hline Boc $E$ & GDTM & 15 & 17,98 & 30,69 & 0,09 & 114,38 & 8,88 & 0,005 \\
\hline Boc $E$ & GC & 21 & 1,96 & 3,39 & 0,21 & 16,47 & 1,13 & \\
\hline Boc D & GDTM & 15 & 17,84 & 30,95 & 0,05 & 123,20 & 7,46 & 0,007 \\
\hline Boc D & GC & 21 & 2,60 & 4,22 & 0,49 & 19,81 & 1,20 & \\
\hline Supra E & GDTM & 15 & 10,59 & 13,41 & 0,07 & 45,01 & 4,60 & 0,046 \\
\hline Supra E & GC & 21 & 2,88 & 3,99 & 0,27 & 18,55 & 1,51 & \\
\hline Supra D & GDTM & 15 & 15,16 & 30,52 & 0,29 & 122,75 & 5,27 & 0,039 \\
\hline Supra D & GC & 21 & 1,98 & 2,06 & 0,33 & 10,32 & 1,40 & \\
\hline Orb Sup & GDTM & 15 & 36,90 & 45,80 & 0,42 & 149,59 & 14,31 & 0,042 \\
\hline Orb Sup & GC & 21 & 8,54 & 11,49 & 0,77 & 52,31 & 4,77 & \\
\hline Orb Inf & GDTM & 15 & 17,09 & 23,09 & 0,88 & 72,85 & 6,47 & 0,409 \\
\hline Orb Inf & GC & 21 & 7,60 & 10,83 & 0,48 & 46,44 & 3,43 & \\
\hline \multicolumn{9}{|c|}{$\begin{array}{l}\text { (*) nível descritivo de probabilidade do teste não-paramétrico de Friedman } \\
\text { Legenda: Mass E - músculo masseter esquerdo; Mass D - músculo masseter direito; Boc E-músculos da } \\
\text { bochecha esquerda; Boc D - músculos da bochecha direita; Supra E - músculos supra-hioideos } \\
\text { esquerdo; Supra D - músculos supra-hioideos direito; Orb Sup - músculo orbicular dos lábios seguiment }\end{array}$} \\
\hline
\end{tabular}


Valores de média, desvio-padrão, mínimo, máximo e mediana do movimento de protrusão de lábios, segundo o grupo e o músculo avaliado

\begin{tabular}{|c|c|c|c|c|c|c|c|c|}
\hline Variável & Grupo & $\mathrm{n}$ & Média & $d p$ & Mínimo & Máximo & Mediana & $p^{*}$ \\
\hline Mass E & GDTM & 15 & 4,10 & 6,72 & 0,11 & 21,69 & 1,64 & 0,096 \\
\hline Mass E & GC & 21 & 1,38 & 1,54 & 0,75 & 8,02 & 0,99 & \\
\hline Mass D & GDTM & 15 & 4,17 & 7,36 & 0,04 & 29,51 & 1,57 & 0,109 \\
\hline Mass D & GC & 21 & 2,42 & 4,84 & 0,10 & 20,89 & 1,00 & \\
\hline Boc E & GDTM & 15 & 19,71 & 42,21 & 0,08 & 131,57 & 4,16 & 0,005 \\
\hline Boc $E$ & GC & 21 & 1,50 & 1,35 & 0,69 & 5,84 & 1,04 & \\
\hline Boc D & GDTM & 15 & 20,59 & 41,93 & 0,09 & 124,17 & 4,49 & 0,117 \\
\hline Boc D & GC & 21 & 2,07 & 2,43 & 0,34 & 9,59 & 1,16 & \\
\hline Supra E & GDTM & 15 & 7,10 & 12,78 & 0,08 & 41,92 & 3,00 & 0,011 \\
\hline Supra E & GC & 21 & 1,29 & 0,64 & 0,69 & 3,61 & 1,05 & \\
\hline Supra D & GDTM & 15 & 11,03 & 30,07 & 0,12 & 119,03 & 3,07 & 0,102 \\
\hline Supra D & GC & 21 & 1,63 & 1,24 & 0,70 & 5,39 & 1,12 & \\
\hline Orb Sup & GDTM & 15 & 49,89 & 85,31 & 0,79 & 326,42 & 28,31 & 0,150 \\
\hline Orb Sup & GC & 21 & 8,49 & 10,83 & 0,99 & 44,93 & 5,17 & \\
\hline Orb Inf & GDTM & 15 & 54,67 & 113,78 & 1,21 & 435,03 & 5,87 & 0,547 \\
\hline Orb Inf & GC & 21 & 10,66 & 21,26 & 0,71 & 101,88 & 4,76 & \\
\hline \multicolumn{9}{|c|}{$\begin{array}{l}{ }^{*} \text { () nível descritivo de probabilidade do teste não-paramétrico de Friedman } \\
\text { Legenda: Mass E - músculo masseter esquerdo; Mass D - músculo masseter direito; Boc E-músculos da } \\
\text { bochecha esquerda; Boc D - músculos da bochecha direita; Supra E - músculos supra-hioideos } \\
\text { esquerdo; Supra D - músculos supra-hioideos direito; Orb Sup - músculo orbicular dos lábios seguimento }\end{array}$} \\
\hline
\end{tabular}


Valores de média, desvio-padrão, mínimo, máximo e mediana do movimento de inflar as bochechas, segundo o grupo e o músculo avaliado

\begin{tabular}{|c|c|c|c|c|c|c|c|c|}
\hline Variável & Grupo & $n$ & Média & $\mathrm{dp}$ & Mínimo & Máximo & Mediana & $p$ \\
\hline Mass E & GDTM & 15 & 11,39 & 25,27 & 0,08 & 87,13 & 1,91 & 0,021 \\
\hline Mass E & GC & 21 & 1,23 & 0,59 & 0,75 & 3,21 & 1,02 & \\
\hline Mass D & GDTM & 15 & 6,19 & 11,16 & 0,05 & 36,35 & 1,95 & 0,238 \\
\hline Mass D & GC & 21 & 1,34 & 0,88 & 0,09 & 4,02 & 1,06 & \\
\hline Boc $E$ & GDTM & 15 & 12,33 & 30,72 & 0,10 & 121,90 & 3,78 & 0,007 \\
\hline Boc $E$ & GC & 21 & 1,44 & 0,97 & 0,27 & 4,97 & 1,12 & \\
\hline Boc D & GDTM & 15 & 9,10 & 14,92 & 0,28 & 57,87 & 3,23 & 0,002 \\
\hline Boc D & GC & 21 & 1,50 & 1,21 & 0,46 & 5,19 & 1,11 & \\
\hline Supra E & GDTM & 15 & 7,45 & 15,30 & 0,19 & 60,51 & 3,11 & 0,089 \\
\hline Supra E & GC & 21 & 1,72 & 1,48 & 0,59 & 6,67 & 1,14 & \\
\hline Supra D & GDTM & 15 & 4,98 & 8,08 & 0,31 & 32,05 & 2,46 & 0,150 \\
\hline Supra D & GC & 21 & 1,85 & 1,64 & 0,48 & 7,61 & 1,23 & \\
\hline Orb Sup & GDTM & 15 & 37,54 & 79,11 & 1,48 & 311,45 & 9,27 & 0,039 \\
\hline Orb Sup & GC & 21 & 7,96 & 11,86 & 0,51 & 52,44 & 4,61 & \\
\hline Orb Inf & GDTM & 15 & 17,42 & 22,87 & 0,87 & 87,81 & 9,99 & 0,067 \\
\hline Orb Inf & GC & 21 & 6,53 & 7,08 & 0,44 & 30,16 & 4,73 & \\
\hline \multicolumn{9}{|c|}{ (*) nível descritivo de probabilidade do teste não-paramétrico de Friedman } \\
\hline
\end{tabular}


Valores de média, desvio-padrão, mínimo, máximo e mediana do movimento de sorriso fechado, segundo o grupo e o músculo avaliado

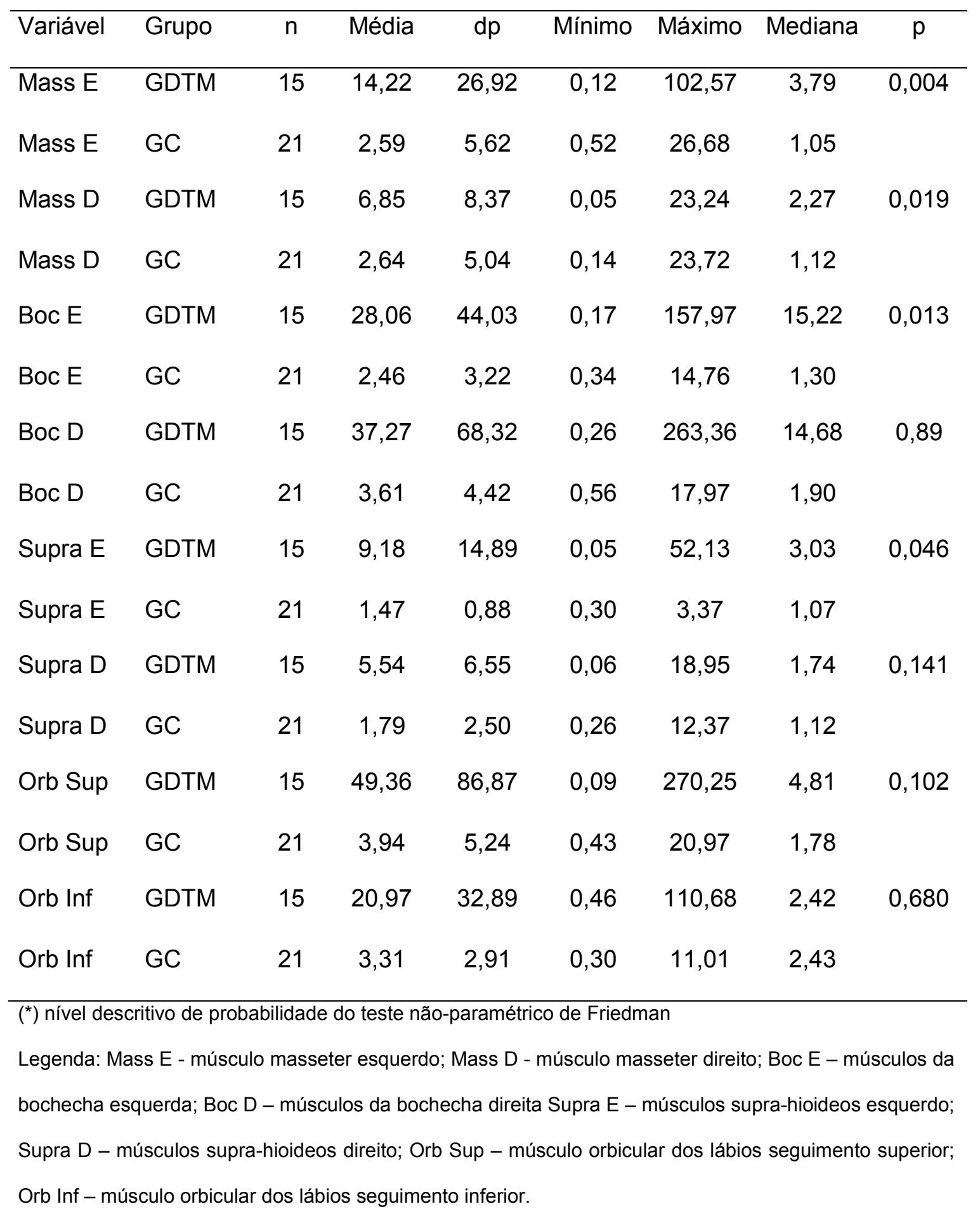


Valores de média, desvio-padrão, mínimo, máximo e mediana do movimento de sorriso aberto, segundo o grupo e o músculo avaliado

\begin{tabular}{|c|c|c|c|c|c|c|c|c|}
\hline Variável & Grupo & $\mathrm{n}$ & Média & $\mathrm{dp}$ & Mínimo & Máximo & Mediana & $p$ \\
\hline Mass E & GDTM & 15 & 9,52 & 14,45 & 0,14 & 57,79 & 4,93 & 0,030 \\
\hline Mass E & GC & 21 & 2,54 & 3,91 & 0,74 & 17,62 & 1,12 & \\
\hline Mass D & GDTM & 15 & 7,23 & 8,85 & 0,13 & 24,46 & 2,33 & 0,180 \\
\hline Mass D & GC & 21 & 2,84 & 4,29 & 0,18 & 19,04 & 1,11 & \\
\hline Boc $E$ & GDTM & 15 & 18,62 & 21,56 & 0,17 & 65,32 & 12,61 & 0,170 \\
\hline Boc $E$ & GC & 21 & 3,11 & 3,86 & 0,73 & 15,58 & 1,66 & \\
\hline Boc D & GDTM & 15 & 31,69 & 44,37 & 0,26 & 136,66 & 13,00 & 0,340 \\
\hline Boc D & GC & 21 & 4,99 & 7,53 & 0,72 & 28,03 & 1,90 & \\
\hline Supra E & GDTM & 15 & 6,57 & 6,56 & 0,23 & 20,51 & 3,76 & 0,102 \\
\hline Supra E & GC & 21 & 2,20 & 1,93 & 0,57 & 7,28 & 1,47 & \\
\hline Supra D & GDTM & 15 & 10,25 & 15,50 & 0,15 & 54,38 & 2,89 & 0,357 \\
\hline Supra D & GC & 21 & 2,79 & 3,04 & 0,48 & 13,25 & 1,58 & \\
\hline Orb Sup & GDTM & 15 & 33,80 & 71,10 & 0,13 & 270,25 & 4,47 & 0,526 \\
\hline Orb Sup & GC & 21 & 15,77 & 47,26 & 0,78 & 219,31 & 2,41 & \\
\hline Orb Inf & GDTM & 15 & 30,38 & 62,01 & 0,97 & 244,97 & 9,62 & 0,214 \\
\hline Orb Inf & GC & 21 & 8,70 & 11,83 & 0,90 & 50,60 & 4,91 & \\
\hline \multicolumn{9}{|c|}{$\begin{array}{l}\left.{ }^{\star}\right) \text { nível descritivo de probabilidade do teste não-paramétrico de Friedman } \\
\text { Legenda: Mass E - músculo masseter esquerdo; Mass D - músculo masseter direito; Boc E - músculos da }\end{array}$} \\
\hline
\end{tabular}

